(UC-25: Metallurgy and Ceramics, TID-4500, 13th Ed., Suppl.)

\title{
DEVELOPMENT AND PROPERTIES OF URANIUM-BASE ALLOYS CORROSION RESISTANT IN HIGH TEMPERATURE WATER
}

Part IV - Radiation Stability of Uranium-Base Alloys

M. L. Bleiberg, J. D. Eichenberg, R. H. Fillnow, L。 J. Jones

I. J. Jones, Editor

$$
\text { May } 1957
$$

Contract AT-11-I-GEN-14

\author{
Printed in U.S.A. Price \$3.25. \\ Available from the Office of Technical Services, \\ U. S. Department of Commerce \\ Washington 25, D. C.
}




\section{DISCLAIMER}

This report was prepared as an account of work sponsored by an agency of the United States Government. Neither the United States Government nor any agency Thereof, nor any of their employees, makes any warranty, express or implied, or assumes any legal liability or responsibility for the accuracy, completeness, or usefulness of any information, apparatus, product, or process disclosed, or represents that its use would not infringe privately owned rights. Reference herein to any specific commercial product, process, or service by trade name, trademark, manufacturer, or otherwise does not necessarily constitute or imply its endorsement, recommendation, or favoring by the United States Government or any agency thereof. The views and opinions of authors expressed herein do not necessarily state or reflect those of the United States Government or any agency thereof. 


\section{DISCLAIMER}

Portions of this document may be illegible in electronic image products. Images are produced from the best available original document. 
EXTERRIAL DISTRIBUTION

(UC-25: Metallurgy and Ceramics, TID-4500, 13th Ed., Suppl.)

\section{INTERNAL DISTRIBUTION}

Manager, Pittsburgh Area Office, AEC

$\begin{array}{ll}\text { S. Aronson } & 1 \\ \text { A. Auskern } & 1 \\ \text { J. Belle } & 1 \\ \text { R. M. Berman } & 1 \\ \text { A. L. Bethel } & 1 \\ \text { F. O. Bingman } & 1 \\ \text { M. L. Bleiberg } & 1 \\ \text { W. A. Bostrom } & 1 \\ \text { E. R. Boyko } & 1 \\ \text { R. F. Boyle } & 1 \\ \text { M. W. Burkhart } & 1 \\ \text { J. H. Bowling } & 1 \\ \text { J. C. Clayton } & 1 \\ \text { I. Cohen } & 1 \\ \text { P. Cohen } & 1 \\ \text { J. C. Conner } & 1 \\ \text { D. J. Clark } & 1 \\ \text { L. J. D'Antonio } & 1 \\ \text { P. G. DeHuff } & 1 \\ \text { R. R. Eggleston } & 1 \\ \text { J. D. Eichenberg } & 1 \\ \text { M. J. Feldman } & 1 \\ \text { R. H. Fillnow } & 1 \\ \text { R. L. Fischer } & 1 \\ \text { R. R. Fouse } & 1 \\ \text { P. W. Frank } & 1 \\ \text { C. P. Gamber } & 1 \\ \text { S. B. Gunst } & 1 \\ \text { E. K. Halteman } & 1 \\ \text { E. H. Hill } & 1 \\ \text { W. J. Hurford } & \\ \text { W. } & \end{array}$

L. J. Jones

R. E. Kettner

T. J. Kisiel

L. B. Kramer

S. Krasik

R. M. Lieberman

E. F. Losco

B. Lustman

J. M. Markowitz

S. L. Mitchell

F. P. Mrazik

T. R. Padden

I. B. Prus

J. C. Rengel

E. L. Richards

G. B. Rosenblatt

N. T. Saunders

B. E. Schaner

W. Schwartz

P. S. Sherba

$\mathrm{J}$. Sherman

J. W. Simpson

F. S. Susko

J. S. Theilacker

D. E. Thomas

K. H. Vogel

F. O. VonPlinsky

R. C. Westphal

R. A. Wolfe

D. M. Wroughton

W. Yeniscavich

Library

Total 


\author{
Table of Contents \\ DEVELOPMENT AND PROPERTIES OF URANIUM-BASE ALLOYS \\ CORROSION RESISTANT IN HIGH TEMPERATURE WATER
}

Part IV - Radiation Stability of Uranium-Base Alloys

Page No.

Abstract

I. SUMMARY

II. INTRODUCTION

III. EXPERIMENTAL CONDITIONS

A. Alloys Investigated

10

B. Fabrication Procedures

11

C. Radiation Procedures

11

1. Types of Tests

2. Heat Transfer and Exposure Calculations

11

12

D. Testing Procedures

12

IV. URANTUM-MOLYBDENUM ALLOYS

14

A. Phase Relationships and Radiation Program 14

B. Dimensional Stability and Density 14

I. Bare Material

2. Clad Material

14

15

C. Electrical Resistivity 16

D. Hardness 18

E. Corrosion Resistance 19

1. Bare Material

2. Clad Material

19

3. Loop Tests

21

23

F。 Bend Ductility 24

V. URANTUM-NIOBIUM ALLOYS

A. Phase Relationships and Radiation Program 25

B. Dimensional Stability and Density 26

1. Bare Material 26

2. Clad Material. 26 


\section{Table of Contents (Cont)}

Page No.

C. Electrical Resistivity

26

D. Microhardness

E. Microstructure

F. Corrosion Resistance

VI. URAIIUM-SILICON ALIOYS

A. Phase Relationships 28

B. Dimensional Stability and Density 29

C. Electrical Resistivity 30

D. X-ray Diffraction 3 I

E. Microhardness 32

F. Microstructure

G. Corrosion Resistance 33

VII. DISCUSSION AND CONCLUSIONS

A. Irradiation Behavior of Single-phase Uranium-base Alloys

B. Crystal Structure of the Reversion upon Irradiation

C. Volume Expansion

D. Corrosion

VIII. REFERENCES

Tables

41

Figures 


\section{LIST OF ILLUSTRATIONS}

Fig. No.

1

2

4

5

6

7

8

10

1.1

12

13

14

15

16

Title

$\underline{\text { Page }}$

Cross-section of capsule used for the irradiation of unclad uranium alloys

Cross-section of clad uranium alloy specimens

94

Photograph of gamma quenched U-13.5 w/o Mo, irradiated to $3200 \mathrm{MWD} / \mathrm{T}$, showing typical

"banding" near end.

Decrease in density vs. exposure of irradiated gamma quenched U-Mo alloys

Change in electrical resistivity of gamma quenched U-Mo alloys vs. exposure

Electrical resistivity as a function of temperature for U-9 w/o Mo alloy

Electrical resistivity as a function of temperature for U-10.5 w/o Mo alloy

Electrical resistivity as a function of temperature for U-12 w/o Mo alloy

Electrical resistivity as a function of temperature for U-13.5 w/o Mo alloy

101

Hardness of uranium and uranium alloys vs. exposure 102

Hardness of U-Mo alloys vs. annealing temperature 103

Photograph of accelerated corrosion failure after irradiation at the $\mathrm{Zirca}$. oy-2 weld contaminated with uranium

Load vs. deflection of U-10.5 w/o Mo irradiated.

bend test samples

Bend test: sample of gamma quenched $\mathrm{U}-12 \mathrm{w} / \mathrm{O}$ Mo after irradiation to $115 \mathrm{MWD} / \mathrm{T}$, showing typical ductile behavior

Bend test sample of gamma quenched U-12 w/O Mo after irradiation to $1050 \mathrm{MWD} / \mathrm{T}$, showing typical brittle behavior

Electrical resistivity of U-10 w/O Nb alloy vs. temperature 
WAPD -127

\section{LIST OF ILLUSTRATIONS (Cont)}

Fig. No.

Title

$\underline{\text { Page }}$

Explanation of irradiation effects on the electrical resistivity of gamma quenched U-Mo and $\mathrm{U}-\mathrm{Nb}$ alloys

Microstructure of $\mathrm{U}-10 \mathrm{w} / \mathrm{O} \mathrm{Nb}$ alloy-Pre and post irradiation

$\mathrm{U}-3.8 \mathrm{w} / \mathrm{O} \mathrm{Si}$, irradiated to $470 \mathrm{MWD} / \mathrm{T}$, showing typical "blistering" and "banding" near end

$\mathrm{U}-3.8 \mathrm{w} / 0 \mathrm{Si}$, irradiated to $680 \mathrm{MWD} / \mathrm{T}$, showing typical "blistering" on end

$\mathrm{U}-3.8 \mathrm{w} / 0 \mathrm{Si}$, irradiated to $660 \mathrm{MWD} / \mathrm{T}$, showing bending and cracking of the specimen end

Electrical resistivity of $\mathrm{U}-3.8 \mathrm{w} / \mathrm{O} \mathrm{Si}$ alloy as a function of temperature

23 X-ray diffraction pattern of unirradiated epsilonized $\mathrm{U}_{3} \mathrm{Si}$

$\mathrm{X}$-ray diffraction pattern of irradiated $\mathrm{U}_{3} \mathrm{Si}$

25 X-ray diffraction pattern of unirradiated $\mathrm{U}_{3} \mathrm{Si}$ (abraded surface)

Volume changes as a result of irradiation

Photograph of a Zircaloy-1 clad U-2 w/o Zr alloy, irradiated to $10,250 \mathrm{MWD} / \mathrm{T}$, showing the splitting of the clad due to volume expansion of core 
DEVELOPMENT AND PROPERTIES OF URANIUM-BASE ALLOYS CORROSION RESISTANT IN HIGH TEMPERATURE WATER

Part IV - Radiation Stability of Uranium-Base Alloys

\author{
$\underline{\text { ABSTRACT }}$
}

The effects of pile irradiations on the physical properties and corrosion resistance of U-9, $-10.5,-12$, and -13.5 $\mathrm{w} / \mathrm{O} \mathrm{Mo} ; \mathrm{U}-10 \mathrm{w} / \mathrm{O} \mathrm{Nb}$; and $\mathrm{U}-3.8 \mathrm{w} / \mathrm{O} \mathrm{Si}$ alloys are reported. The dimensional stability under irradiation of the gamna phase U-Mo and U-Nb alloys is excellent; however, an isotropic volume increase of $4-6 \%$ per w/o burnup may limit the ultimate fuel element life. Corrosion resistance of the gamma-phase alloys appears to be improved when subjected to a neutron field; this is attributed to an irradiation induced stabilization of the gamma phases. The UzSi alloy, on the other hand, suffered severe deterioration, particularly of corrosion resistance. Changes in electrical resistivity, hardness, mechanical properties, and crystal structure are presented and tire mechanisms producing the observed changes discussed.

\title{
I. SUMMARY
}

The effects of pile irradiations on the physical properties aind corrosion resistance of $\mathrm{U}-9,-10.5,-12$, and $-13.5 \mathrm{w} / \mathrm{O} \mathrm{Mo}$; U-IO w/O No; and $\mathrm{U}-3.8 \mathrm{w} / \mathrm{O}$ Si alloys having properties sufficiently promising to justify their development as PWR fuel material were studied. These investigations have been limited to the binary uranium alloys; the effects of further additions were not studied. Bare and clad alloys of $\mathrm{U}-\mathrm{Mo}$ and $\mathrm{U}-\mathrm{Nb}$ were irradiated in both the gamma-quenched and the alphatransformed conditions. The U-Si alloy was irradiated bare in the epsilonized condition only. Several in-pile loop tests were performed on defected clad specimens exposed to conditions similar to PWR fuel elements in service. The results of these tests are summarized.

Irradiation of uranium and uranium alloys induces two coexistent dimensional effects: (I) anisotropic or "plastic" growth, with little change in density accruine from irradiation-induced strain within the metallic crystalites, and (2) the increase of all dimensions concurrently, as evidenced by a density decrease. The terms "plastic growth" and "volume change" are used throughout this report in referring to these two dimensional effects. 
Irradiation induced no significant plastic growth in U-9, -10.5, -12, and $-13.5 \mathrm{w} / 0 \mathrm{Mo}$ alloys and $\mathrm{U}-10 \mathrm{w} / 0 \mathrm{Nb}$ alloy. The density of gammaquenched $U-M o$ alloys decreased with increasing exposure; a maximum density decrease of $4.4 \%$ in unclad specimens was noted at an exposure of $8800 \mathrm{MWD} / \mathrm{T}$. Zircaloy-2 clad U-Mo samples also increased in dimensions with increasing exposure; the maximum volume increase of $4.3 \%$ occurred at an exposure of $28,200 \mathrm{MWD} / \mathrm{T}$ and caused the cladding to split.

The densities of U-Mo and U-No samples irradiated in the alphatransformed conditions decreased toward the densities of these alloys in the gamma-quenched conditions.

Radiation decreased the density of epsilonized U-3.8 w/O Si alloy by $4.1 \%$. Associated with these density changes were a peculiar banding and blistering on the sample surface.

Electrical resistivity of gamma-quenched U-Mo alloys decreased sharply from radiation to low exposures. With increasing exposure, resistivity increased steadily. In contrast, the $\mathrm{U}-10 \mathrm{w} / \mathrm{O} \mathrm{Nb}$ alloy samples irradiated in the gamma-quenched condition showed an initial increase in electrical resistivity at low exposures followed by a sharp decrease with increasing exposure. These results have been attributed to the combination of the formation of vacancy-interstitial pairs and partial ordering in the U-Mo alloys and the combination of the formation of vacancy-interstitial pairs and clustering of like atoms in the U-NB alloy.

Increased electrical resistivity in irradiated alpha-transformed samples of U-Mo and U-Nb alloys indicated a reversion of these alloys to the gamma phase. Resistivity approached a constant value with increasing exposure regardless of pre-irradiation conditions.

The hardness of gamma-quenched U-Mo alloys increased with exposure to a saturation level, after which no further increment was noted. A maximum increase of $90 \mathrm{DPH}$ units occurred after an exposure of $8000 \mathrm{MWD} / \mathrm{T}$. Samples of gamma-quenched U-10 w/O No showed an increase of $61 \mathrm{DPH}$ units after an exposure of $820 \mathrm{MWD} / \mathrm{T}$. As low an exposure as $105 \mathrm{MWD} / \mathrm{T}$ increased the hardness of epsilonized U-3.8 $\mathrm{Si} 215 \mathrm{DPH}$ units.

Samples of U-Mo and U-Nb alloys irradiated in the alpha-transformed conditions decreased in hardness toward the hardness values of the alloys in the gamma-quenched conditions.

Radiation induced no significant changes in the corrosion rates of gamma-quenched U-Mo alloys in $650^{\circ} \mathrm{F}$ static water. However, radiation accelerated the failure time of unclad samples; samples of U-12 w/O Mo irradiated to a maximum exposure of $2000 \mathrm{MWD} / \mathrm{T}$ disintegrated in $650^{\circ} \mathrm{F}$ water in 1 to 7 days, as compared with 66 days for unirradiated control samples. Irradiation to a maximum exposure of $820 \mathrm{MWD} / \mathrm{T}$ increased the corrosion rate of $\mathrm{U}-10 \mathrm{w} / \mathrm{O} \mathrm{Nb}$ samples. Irradiation to low exposures caused samples of epsilonized U-3.8 w/O Si alloy to lose essentially all corrosion resistance to $650^{\circ} \mathrm{F}$ water; irradiated samples disintegrated in 22 hours as compared with 84 days for control samples. 
Clad gamma-quenched U-Mo alloys irradiated to approximately $5000 \mathrm{MND} / \mathrm{T}$ and defected after irradiation showed no significant changes in their corrosion lives.

Clad samples of $\mathrm{U}-12 \mathrm{w} / 0 \mathrm{Mo}$ and $\mathrm{U}-10 \mathrm{w} / 0 \mathrm{Nb}$ defected and irradiated in hot water loops successfully survived irradiation. Maximum exposures of 4000 and $1200 \mathrm{MWD} / \mathrm{T}$ were reached for the U-12 w/O Mo and U-10 $\mathrm{w} / \mathrm{O} \mathrm{Nb}$ alloys, respectively.

As determined by room temperature bend tests irradiation of gammaquenched $U-10.5$ and $-12.0 \mathrm{w} / 0$ Mo samples sharply reduced ductility after $700 \mathrm{NWD} / \mathrm{T}$ exposure. However, the addition of molybdenum to uranium improved the resistance to radiation-induced embrittlement, as complete embrittlement of unalloyed uranium is realized at exposures as low as $65 \mathrm{MWD} / \mathrm{T}$ 。

It is concluded from the results show in this report that additions of 9 to $13.5 \mathrm{w} / \mathrm{O}$ Mo and of $10 \mathrm{w} / \mathrm{Nb}$ to uranium stabilize the gamma phase and hence yield an alloy with suitable radiation properties for use in pressurized water reactors.

\section{INTRODUCTION}

As indicated in WAPD-127, Part I, radiation stakility is one of the major requirements in the over-all program of alloy development for the Pressurized Water Reactor. That is, critical properties of the fuel, such as dimensional stability and corrosion resistance in high temperature water, must not deteriorate under neutron rombardment to the point that fuel element integrity would he seriously jeopardized during core Iife, even in the case of clad penetration. To accumulate information on the effects of radiation on dimensional stability, corrosion resistance, and related factors such as density, mechanical, and structural changes, an extensive experimental program was undertaken.

Fy May 1953, the core alloy development work for PIR had estatlished that U-Mo alloys in the range of $9-13.5 \mathrm{w} / \mathrm{O}$ Mo; U-Nb alloys in the range of approximately $10 \mathrm{w} / \mathrm{O} \mathrm{Nb}$, and the epsilon phase of U-Si $(3.8 \mathrm{w} / 0 \mathrm{Si}$ ) were the most promising. Primary development effort was directed to U-Mo alloys with relatively less effort eypended on the development of U-Nb and U-Si alloys. The radiation program followed the same emphasis。

Although fuel elements utilizing these alloys would have a Zircaloy-2 cladding for primary corrosion resistance, $100 \%$ cladding integrity cannot be guaranteed; consequently, determining the effect of radiation on the corrosion behavior of such alloys in both the unclad and clad conditions was necessary, particularly since very little work concerning the effect of radiation on the corrosion behavior of fissionable alloys had been reported. Another parameter of primary interest was the radiation effect on the dimensional stability of these alloys. The dimensional instability of unalloyed uranium under radiation is well known. However, alpha uranium has an orthorhombic crystal structure, whereas gamma-phase U-Mo and U-Nb alloys have a body-centered cubic 
structure and epsilon-phase U-Si alloy a tetragonal structure. It was believed that the behavior of these crystal structures under radiation would be quite different and in each case superior to that of alpha uranium. Here again, it was necessary to irradiate both unclad and clad alloys to ascertain the effect of the cladding on possible dimensional instability of these alloys.

Because power reactor fuel elements are subjected to thermal, hydraulic, and mechanical stresses, the effect of radiation on the strength and ductility of these alloys had to be considered. In the case of unalloyed uranium, very slight radiation (65 MWD/T) severely reduces ductility; 1 radiation to $630 \mathrm{MWD} / \mathrm{T}$ almost completely embrittles the material and also increases the yield point by a factor of two.? The different crystal structures made it difficult to estimate the radiation effects on the mechanical behavior of these alloys from those of unalloyed uranium. Therefore, the radiation effect on the strength properties of U-Mo alloys was checked by a series of bend tests which lent themselves readily to the sample configuration available.

Data were obtained on the effects of radiation on the density, electrical resistivity, microstructure, and hardness of the alloys. Information about radiation-induced changes in these basic properties was needed to obtain a better understanding of the fundamental processes involved in radiation effects on uranium-base alloys. Initial results, when correlated with dimensional, corrosion, and mechanical property changes, were expected to indicate modifications in alloy composition and fabrication procedure to improve radiation stability of uranium-base alloys developed in the future. Also, since the gamma-phase U-Mo and $\mathrm{U}-\mathrm{Nb}$ alloys are kinetically rather than thermodynamically stable in the gamma condition at reactor operating temperatures, it was necessary to measure the effects of radiations on structures initially heat-treated to the transformed condition. The information from these studies has been reported in Reference 9 and is repeated in this report.

\section{EXPERIMENTAL CONDITIONS}

\section{A. Alloys Investigated}

The alloys investigated were

$$
\begin{aligned}
& \text { 1. U-9 w/O Mo, } \\
& \text { 2. U-10.5 w/o Mo, } \\
& \text { 3. U-12 w/O Mo, } \\
& \text { 4. U-13.5 w/O Mo, } \\
& \text { 5. U-10 w/O Nb, } \\
& \text { 6. U-3.8 w/O Si. }
\end{aligned}
$$

Both bare and Zlrcaloy-2 clad alloys have been irradiated and tested. To obtain data at high burnups and heat fluxes, the alloys were sometimes made by using uranium enriched in $\mathrm{J}^{2} 235$. 


\section{B. Fabrication Procedurës}

Because of the relatively long lead times involved in irradiating samples in-pile and subsequently determining their property changes, it was necessary to initiate experiments as soon as possible after feasible melting, fabricating, and heat treating procedures were developed, even though optimum procedures had not been established. As development progressed, appropriate changes were incorporated in material fabrication for new radiation experiments. In general, the melting, fabrication, and heat treatments employed were the best known when the experiment was initiated. Because of its effect on alloy homogeneity and crystallographic structure, heat treatment was particularly important insofar as radiation-induced effects were concerned and, therefore, is indicated for the samples included in each experiment following.

For the majority of the experiments described, the core alloy was duplex melted (induction melted. followed by consumable arc melting) from Fernald uranium and pure additive metal. (WAPD-127, Parts I and II, give the melting techniques, compositional variables and impurities, and resultant microstructures.) These duplex-melted ingots were used, without prior heat treatment, to prepare either bare or Zircaloy-2 clad rod-shaped extrusions. Except the specimens for experiment 1B, which were machined from cast buttons, all specimens were machined from the extrusions. Bare specimens were machined from either bare uranium alloy extrusions or Zircaloy-2 clad coextrusions, depending upon availability of extruded material, whereas clad specimens were obtained directly from the coextrusions. A description of the end-plugging procedures used for the preparation of clad fuel element specimens is given in Section C-I. The extrusion processes discussed in Part II are applicable to the materials used for the radiation experiments.

All pre-irradiation heat treatments were performed in evacuated and sealed Vycor bulbs. In most cases, zirconium chips were included in the sealed bulb as a getter for impurity gases. Where heat treatments indicated water quenching, the Vycor bulbs were water quenched; water did not contact the specimens. Because of the sluggishness of gamma-phase decomposition, rapid quenching was not required. Clad specimens were heat treated before end plugging to avoid bulging of the clad at the base of the end plugs due to expansion of entrapped gases during heat treatment.

\section{Radiation Procedures}

\section{Types of Tests}

In general, radiation tests are classified as (l) "in-pile" experiments (the property change involved is measured while the samples are in-pile), and (2) "pre-post" experiments (the property changes are determined by comparing sample measurements before and after radiation in the reactor). Most of the results described are from "pre-post" experiments irradiated in the Materials Testing Reactor (MTR) in vertical lattice and reflector positions, depending upon the thermal flux desired. 
For insertion in a reactor all experimental core alloys must be enclosed so that no contact with reactor process water is possible. To study dimensional stability, a capsule that would not impose restraint upon the samples had to be provided. This was accomplished by inserting the unclad core alloy sample in the NaK-filled Zircaloy-2 capsules shown in Fig. I; NaK, a liquid at room temperature, provided a suitable heat transfer medium.

Sufficient evidence of clad integrity of Zircaloy-2 clad alloys was available to show low probability of failure in the low temperature process water $\left(40^{\circ} \mathrm{C}\right.$ maximum). Therefore, all clad rods were irradiated directly in process water. As shown in Fig. 2, the rods were cut from coextrusions, the core alloy bored from each end, and suitable Zircaloy-2 plugs arc-welded to the cladding. Early experiments indicated the necessity of removing all core alloy from the cladding in the vicinity of the arc-weld because radiation adversely affects corrosion of contaminated welds. Therefore, after boring, the ends were etched free of all uranium alloy. After welding, all clad specimens were corrosion tested 2 days in $650^{\circ} \mathrm{F}$ water to assure weld and clad integrity.

Specimens in loop experiments were similar to the clad specimens just described. The specimens were inserted into closed loops in the reactor. Since the water supply for each loop was independent of reactor process water, it was permissible to irradiate defected clad specimens. Water temperature and pressure were similar to the PWR design conditions. Loop designs and operations are not described in detail in this report because they are included in WAPD-PWR-Chemistry reports. 3

\section{Heat Transfer and Exposure Calculations}

For experiments irradiated in the MTR, the value of the thermal flux was either supplied by the reactor operator or indicated by flux monitors irradiated with the samples. Where the flux value was supplied by the reactor operator, the vertical flux distribution for any single train of specimens was determined from the flux plots given in IDO-16047.4 In the case of loop specimens, the exposures were calculated from a heat balance of the loop operations and the known vertical flux distribution. Exposure values are in megawatt days per ton of alloy, and burnups are given as percent of total atoms in the core alloy.

The temperature distributions were calculated on the basis of radial heat flow only. It was assumed that no perturbation of flux existed within the specimens and that the contact drops between core and clad and the film drops at NaK interfaces (in case of capsule irradiations) were zero.

\section{Testing Procedures}

Pre-irradiation measurements were made on standard laboratory equipment. Post-irradiation dimensions were measured on remotely operated micrometers accurate to \pm 0.0005 in. Density was measured hydrostatically 
with a standard Grammatic balance modified for remote operation.

Post-irradiation microhardness was obtained on a Tukon hardness tester operated by remote control; samples were cut from the irradiated specimens, mounted in bakelite, and polished. Hardness values are in DPH units.

Pre-irradiation and post-irradiation electrical resistivity was measured by the current-potential method; the apparatus used for the gamma-quenched uranium-molybdenum alloys is described in WAPD-78.5 A revised apparatus, utilizing a Kelvin double bridge, was used to measure the transformed uranium-molybdenum alloys and the uranium-niobium alloy.

Bend tests were made on a self-aligning jig having two $1 / 4-i n$ diam cylindrical supports $I$ in. apart and a ram with a l/4-in. diam bending surface. The bending. was done at room temperature on a $20,000-1 b$ Baldwin tensile machine. Autgographic records of head motion versus load. were made with a differential transformer type extensometer and a Baldwin stress-strain recorder.

The equipment for corrosion testing irradiated materials is described in WAPD-T-179.6 With the exception of the first unclad uranium-molybdenum experiment, corrosion tests were performed in degassed distilled water at $650^{\circ} \mathrm{F}\left(343^{\circ} \mathrm{C}\right)$ at saturation pressure (2200 psi). The corrosion rates of the control samples in experiment $1 B$ were excessively high at this temperature; consequently, the experiment $I B$ samples were tested in degassed distilled water at $575^{\circ} \mathrm{F}\left(302^{\circ} \mathrm{C}\right)$ at saturation pressure (1260 psi).

Corrosion rates of various unclad samples heat treated in NaK-filled capsules were similar to those of control samples treated in the absence of $\mathrm{NaK}_{\text {, }}$ indicating that $\mathrm{NaK}$ was satisfactory as a heat transfer medium for the in-pile samples.

Clad samples were defected after irradiation by drilling a 0.040-in. diam hole through the clad into the core material to a total depth of $0.050 \mathrm{in}$. The defect was approximately midway between the bases of the end plugs. Clad thickness varied between 0.030 and 0.035 in.; therefore, the penetration of the defect into the core alloy was approximately 0.015 to 0.020 in. The defected samples were tested in degassed distilled water $650^{\circ} \mathrm{F}\left(343^{\circ} \mathrm{C}\right)$ at saturation pressure (2200 psi). Sample failure was determined visually after a test period. Types of failure included (1) clad swelling, (2) clad splitting, and (3), in the particular case of samples from experiment 1C, corrosion of contaminated weld metal.

During experiments $\mathrm{IL}, 2 \mathrm{~L}$, and $3 \mathrm{~L}$ in the hot water loops, observation of general activity levels, uranium and "crud" concentrations, activities of specific nuclides, and delayed neutron and rare gas activities were made on the loop water. Descriptions of the monitoring equipment and an analysis of the radiochemical observations are presented in WAPD-CPM-1.3 
WAPD-127

\section{URANTUM-MOLYBDENUM ALLOYS}

\section{A. Phase Relationships and Radiation Program}

The solid solubility of molybdenum is $1.7 \mathrm{w} / 0$ in alpha uranium and $25 \mathrm{w} / 0$ in gamma uranium at $128^{\circ} \mathrm{C}$. Transformation of the gamma phase to room temperature stable phases occurs by eutectoid decomposition at $562^{\circ} \mathrm{C}$ and 11.4 w/o Mo.7. The gamma phase, which is the most corrosion resistant in high temperature water, can be retained at room temperature by cooling from above the eutectold temperature. It can be transformed by prolonged heating at temperatures below the eutectoid; 8 the transformation products are alpha and epsilon. The latter phase, which also forms by a peritectoid reaction at $605^{\circ} \mathrm{C}$ and $16.5 \mathrm{w} / \mathrm{O} \mathrm{Mo}$, has a tetragonal crystal structure and may be considered an ordered form of the gamma phase. Phase diagrams of the U-Mo system, together with a more complete discussion of the phase relationships, are given in WAPD-127, Part I.

Four nominal compositions of uranium-molybdenum alloys have been investigated in the irradiation program. The U-9 and $-10.5 \mathrm{w} / 0$ Mo compositions are inypoeutectoid, whereas the U-l2 and $-13.5 \mathrm{w} / 0$ Mo compositions are hypereutectoid alloys.

The U-Mo alloy irradiation experiments are listed in Table 1, together with the maximum exposures in each experiment. The maximum exposure given any gamma-quenched unclad material was 8800 MWD/T. Six experiments on bare material were performed, including one on material heat-treated to provide the alpha-plus-epsilon phases (experiment $6 \mathrm{~B}$ ). The behavior of the bare alpha-transformed material is described in detail in WAPD-T-300.9 The experimental results, however, are summarized in this report for the sake of completeness.

Eight experiments were performed on Zircaloy-2 clad material: one (experiment 5C) was on alpha-transformed material; the others were on as-extruded or gamma-quenched material, both resulting in a gamma-phase structure for the core alloys. Three hot water loop tests, each containing a specimen having a defect through the clad, were conducted to provide qualitative evaluations of irradiation effects on dimensional stability and corrosion life of prototype PWR fuel elements. Specimen exposures (maximum, 28,200 MWD/T) and calculated specimen temperatures are shown in Tables 2 through 9 .

\section{B. Dimensional Stability and Density}

\section{Bare Material}

No measurable changes in dimensions and density were observed for samples of gamma-quenched U-Mo alloys exposed to less than $1200 \mathrm{MWD} / \mathrm{T}$. For higher exposures the changes observed for U-10.5, -12, and -13.5. w/o Mo alloy samples are shown in Table 10. Comparison of the changes in diameter and length indicated no appreciable anisotropic growth, since the percent increase in both was approximately equivalent. For pure isotropic volume expansion, these changes in length and diameter should be equivalent. 
In general, both diameter and length appear to increase directly with exposure. Although the surface of the samples did not show any roughening, a slight bow distortion did occur in the highest exposure samples. The samples were very brittle--the ends were chipped. Whether this chipping occurred during irradiation or subsequent handling is not known. Samples irradiated to high exposures exhibited a "banding" near the ends (Fig. 3), tentatively attributed to a localized dimensional or structural instability within the material or to some effect of the NaK environment in which the specimens were exposed, though the exact cause is unknown.

The density decreases of gamma-quenched U-10.5, -12, and -13.5 w/o Mo alloys versus exposure are plotted in Fig. 4. Because of the scatter in the data, any effects of molybdenum content on density change are inconclusive. Volume changes under radiation are discussed in Section VII-C. Although the temperatures indicated in Table 10 are considered too low to cause any appreciable transformation to alpha plus epsilon, the possibility should be considered. The density of the transformed products is greater than that of the gamma-phase material. Thus, any transformation during irradiation would cause an increase in density rather than the decrease observed. It may be concluded from the data that gamma-phase alloys irradiated at temperatures of $400^{\circ} \mathrm{C}$ and below decrease in density about $0.5 \%$ per $1000 \mathrm{MWD} / \mathrm{T}$ (O.I a/o burnup).

Twenty specimens of U-9, $-10.5,-12$, and $-13.5 \mathrm{w} / 0$ Mo alloys, some heat treated prior to radiation to produce the transformation products alpha plus epsilon, were irradiated as experiment $6 \mathrm{~B}$ in the MTR; maximum exposure was $790 \mathrm{MWD} / \mathrm{T}$. The alpha-transformed U-9 w/o Mo a.loy specimens decreased 1.0 and $1.3 \%$ in density after exposures of 755 and $790 \mathrm{MWD} / \mathrm{T}$, respectively. One U-10.5 w/O Mo alloy specimen, transformed to alpha plus epsilon, showed a density decrease of $0.5 \%$ after an exposure of $730 \mathrm{MWD} / \mathrm{T}$. No density or diametral changes were found in the U-9 or $-10.5 \mathrm{w} / 0$ Mo alloy specimens irradiated in the gamma phase. This is in agreement with the results from experiments $I B$ and $2 B$. The $U-12$ and $-13.5 \mathrm{w} / 0$ Mo alloy specimens showed no changes in diameter or density, regardless of their prior heat-treated condition or neutron flux exposure. (Results are summarized in Table 11.) The density decreases in the U-9:w/O Mo alloy specimens were such that the transformed specimens after radiation had density values close to that of gamma-quenched U-9 w/o Mo alloys, indicating a change in phase from the transformed back to the gamma condition. 8 The differences in density values of U-10.5, -12 , and -13.5 w/O Mo between the gammaquenched and the transformed conditions are small or negligible. If phase transformation reversal occurred in these alloys, no density changes would be discernible.

\section{Clad Material}

Dimensional and density changes in Zircaloy-2 clad U-9, -10.5, -12 and $-13.5 \mathrm{w} / 0$ Mo alloy samples are summarized in Table 12. Samples irradiated in the gamma-quenched condition showed no significant changes in dimensions when exposed to $5610 \mathrm{MWD} / \mathrm{T}$ or less. This is to be compared with density decreases of about $3 \%$ for unclad garma-quenched material 
given a similar exposure. As shown in Table 12 under experiments $3 \mathrm{C}$ and $4 \mathrm{C}$, the length changes increased with increasing exposure and decreased with increasing molybdenum content.

Specimen B-32, a Zircaloy-2 clad uranium-10.5 w/O Mo sample exposed to 28,200. MWD/T (see Table 9) had longitudinal splits in the cladding after irradiation. Close examination indicated some plastic flow in the cladding prior to failure. Since this specimen was irradiated in low temperature water $\left(100^{\circ} \mathrm{C} \max \right)$, it is doubtful that corrosion of the cladding was a signiflcant factor in its failure. The failure probably occurred by the volume expansion of the core material with a consequent straining of the cladding to the rupture point. Fracture of Zircaloy tubing at a volume expansion of $4 \%$ is not unexpected. The unfform strain to necking of Zircaloy-2 in the transverse direction is about il\% in a tensile test. Under hydrostatic pressure, therefore, the cladding would be expected to reach its instability strain at about $5.5 \%$ expansion. In contrast to unclad samples, clad samples decrease in density about 0.13 to $0.18 \%$ per $1000 \mathrm{MWD} / \mathrm{T}$.

Four samples each of Zircaloy-2 clad U-9 and -10.5 w/o Mo alloys, heat treated so that the core alloys were partially transformed, were irradiated in MTR process water to estimated maximum exposures of $2100 \mathrm{MWD} / \mathrm{T}$. The maximum length increases (shown under experiment $5 \mathrm{C}$ in Table 12) were $0.07 \%$ and $0.12 \%$ for the U-9 and -10.5 w/O Mo alloys, respectively. Because the specific volumes of these alloys in the transformed condition are less than the specific volumes in the gamma condition, the length increases can be attributed to the reversion of the core alloys to the gamma condition.

\section{Electrical Resistivity}

Electrical resistivity changes in irradiated bare samples of gamma-quenched $U-10.5$ and -12 w/O Mo alloys are shown in Tables 13 and 14. Resistivities for unirradiated samples given simulated reactor heat treatments are given in Table 15. Table 16 lists the changes produced by irradiating both gamma-quenched and alpha-treated samples of U-9, $-10.5,-12$, and $-13.5 \mathrm{w} / \mathrm{O}$ Mo. Resistivity at various temperatures was obtained before and after irradiation for all alloys and all heat treatments. Figures 6 through 9 show the results for U-9, -10.5, -12, and $-13.5 \mathrm{w} / 0$ Mo alloys, respectively. Since the absolute values of resistivity for the U-12 and $-13.5 \mathrm{w} / \mathrm{O}$ Mo alloys demonstrated little change with temperature, the resistivity has been normalized with respect to the resistivity of the gamma-quenched alloy at liquid nitrogen temperature $\left(-196^{\circ} \mathrm{C}\right)$.

In these curves (FIgs. 6-9) the electrical resistivity of gammaphase U-Mo alloys shows a negative temperature coefficient over the temperature range of measurements $\left(-196^{\circ}\right.$ to $\left.+150^{\circ} \mathrm{C}\right)$. This anomaly has been attributed to an overlap of the Brillouin zones in body-centered cubic structures at an electron-to-atom ratio of 4.19.* "Fulize trans. formed material has the normal positive temperature coefficient of electrical resistivity. The small increase in resistivity upon heat treating gamma-quenched U-12 w/O Mo at $300^{\circ} \mathrm{C}$ for 6 weeks (see Table 15)

*E. K. Halteman, Private Communication, Bettis Plant. 
is explained by the precipitation of impurities at the grain and subgrain boundaries, which occurs prior to actual transformation.10

Tables 13 and 14 and Fig. 5 indicate that resistivity decreased in all irradiated gamma-quenched samples. The initial sharp decrease in resistivity at low exposures is attributed to a partial ordering due to neutron bombardment. Since partial transformation to alpha plus epsilon also causes a decrease in resistivity, this possibility during radiation must be considered. The calculated bulk temperature of the specimens (Tables 2 and 3) was much lower than temperatures which cause any appreciable resistivity change (Table 15). It is postulated that short radiations produce an equilibrium amount of ordering, whereas longer radiations cause the normal resistivity rises associated with the production of vacangy-interstitial pairs and the introduction of impurity atoms formed by fissioning.9. The results on gamma-quenched U-Mo alloys from experiment 6B (Table 16) agreed closely with those from experiment $2 B$. The $3.0 \%$ decrease in resistivity for specimen C6 (gamma-quenched $\mathrm{U}-12 \mathrm{w} / \mathrm{O} \mathrm{Mo}$ ) irradiated to an exposure of $265 \mathrm{MWD} / \mathrm{T}$ may be compared with the $3.2 \%$ decrease for specimen 81 irradiated to an exposure of $230 \mathrm{MWD} / \mathrm{T}$ in experiment $2 B$.

When alpha-transformed uranium-molybdenum alloys were irradiated, electrical resistivity increased markedly (see Table 16 and Figs. 6 through 9). All transformed specimens of U-9, -10.5, -12, and -13.5 w/O Mo (heat treatment 4: $525^{\circ} \mathrm{C}, 312 \mathrm{hr}, \mathrm{W} . \mathrm{Q}$.) showed not only large resistivity increases after irradiation but also temperature coefficient changes from positive to negative. The resistivity of all gammaquenched specimens and partially transformed specimens (heat treatment 1,2 , and 3) decreased upon radiation, and the temperature coefficients remained negative. These data indicate an approach to a common resistivity with increasing exposure, regardless of the pre-irradiation condition of the material. At liquid nitrogen temperature $\left(-196^{\circ} \mathrm{C}\right)$, the apparent equilibrium values of resistivity were 68-71, 69-73, 74, and $76 \mu \Omega \mathrm{cm}$ for $U-9,-10.5,-12$, and $-13.5 \mathrm{w} / \mathrm{O}$ Mo, respectively.

The behavior of the irradiated specimens cannot be duplicated by thermally transforming unirradiated gamma-quenched specimens. This is shown by the dotted curve in Fig. 8 , which relates resistivity and temperature for a specimen aged 76 hours at $525^{\circ} \mathrm{C}$. Heat treatments gave a resistivity at $-196^{\circ} \mathrm{C}$ in the thermally transformed sample equal to the equilibrium value after radlation; however, the higher temperature resistivity of the thermally transformed sample was appreciably different.

To check whether the resistivity values for thermally transformed and irradiated samples could also be obtained on samples having an alpha-plus-gamma structure, the following experiment was performed. A sample of U-9.w/o $\mathrm{Mo}_{9}$. gamma-quenched and thermally transformed to produce alpha plus epsilon (Iike the Irradiated samples); was heated at $580^{\circ} \mathrm{C}$ for periods up to 11 hours. Since this temperature was in the alpha-plusgamma field, the ordered epsilon phase was expected to disorder and result in only a small change in the amount of alpha present. Resistivity at first increased rapidly and then leveled off, reaching an equilibrium value only half that observed after neutron bombardment of a similar sample. The increase was from 31.5 to $52.5 \mu \Omega \mathrm{cm}$ at $-196^{\circ} \mathrm{C}$ as compared 
with 31.5 to $71 \mu \Omega \mathrm{cm}$ for the irradiated sample. X-ray diffraction indicated alpha and gamma present and no epsilon. The microstructure before and after the $580^{\circ} \mathrm{C}$ treatment appeared unchanged. The same sample was then held at $650^{\circ} \mathrm{C}$ (In the gamma-phase field) for approximately 16 hours. After this heat treatment the resistivity reached that of gama-quenched material $(72.5 \mu \mathrm{cm})$, and the microstricture showéd a normal gamma phase with no second phase present. These results indicate that the high resistivity values of transformed and irradiated samples cannot be explained by epsilon phase disordering alone. Alpha must be redissolved during radiation to attain the observed resistivities.

\section{Hardness}

Dirter

aresult of pre-post hardness measurements ion unclad alloys of $\mathrm{U}-10.5,-12$, and $-13.5 \mathrm{w} / 0$ Mo irradiated in the gamma-phase condition are show in plotted ln Fig. 10 together with data on hardness changes in alpha uranium. 11

In Table 18, data are presented for both cast and extruded material. The pre-irradiation hardness of the cast material (327 DPH) was higher than that of the extruded material (307. DPH). However, the hardness of the extruded material increased rapidly upon exposure to neutron bombardment and reached approximately the same val ue as the cast material at exposures as low as $115 \mathrm{MWD} / \mathrm{T}$.

Figure 1 is is curve of hardness versus annealing temperature for unirradiated gamma-queriched $\mathrm{U}-10.5$ and $-12 \mathrm{w} / \mathrm{O}$ Mo alloys. At annealing temperatures as high as $300^{\circ} \mathrm{C}$, the hardness of $\mathrm{U}-10.5 \mathrm{w} / 0$ Mo alloy remained constant, whereas that of the U-12 w/o Mo alloy decreased slightly with lncreasing temperature. At $400^{\circ} \mathrm{C}$ annealing temperature, both alloys increased markedy in hardness, indicative of precipitation and of phase transformation to the alpha-plus-epsilon phases. Therefore, consideration must be given to the possibility that the radiation-induced hardness increases may be attributed to slight transformation However, the calculated specimen temperatures, as shown in Tables 2,3 ; and 4 ; were less than $300^{\circ} \mathrm{C}$, except for two U-10.5 w/O Mo samples (specimens 47 and 48, experiment $5 B$ ). From a comparison of these temperatues with the annealing temperatures shown in Fig. Il, no change in hardness due to transformation would be expected. Secondly, since the samples exposed to' the lowest neutron flux showed a large hardness increase, phase transformation did not appear to be significant. More likely, the introduction of vacancies and interstitials due to neutron bombardment and fission fragment damage caused strains within the metal lattice and a consequent hardness increase." The hardness changes o(kig. IO') were very apreciable: However, the gamma-phase alloys showed Mess Change lin hardness upon irradiation than did alpha uranium, pertaps because of the less closely-packed structure of the body-centered cubic gammatlice and, hence, "its ability to accommodate foreign atoms with Iésts ilattice strain.

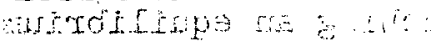

'TSamples of U-Mo alloys irradiated in the alpha-transformed condition mereased in hardness toward the values of the samples in the 
gamma-quenched condition (see Table 20). In general, the decreases were sufficient to bring the hardness values to that of the gamma-quenched condition at the same exposure. It may be assumed that upon radiation an equilibrium value of hardness was produced similar to the equilibrium values of resistivity discussed in Section C. Certainly these hardness decreases are in agreement with the observation that alpha-transformed U-Mo alloys upon radiation revert toward the gamma phase.

\section{E. Corrosion Resistance}

\section{Bare Material}

When unclad U-Mo alloy samples are corrosion tested in high temperature water $\left(\sim 650^{\circ} \mathrm{F}\right)$, they corrode at a fairly uniform rate until embrittlement caused by hydride formation results in gross cracking. Thereafter, corrosion rate increases with surface exposure, and the samples disintegrate rapidly, depending on the surface exposed. A reaction between the uranium alloy and the nascent hydrogen released from the water during the corrosion process produces the hydride phase. Subsequent corrosion of this phase is manifested by oxide fingers extending into it, causing severe local stresses in the samples. (The mecharism of corrosion is the subject of WAPD-127, Part III, in which a more complete analysis of the disintegration process is made.)

All samples, except those in experiment IB which were fabricated from quadruple arc-melted buttons, were submitted to standard test conditions- $-650^{\circ} \mathrm{F}\left(343^{\circ} \mathrm{C}\right)$, static, degassed water at saturation pressure. Results from control specimens of experiment $\mathrm{IB}$ tested in $650^{\circ} \mathrm{F}$ water indicated excessively high corrosion rates. Consequently, the testing temperature was lowered to $575^{\circ} \mathrm{F}\left(302^{\circ} \mathrm{C}\right)$ so that a better comparison could be made between the corrosion rates of the irradiated and the control samples. It is emphasized here that the decision to lower the testing temperature was based on the material properties prior to radiation and does not reflect any deleterious effect due to radiation.

Radiation induced no significant changes in the corrosion rates of gamma-quenched U-Mo alloys. Representative corrosion rates of irradiated and non-ixradiated samples (from experiments $I B$ and $2 B$ ) in $650^{\circ}$ static water are listed in Table 21.

The days to failure for the experiment $I B$ samples are also shown in Table 2l. Heat treating up to $400^{\circ} \mathrm{C}$ for 6 weeks produced practically no change in the corrosion life of control samples, but a heat treatment at $500^{\circ} \mathrm{C}$ for 6 weeks caused the samples to disintegrate in 1 day. Because such a treatment produces essentially complete transformation to the stable epsilon and alpha phases, the drastic reduction in corrosion resistance was expected. The time to failure for the irradiated samples, however, was considerably less than that for the control samples and was directly related to exposure. The higher exposure samples disintegrated in 1-7 days, whereas the lower exposure samples disintegrated in 7-2l days. Since physical property measurements, discussed previously, indicated little or no transformation to epsilon and alpha phases, the deterioration of corrosion life cannot be attributed to transformation but must be a result of radiation. 
It is concluded from these observations that radiation does not affect corrosion rates of cast U-Mo alloys but does accelerate failure time. Radiation even to low burnups increased hardness markedly, and also, as shown in Section IV-F, decreased ductility considerably. Thus, it is reasonable to expect that cracking will occur at lower stresses after radiation. Less hydride formation is required to cause cracking in radiation-embrittled samples than in control samples; therefore, the former fail sooner.

As shown in Table 2l, the results of corrosion testing gammaquenched control samples and heat-treated control samples of the U-10.5 and $-12 \mathrm{w} / 0$ Mo alloys included in experiment $2 B$ differed markedly from those just described. The irradiated experiment $2 B$ samples survived as long and in some cases longer than the control samples, although the corrosion rates given in Table 21 were unaltered by radiations. Several samples survived a 42-day corrosion test, whereas all control samples disintegrated in 35 days.

The corrosion results from experiment $2 B$ directly contrasted those from experiment $1 B$. Aside from the differences in corrosion test conditions, which should have been corrected by testing control and irradiated specimens under identical conditions, the only known difference between the experiments was the fabrication procedure. Experiment $1 \mathrm{~B}$ specimens were machined from cast buttons, experiment $2 B$ specimens from extruded rod. Insufficient data have been accumulated to tie down the effects definitely to a difference between cast and extruded material. However, when the known dissimilarities in mechanical behavior between cast and hot worked materials are considered (Table 18), it would be expected that the effects of radiation-induced embrittlement would be more pronounced in cast than in extruded material. As shown in WAPD-127, Part III, failure time in bare samples is not a material property but is affectea by sample size and shape. Therefore, the fact that corrosion rates of unclad samples are insensitive to radiation indicates that the corrosion life of fuel elements should be independent of radiation, at least to the exposures listed in Table 21. This again is not unexpected. It was shown in the Part I report that the corrosion rates of gammaphase alloys are quite insensitive to practically all additions; thus, the effect of contamination by fission atoms could not be expected to be severe. Similarly, structural damage to the metal matrix by radiation should not have a first-order effect on corrosion rates when these rates are controlled by external oxide formation.

A few corrosion results on irradiated U-Mo alloys, which had been thermally transformed to epsilon and alpha prior to radiation (see Table 22), can be analyzed as further indications of the reversal toward gamma phase during radiation. Because the corrosion rates of these alloys in the transformed state were high in $650^{\circ} \mathrm{F}$ water, interpretation of 24-hr corrosion data must be considered qualitative at best. The improvement in corrosion resistance of the unirradiated samples with increasing molybdenum content is attributed to the incomplete transformation of the higher molybdenum containing alloys by the heat treatment shown and the decreasing amount of alpha present with increasing molybdenum content. However, the data indicate an improvement due to radiation in all four alloys tested, which may be 
considered a result of gamma-phase formation at the expense of epsilon and alpha phases. That the corrosion resistance of the irradiated transformed material did not revert to that of the irradiated gammaquenched samples is attributed to the segregation of impurities during transformation which are not homogenized by radiation.9.

\section{Clad Material}

As described in WAPD-127, Part II and Part III, a correlation exists between the corrosion rate of bare samples and the life of the clad material, but there is no correlation between the lives of bare and clad samples. The corrosion rate controls the rate of formation of hydride within the core alloy. In bare samples, the hydride precipitates and subsequently causes disintegration of the samples. In clad material, however, the Zircaloy-2 cladding getters the hydrogen produced by the corrosion of the core alloy. Therefore, two factors control failure time for clad samples: the integrity of the bond between core alloy and Zircaloy-2 cladding and the diffusion rate of hydrogen in the core alloy. In an analysis of corrosion life of irradiated clad samples, the effects of radiation on these controlling factors must be considered. Since radiation produced no significant changes on the corrosion rates of gamma-quenched U-Mo alloys, any effects on the life of clad samples should be associated with bond line integrity or with hydrogen diffusion rates. No information was developed in these tests which can permit assessment of the hydrogen diffusion rate factor; any such effect, if it exists at all, is probably small.

Eight samples of as-extruded Zircaloy-2 clad natural uranium-10.5 w/o Mo alloy, irradiated to a maximum exposure of $1120 \mathrm{MWD} / \mathrm{T}$, were defected and corrosion tested in $650^{\circ} \mathrm{F}$ static water to failure. The results, together with the results of corrosion tests of two groups of control samples, are shown in Table 23. One group of controls was tested in the as-extruded condition, as were the irradiated samples; the second group was tested as heat-treated at $750^{\circ} \mathrm{C}$ for 40 minutes. In general, the heat-treated controls failed sooner than the as-extruded controls. Unfortunately, the samples which were irradiated had been fabricated in such a manner that the weld metal was contaminated with fuel alloy. The premature failure of several specimens resulted from the excessively high corrosion rate of the contaminated welds. This corrosion failure is shown in Fig. 12. The 2-day corrosion test in $650^{\circ} \mathrm{F}$ water prior to radiation was not sufficiently severe to show up this weld condition. Apparently, radiation greatly increased the corrosion rate of the contaminated weld metal, since the same fabrication procedures had previously been used for the preparation of corrosion specimens for experiments other than radiation tests without any indication of serious damage. The control samples for this experiment were fabricated after the weld metal contamination problem had been recognized, and special precautions were taken to prevent weld metal contamination during welding.

Four irradiated samples failed in $45-47$ days as a result of corrosion at the drilled defect rather than by corrosion of contaminated weld metal. The control specimens of the same alloy had corrosion lives which bracketed the four irradiated samples: two control samples failed 
in the 33-44 day test period, and three lasted 145 days or longer. It may be concluded that the variability in the unirradiated corrosion behavior was sufficient to overshadow any harmful effects of radiation on the corrosion properties. As discussed in the introduction, these samples were fabricated and exposed before many of the factors (described in WAPD-127, Part II) which deteriorate the corrosion resistance of clad specimens were recognized and rectified.

All the irradiated U-I2 and $-13.5 \mathrm{w} / 0$ Mo samples in experiment IC failed in corrosion at contaminated welds. Therefore, it was not possible to ascertain any effects of the radiation, and the data are not reported.

Thirty Zircaloy-2 clad $5 \mathrm{w} / 0$ enriched U-Mo alloy specimens from experiments $2 \mathrm{C}$ and $3 \mathrm{C}$, irradiated to a maximum exposure of $10,490 \mathrm{MWD} / \mathrm{T}$, were defected and corrosion tested to failure in $650^{\circ} \mathrm{F}$ static water. All had been fabricated in a manner to avoid weld contamination. The results are shown in Table 24.

Before radiation, these specimens were given a heat treatment of $750^{\circ} \mathrm{C}$ for $1 / 2$ hour. Early in the development of coextruded clad U-Mo rods, a heat treatment to homogenize the fuel alloy and relieve any residual stresses remaining from the extrusion process was believed desirable. Subsequent to the insertion of the specimens in-pile, such a heat treatment following extrusion was found to decrease the corrosion life of the samples. (Further discussion can be found in WAPD-127, Part II.) Failure in such interdiffused samples is attributed to the precipitation of a molybdenum-bearing compound in the diffusion zone, depletion of molybdenum in the matrix, and consequently poor corrosion resistance. To differentiate between the deleterious effects of heat treatment and radiation on corrosion life, two groups of control samples of each alloy have been tested. Half the control samples were given the same heat treatment as the irradiated samples $\left(750^{\circ} \mathrm{C}-1 / 2\right.$ hour $)$; half were treated in the as-extruded condition. The results are shown in Table 25. From these data, the $750^{\circ} \mathrm{C}-1 / 2$ hour heat treatment evidently damages the corrosion life of all four alloys. However, the decrease in corrosion life due to heat treatment is not sufficient to account for the poor corrosion life of the irradiated specimens.

The data from corrosion testing irradiated specimens, Table 24, indicate that the corrosion life of at least the core-clad interdiffusion layer is adversely affected by neutron bombardment. That all the failures of irradiated specimens were indicative of diffusion zone corrosion is of prime importance. The deterioration of corrosion resistance of the diffusion zone by radiation is consistent with the known structure of this zone. Information from Argonne National Laboratoryli2 has shown that radiation of $\mathrm{U}-\mathrm{Zr}-\mathrm{Nb}$ alloys of insufficient alloy content to stabilize the gamma phase markedly deteriorates hot water corrosion resistance. Thus, the diffusion zone in which molybdenum is precipitated as an insoluble compound in these clad rods would be expected to approach the alpha-prime alloys, of which the U-Zr-Nb composition is an example, in matrix properties and composition and hence to suffer deterioration in corrosion resistance upon radiation. In properly prepared clad rod samples little or no acceleration of corrosion failure occurs, as shown by the results of the loop tests. 


\section{Loop Tests}

Nine clad specimens of U-Mo alloys were irradiated in hot water loops with the core alloy exposed to high temperature water through drilled defects with no evidence of failure. No accelerated corrosion of the core alloy was found, although the total time in-pile for at least one specimen was sufficient to cause failure in an out-of-pile autoclave. This may be indicative of the known effect of radiation, as discussed above, in promoting homogenization and, thus, preventing decomposition of the gamma phase.

The first loop test of 14 Zircaloy-2 clad uranium-molybdenum coextruded samples, half of which were defected, was performed in the X-1 hot water loop at the NRX reactor of Atomic Energy of Canada, Ltd. (AECL). Specimen descriptions and irradiation data are shown in Table 26. Samples were at maximum temperature conditions for approximately 2 days. However, the samples were at temperatures approximately $30^{\circ} \mathrm{F}$ lower than those reported for about 40 days for reasons extraneous to the behavior of the metal alloy samples. (The loop operation and activity measurements are discussed in detail in a separate report.3) After removal from pile, no evidence of corrosion failure was found in any of the defected metal alloy samples. The release of activity in the loop water was consistent with the low corrosion rate of the samples.

After radiation eight of the loop samples, including three which had been defected while in the loop, were corrosion tested in $650^{\circ} \mathrm{F}$ static water. Fourteen similar specimens, irradiated in MTR process water to an estimated maximum exposure of $8830 \mathrm{MWD} / \mathrm{T}$, and five unirradiated control specimens were corrosion tested with these samples. The results, as shown in Table 27, indicate that the samples exposed in the $100 \mathrm{p}$ falled in post-irradiation tests earlier than either the MTR irradiated samples or the unirradiated control samples. Note that the previously defected samples on subsequent corrosion testing did not fail sooner than the previously undefected samples exposed in the Chalk River Loop. Note also that the control samples failed sooner than those irradiated at MTR prior to corrosion testing. Heresgain, the quality of the specimens was very poor, since they were fabricated at an early stage in the U-Mo alloy development. There is also a strong suspicior that corrosion testing after radiation does not give a true picture of irradiation effects on corrosion life. Neither a reason for the early corrosion failure of the loop specimens on post-irradiation corrosion testing nor a correlation of corrosion results with exposure, extrusion temperature, type of end closure, or defecting has been found.

It may be concluded from the data that in-pile corrosion is a less severe test than post-irradiation corrosion. Undoubtedly, the increased stability of the gamma phase during irradiation (Section VII-A) improves in-pile corrosion behavior.

The second loop test consisted of 13 extruded specimens of Zircaloy- 2 clad U-II and $-12 \mathrm{w} / 0 \mathrm{Mo}$, including one defected specimen, which were irradiated in the $\mathrm{X}-3$ hot water $100 \mathrm{p}$ at the $\mathrm{NRX}$ reactor of $\mathrm{AECL}$ to an estimated exposure of $4000 \mathrm{MWD} / \mathrm{T}$. The estimated temperature at the base of the defect was $688^{\circ} \mathrm{F}$. Description of the specimens and radiation 
history are shown in Table 28. The radioactivity of water samples, less than 2000 counts/min-ml throughout the total test time of approximately 4-1/2 months, indicates that the corrosion rate of the exposed fuel was extremely low during the entire in-pile period and consistent with outof-pile corrosion rate at this temperature. Visual examination of the specimens after irradiation showed no bulging or failure. A microscopic examination of a transverse section through the defect of the specimen defected in-pile revealed no corrosion attack on the fuel alloy.

The post-irradiation static corrosion test results for loop specimens, MTR process water control specimens, and unirradiated control specimens (Table 28) were inconclusive because of the poor quality of original extrusions from which all these irradiation specimens were machined. However, it is of particular significance that one defected specimen operated in-pile 4-1/2 calendar months. ( 135 days), including 98 days of reactor power operation, without any signs of failure, whereas similar specimens failed in 23 days or less in out-of-pile corrosion tests.

The third loop test consisted of a defected Zircaloy-2 alad $3.6 \mathrm{w} / 0$ enriched U-12 w/o Mo extruded sample, irradiated 6 weeks in the HB-5 loop in the MTR to an estimated 1200 MWD/T at a calculated coreclad interface temperature of $710^{\circ} \mathrm{F}$. The bare fuel material was exposed to neutral water $(\mathrm{pH}=7$ ) for the first 3 weeks and to water containing LiOH ( $\mathrm{pH}=9.5-10$ ) for the last 3 weeks. The average activity of water samples during the first 3 weeks was approximately 1200 counts/min-ml, which was reduced to 120 counts/min-ml after the LiOH addition. A spectrographic analysis of a water sample showed a high $\mathrm{Mn}$ content, indicating that the activity in the loop water was mainly from stainless steel corrosion. Also, the water activity was reduced to zero after passing through the ionexchanger, so that solids or solubles were responsible for the activity rather than fission gases, which would not be removed by the ion exchanger.

Microscopic examination of a transverse section through the defect of this specimen showed no indication of any corrosive attack on the fuel alloy:

The most important observation that can be made concerning these three loop tests is that exposure to water during radiation tends to improve the corrosion life of defected clad uranium-molybdenum alloys as compared with control samples or post-irradiation samples tested out of pile. That is, while the samples are under neutron bombardment, the resistance to hot water corrosion is improved, which may be explained by assuming that radiation tends to stabilize the gamma phase, the corrosion-resistant phase in uranium-molybdenum alloys.

\section{F. Bend Ductility}

In order to determine radiation effects on the ductility of bare gamma-quenched U-Mo alloys, a series of bend tests was performed on bare U-Mo alloys after maximum exposure of $1050 \mathrm{MWD} / \mathrm{T}$. The results of room temperature tests on four U-10.5 w/O Mo samples and four U-12 w/o Mo samples are shown in Table 29; curves of load versus head motion for the 
U-10.5 w/O Mo samples are shown in Fig. 13. Exposures up to $375 \mathrm{MWD} / \mathrm{T}$ affected neither the ductility nor the yield point of either U-10.5 or $-12 \mathrm{w} / \mathrm{O}$ Mo. Considering the marked effect of radiation on alloy hardness (Fig. 10), it is surprising that the load-deflection curves superimpose, despite radiation, up to the point of fracture. However, an exposure of $700 \mathrm{MWD} / \mathrm{T}$ sharply reduced the ductility of U-10.5 w/O Mo and markedly embrittled the U-12 w/O Mo sample; no evidence of plastic strain was observed in the latter specimen. An exposure of $940 \mathrm{MWD} / \mathrm{T}$ markedly embrittled both U-10.5 and -12 w/o Mo samples. A ductile sample and a brittle sample are shown in Figs. 14 and 15.

To separate the thermal contribution of bulk temperature during radiation from other radiation effects, bend tests were run on samples of $\mathrm{U}-10.5$ and $-12 \mathrm{w} / \mathrm{O}$ Mo which had been heat treated for 6 weeks at $200^{\circ}, 300^{\circ}, 400^{\circ}$, and $500^{\circ} \mathrm{C}$, respectively. The results (Table 30 ) indicate that heat treatment at temperatures which cause transformation to alpha plus epsilon $\left(400^{\circ}\right.$ and $500^{\circ} \mathrm{C}$ ) embrittles the alloys. However, the maximum calculated temperatures of all irradiated specimens tested were $239^{\circ} \mathrm{C}$ or less (Table 3 ). Therefore, the radiation-induced embrittlement cannot be attributed to a bulk temperature effect but, rather, to neutron bombardment.

\section{URAIVIUM-NIOBIUM ALLOYS}

\section{A. Phase Relationships and Radiation Program}

Niobium is completely soluble in gamma uranium. Transformation to room temperature stable phases occurs by eutectoid decomposition to alpha uranium having slight solubility for niobium and a niobium-rich, gammaprime phase which appears to be isomorphous with gamma. The eutectoid composition and temperature are $11 \mathrm{w} / 0 \mathrm{Nb}$ and $657^{\circ} \mathrm{C} .13$ As in the case of U-Mo alloys, the gamma phase is the corrosion-resistant phase and may be retained in alloys having a niobium content of greater than 6 w/o by relatively slow cooling. 14 However, the transformation to alpha plus gamma prime occurs much more readily on annealing below the eutectoid temperature than in the case of U-Mo alloys of similar alloy content. 8 Significantly, the gamma phase in U-Nb decomposes by separation of $U$ and $\mathrm{NL}$, whereas in U-Mo decomposition occurs by formation of an ordered phase as well as rejection of uranium.

Since transformation of the gamma phase to low temperature phases was known to occur readily at temperatures approximating PWR design temperatures 15 --maximum central metal temperature, $865^{\circ} \mathrm{F}$ ( $463^{\circ} \mathrm{C}$ )--both gamma-quenched and garma-quenched-and-aged samples were irradiated. One experiment of seven unclad samples and two experiments of Zircaloy-2 clad samples ( 10 and 12 specimens, respectively) were irradiated. All samples were obtained from extrusions of $\mathrm{U}-10 \mathrm{w} / 0 \mathrm{Nb}$. (Exposure and temperature data are shown in Tables 31, 32, and 33.) In addition, one defected clad specimen in the gamma-quenched condition was irradiated in an in-pile loop. The effort on $\mathrm{U}-\mathrm{Nb}$ alloys was more restricted than on U-Mo alloys because the proposed PWR fuel element dimensions lead to operation at temperatures that might result in the decomposition of the gamma phase in $\mathrm{U}-\mathrm{Nb}$. 
B. Dimensional Stability and Density

\section{Bare Material}

Changes in dimensions and density of unclad U-10 w/O $\mathrm{No}$ irradiated in $\mathrm{NaK}$ capsules to a maximum exposure of $820 \mathrm{MWD} / \mathrm{T}$ are shown in Table 34. The dimensions and density of the gamma-quenched specimens were essentially unchanged by radiation. The density decreases and length increases of the transformed samples (as with the U-Mo alloys) are toward the gamma condition because, on transformation of gamma, density increases. These results reconfirm the good radiation stability of gamma-phase alloys.

\section{Clad Material}

The first clad experiment consisted of ten samples in the gamma-quenched conditions listed here irradiated to a maximum exposure of $840 \mathrm{MWD} / \mathrm{T}$.

No. of

Samples

Fabrication History

Heat Treatment

\begin{tabular}{|c|c|c|}
\hline & As-extruded & $800^{\circ} \mathrm{C}, 4 \mathrm{hr}, \mathrm{W} \cdot \mathrm{Q}$. \\
\hline & A & $900^{\circ} \mathrm{C}, 24 \mathrm{hr}, \mathrm{W} \cdot \mathrm{Q}$. \\
\hline & Extruded + cold swaged + str & $h r, W \cdot Q$. \\
\hline & Extruded + cold swaged + straightene & $900^{\circ} \mathrm{C}$, \\
\hline & Extruded tc & \\
\hline
\end{tabular}

No significant dimensional changes due to radiation were observed.

The second clad experiment consisted of 12 samples given various heat treatment before radiation. Pre-post dimensional measurements indicated only minor changes due to the low level of exposure. Dimensional data, heat treatment conditions, and exposures are shown in Table 35. The percent change in length was computed on the basis of a 2-in. core length. The length decreases of some samples are probably due to warpage of the rods during radiation. Since no pre-test warpage measurement had been made, it was impossible to determine the extent. No correlation with degree of transformation, thickness of diffusion zone, or exposure is apparent. In any case, no appreciable dimensional changes occurred even in specimens transformed to the $\alpha+\gamma^{\prime}$ condition.

\section{Electrical Resistivity}

The changes in electrical resistivity of the unclad samples (Table 36) are plotted against temperature in Fig. 16. The direction of resistivity change of all transformed specimens was toward that of the gamma-quenched condition. As in case of transformed U-Mo specimens, radiation causes a reversion of the products of aging to the gamma phase. These effects, discussed in detail in Ref. 9, are summarized here.

(1) At corresponding exposures, transformed U-ND alloys show much less change in resistivity than do the corresponding U-Mo alloys. 
(2) As shown in Fig. 5: camm-phase U-Mo alloys first decrease in vertivity an then $104 \mathrm{y}$ increace however, gamm-phase U-Nb alloys first increase in resistivity then drastically decrease.

Although the behavior of $\mathrm{Um}$ Mo and $\mathrm{U}-\mathrm{Nb}$ alloys on radiation is generally similar, the details differ kecause of the tendency for segregation or clustering in $\mathrm{U}-\mathrm{Nb}$ alloys in contrast to the terdency toward superlattice formation in U-Mo alloys. An explanation of the resistivity changes is sketched in Fig. I7. It is suggested that in U-Mo alloys the resistivity change is the resultant of a resistivity increase caused by formation of lattice defects and fission atoms and a resistivity decrease caused by ordering of the gamma solid solution. The latter effect has been noted to occur even at low exposures in the case of ordered $\mathrm{Cu}_{3} \mathrm{Au}$ alloys 76,17 and was attributed to increased atom mobility in the radiation field. In U-Nb alloys the resistivity change is suggested to be a resultant, as before, of an increase caused by defects and fission product contamination and a decrease caused by clustering of $\mathrm{U}$ and/or $\mathrm{Nk}$ atoms. This clustering effect was found necessary in Ref.9 to explain observation (1), preceding. It is reasonable to assume that clustering, which requires long-range diffusion, would occur more slowly than ordering, which can occur by nearest neightor interchanges.

\section{Microhardness}

The microhardness of $\mathrm{U}-10 \mathrm{w} / \mathrm{O} \mathrm{Nb}$, as determined with a $5-\mathrm{kg}$ load and a $136^{\circ}$ diamond indenter, is shown in Table 37 and plotted in Fig. 10 for gamma-phase samples. In unirradiated specimens the hardness increases to a maximum during the early stages of transformation and decreases as transformation proceeds. After radiation the gamma-quenched specimens showed hardness increases, whereas the transformed specimens showed decreases. The hardness of all specimens was similar after radiation; that is, a common value of hardness was approached regardless of preirradiation heat-treatment. The results of the transformed specimens can be interpreted as an indication of their more complete transformation. However, when the changes in density and electrical resistivity are considered, these hardness decreases more likely represent a reversion towerd gamma. Fjgure 10 shows that the hardness increases for the three gamma-quenched specimens are dependent on exposure.

\section{E. Microstructure}

The structure of the samples, examined at the highest magnifications available with Iight microscopy, revealed no change due to radiation. Pre- and post-microstructures of a gamma-quenched sample, a partially transformed sample, and a fully transformed sample are shown in Fig. 18 . Notice in particular that, although the properties of the gamma-quenched specimen and the partially transformed specimen are similar after radiation, the microstructure is entirely different. Similarly, it is shown in Ref: 9 that U-Mo alloys do not alter in microstructure upon radiation, and it is postulated there that impurities precipitated during transformation are not homogenized by radiation, whereas the matrix is. Hence, a ghost structure of the transformed specimens persists, delineated by impurity precipitates. 


\section{F. Corrosion Resistance}

The corrosion properties of bare $\mathrm{U}-10 \mathrm{w} / \mathrm{O} \mathrm{Nb}$ samples upon radiation (Table 38) differed from those noted previously for U-Mo alloys. First, the corrosion rates were markedly increased by radiation, the rate increasing with exposure. Second, failure time was markedly accelerated, which is, of course, to be expected from the increased corrosion rate. These results are again consistent with the U-Nb model just described and for which radiation-induced clustering has been postulated.9 Such clustering should markedly accelerate decomposition to alpha and gamma prime upon subsequent exposure to high temperature water. Thus, the post-irradiation corrosion rate will depend directly on the amount of clustering during radiation. Low temperature corrosion tests would probably not indicate so serious an exposure effect, since the radiation-induced clustering may not progress toward deleterious transformation at temperatures below $610^{\circ} \mathrm{F}$. Similarly, corrosion testing under radiation would not be expected to reveal a damaging effect, since the radiation field would be expected to prevent transformation progression beyond the clustering stage. Previously transformed irradiated specimens all disintegrated on corrosion testing because, at the exposures used, incomplete reversion to the gamma phase resulted (Fig. 16).

The ten clad U-10 $\mathrm{w} / \mathrm{O} \mathrm{Nb}$ specimens (Table 32 ), irradiated in the gamma-quenched condition to an estimated maximum exposure of $840 \mathrm{MWD} / \mathrm{T}$, have been defected and corrosion tested in $650^{\circ} \mathrm{F}$ water for 35 days without any evidence of failure. Clustering or partial transformation during corrosion testing will be less injurious to Zircaloy-clad specimens than to bare specimens (WAPD-127, Parts II and III) because of the beneficial effect of the clad in gettering hydrogen.

A Zircaloy-2 clad 5 w/o enriched U-10 w/O Nb specimen gamaquenched and with a 0.040 -in. hole (defect) through the cladding ran for one 3-week fuel cycle in the HB-5 loop in the MIR. Estimated exposure was $850 \mathrm{MWD} / \mathrm{T}$, calculated temperature at the bottom of the defect was $705^{\circ} \mathrm{F}$, water counts during the test were 600 counts/min-ml or less. Examination of the specimen at the base of the defect indicated no apparent corrosion of the diffusion zone or the core alloy. These results are consistent with the explanation just presented.

\section{URANIUM-SILICON ALLOYS}

\section{A. Phase Relationships}

In the uranium-silicon system, the epsilon phase (U3Si), which is composed of $3.8 \mathrm{w} / \mathrm{O} \mathrm{Si}$ and the remainder uranium, shows quite good corrosion resistance to high temperature water (WAPD-127, Part I). This phase, formed as the product of a peritectoid reaction at $930^{\circ} \mathrm{C}$, has very narrow compositional limits; alloys outside the single-phase region have poorer corrosion resistance in high temperature water than the single-phase alloy. On the uranium side of the epsilon phase in the $\alpha-U+\epsilon$ phase field, any appreciable quantity of free $\alpha-U$ will cause poor corrosion resistance. On the high silicon side of the epsilon phase 
is a two-phase field of $\delta$ (U3Si2) and $\in$ (U3Si). Experiments indicate that alloys containing appreciable amounts of $\delta$ have less corrosion resistance than those consisting entirely of the epsilon phase.

Two experiments, each consisting of seven unclad natural $\mathrm{U}-3.8 \mathrm{w} / \mathrm{O}$ Si alloy samples $0.187 \mathrm{in}$. in diameter and 2 in. long enclosed in NaK-filled Zircaloy-2 capsules, were irradiated in the MTR for 6 weeks to maximum exposures of 755 and $1120 \mathrm{MWD} / \mathrm{T}$, respectively. All samples were machined from the core of Zircaloy-2 - U3Si coextrusions: those for the first experiment were epsilonized after machining at $800^{\circ} \mathrm{C}$ for 91 hours; those for the second experiment were machined from an extrusion made from a billet that had been epsilonized at $800^{\circ} \mathrm{C}$ for 1 week: The calculated exposures and specimen temperatures are given in Tables 39 and 40. No clad J-Si alloys have been irradiated. The effects of radiation on the uranium-silicon alloys are discussed in greater detail in WAPD-T-497, 18

\section{B. Dimensional Stability and Density}

After radiation local dimensional changes were visible in the specimens from both experiments. In general, this damage was in the form of bending and/or cracking (Fig. 2l) and a peculiar "banding" effect with small "blisters" in the banded area (Figs. 19, 20). The end of one specimen in the first test looked as if it had melted during radiation, which may have been caused by insufficient NaK to cover the specimen and the resultant poor heat transfer at the uncovered end. All the damage was first thought to be associated with either an insufficient quantity of $\mathrm{NaK}$ or oxidation of $\mathrm{NaK}$ and subsequent corrosion of the specimens. However, since both ends of the specimens showed similar damage, the end distortion was apparently caused by a dimensional instability in the material. In the second test no possibility of insufficient coverage by $\mathrm{NaK}$ existed, and yet bending and distortions were noted. Therefore, a real dimensional instability in these alloys is indicated. Similar radiation experiments performed by Argonne National Laboratory (ANL) * on cast and wrought U3Si have shown evidence of "banding" but no serious bending or splitting. Even specimens of the stoichiometric U3Si composition have been noted to contain regions of the alpha and $U_{3} \mathrm{Si}_{2}$ phases because of incompletion of the peritectoid reaction. During extrusion, these regions are strung out parallel to the axis of extrusion. It is therefore possible that the bending and distortions noted are evidence of instability of residual alpha uranium. However, density changes cannot be ascribed to residual alpha.

As shown in Tables 41 and 42 , post-irradiation length measurements indicated that some specimens increased, whereas others decreased. The maximum increase and decrease were 0.022 and 0.035 in., respectively. However, post-irradiation diameter measurements indicated increases of frön 0.002 to 0.007 in. (1.1. to $3.9 \%$ change). The minimum postixradiation density of $14.82 \mathrm{~g} / \mathrm{cm} 3$ may be compared with the calculated density of $14.65 \mathrm{~g} / \mathrm{cm}^{3}$ for a $3.8 \mathrm{w} / 0$ S1 alloy consisting entirely of alpha uranium and delta phase (U3Si). The post-irradiation density decrease (Tables 41 and 42) was almost independent of exposure in all specimens from burnups of about 0.01 to $0.12 \%$. A slight additional decrease (about $0.5 \%$ per $1000 \mathrm{MWD} / \mathrm{T}$ ) on exposures from 100 to $1100 \mathrm{MWD} / \mathrm{T}$ F. H. Kittel, Private Communication, Argonne National Laboratory 
is considered the normal density decrease due to radiation of uraniumbase alloys. However, the major decrease of almost $4 \%$ which occurred at trifling exposures is indeed unexpected. The density changes indicative of transformation also occurred at relatively. low exposures (Tables 11 and 35). It is estimated that complete reversion of alpha to gamma in U-9 w/O Mo alloys will occur at about $900 \mathrm{MWD} / \mathrm{T}$ exposure.9 In the case of the U3Si samples, major density changes were complete at $100 \mathrm{MWD} / \mathrm{T}$ exposure. Certainly the direction of the density changes was toward decomposition of the stable epsilon phase; however, only about $60 \%$ of the total obtainable density decrease was observed even at $1120 \mathrm{MWD} / \mathrm{T}$ exposure.

As discussed in Section VI-C, the electrical resistivity results indicate that radiation has caused an atomic rearrangement of the $\epsilon$ phase resulting in a disordered solid solution. The structure of the $\epsilon$ phase is body-centered tetragonal, which can be shown to be pseudoface-centered cubic. Assuming that the $U$ and Si atoms are randomly arranged on a face-centered cubic lattice, Bleiberg and Jones 18 have calculated a theoretical density of $14.91 \mathrm{~g} / \mathrm{cm}^{3}$ for a U-Si alloy containing $25 \mathrm{a} / \mathrm{O}(3.78 \mathrm{w} / \mathrm{o}) \mathrm{Si}$. It may be seen in Table 41 that this density value agrees very well with the data in the first experiment where the Si content was $3.75 \mathrm{w} / \mathrm{O}$. The lower post-irradiation density values obtained in the second test (Table 42) can be attributed to the excess $\mathrm{Si}$ in the alloy $(3.84 \mathrm{w} / 0)$.

\section{Electrical Resistivity}

The electrical resistivity values of the $U-3.8 \mathrm{w} / \mathrm{O}$ Si alloy specimens are shown in Fig. 22 where they are plotted as a function of temperature in the range of $-196^{\circ} \mathrm{C}$ to $+100^{\circ} \mathrm{C}$. The irradiated epsilonized samples exhibited very large increases in electrical resistivity after irradiation (approximately $50 \%$ at $-196^{\circ} \mathrm{C}$ ), and the temperature coefficient of electrical resistivity changed from the normally positive to negative. Also, these large changes in electrical properties occurred at relatively low exposures and no further changes occurred at higher exposures, as shown by the measurements on samples irradiated to 0.028 and 0.102 a/o burnup, respectively. The negative temperature coefficient of the irradiated specimens was similar to that occurring in the disordered metastable ganma phases of U-Mo and U-Nb alloys (Figs. 8 and 16). Furthermore, the changes in electrical properties due to neutron bombardment of the U-3.8 w/O Si alloy were remarkably similar to the changes in electrical properties of these gamma-phase alloys due to the neutron-induced phase reversal of the low temperature stable $\alpha+\mathrm{U}_{2}$ Mo phase to the metastable $\gamma$ phase. The cause of the effects observed in the U-Si alloy, however, must be dissimilar to that noted in the case of transformed U-Mo and U-Nb alloys since no disordered stable solid solution exists in this system similar to the $\gamma$ phases in $\mathrm{U}-\mathrm{Mo}$ and $\mathrm{U}-\mathrm{Nb}$ alloys, and the alloy as inserted in the reactor was predominantly single phase rather than two phase. Furthermore, the de-epsilonized phases of $\alpha+\delta$ showed similar electrical resistivity behavior to the unirradiated epsilonized samples as shown in Fig. 22. 
The change in electrical resistivity of the $\epsilon$ phase of the U-Si system (U-25 a/o Si) due to neutron bombardment is most significant. The presence of a negative temperature coefficient of resistivity at low temperatures has been observed in several disordered body-centered solid solutions of binary uranium alloys, and the magnitude of the electrical resistivity values observed in irradiated U3Si correspond very well with the values obtained in the $\gamma$ phases of U-25 a/O Mo and U-25 a/O No a.lioys (Figs. 8 and 16 ). Such a behavior in the U-Si system suggests that an atomic rearrangement of the $\epsilon$ phase has taken place resulting in a disordered solid solution. Such a suggestion is not unrealistic if the crystal structure of this phase is considered. This structure was determined by Zachariasen 19 to correspond to a body-centered tetragonal lattice. The structure is pseudo-cubic so that if the axial ratio, $c / a$, were reduced from 1.442 to 1.414 and the uranium atoms were shifted so that the variable parameter, $u$, fixing their positions was equal to 0.25 instead of 0.231 , then this phase would have the CuzAu-type structure. Significantly, CuzAu has been studied very extensively, and it has been shown by numerous investigators that the ordered structure disorders due to neutron bombardment whereas the disordered structure partially orders. Therefore, if the $\epsilon$ phase of the U-Si system is considered to be similar in stmucture to ordered CuzAu and was similarly disordered by the neutron bombardment, then a disordered structure would result which would be consistent with the observed electrical resistivity results. It should be pointed out that such an orderdisorder type of reaction in this alloy has not been reproduced by therrnal means to date.

\section{X-ray Diffraction}

In order to determine the crystal structure of the irradiated material, sample 1 of the second experiment was sectioned into three pieces about $1 / 8$ in. long. These pieces were mounted in a thermosetting plastic mold so that the three transverse faces were touching and were flush with the top surface of the mold. A diffraction pattern was then obtained on this sample by means of a double crystal spectrometer similar to that described by Cumings et al. 20 This pattern $2 n 0$ that obtained on an unirradiated control sample prepared in the same manner ane shown in Figs. 23 and 24, respectively. These data show that no diffraction lines were obtained on the irradiated sample. The maximum inteasity of the strongest peak (202) at 36.2 degrees in $2 \theta$ in the unirradiated control specimen was 65 counts per second. If this peak were present on the irradiated specimen, it would have certainly been detected since the background was only about 30 counts per second. A small diffraction peak (about 10 counts per second) was obtained on the irradiated specimen pattern at a $2 \theta$ value of 39 degrees. This peak was caused by diffraction of the $\mathrm{X}$-rays by a small area of an aluminum specimen holder which supported the sample in the apparatus. The appearance of this peak is further evidence that the apparatus was capable of detecting diffraction lines if they were present on this sample.

A further observation was made in the process of obtaining these patterns. It was found that the diffraction pattern of the unirradiated $\mathrm{U}-3.8 \mathrm{w} / \mathrm{O} \mathrm{Si}$ alloy in the epsilonized condition could be considerably altered by very light abrasion. The unirradiated specimen whose pattern 
is shown in Fig. 23 was very lightly abraded on 600 grit silicon-carbide paper, and the diffraction pattern obtained on the specimen after this abrasion is shown in Fig. 25. It may be seen that the intensity of the strongest line (202) was reduced about 50\%. Furthermore, the lines that-correspond to the cubic lattice $\left(h^{2}+k^{2}+12-4,8,11\right.$ and 12), which were clearly resolved as doublets, have merged into single broad peaks while the remaining weak lines have entirely disappeared. This effect is similar to that observed in the ordered $\epsilon$ phase by the U-Mo binary system, wherein the $\epsilon$ phase is disordered to the metastable $\gamma$ phase by light abrasion. 21 When the abraded surface of this specimen was removed by etching, the diffraction pattern returned to that shown in Fig. 23. Sufficient care was taken during preparation of the irradiated sample to ensure that diffraction effects were not obscured by improper surface preparation.

It must be postulated that a marked reduction occurs in the crystallite size in the irradiated U3Si such that a close approximation of the ordered crystalline arrangement exists in the lattice but the lattice periodicity over a sufficiently large number of unit cells is destroyed. It is estimated that the crystallite size in the irradiated U3Si must be less than $20 \mathrm{~A}$ to cause the diffraction pattern to become sufficiently diffuse to produce the observed effect. This effect was perhaps simulated to a lesser degree in the unirradiated, abraded sample since the intensity of the diffraction peaks was reduced about $50 \%$ from the unabraded condition.

\section{E. Microhardness}

Microhardness measurements were made on transverse sections of all. irradiated specimens from the first experiment and on four specimens from the second. Hardness (Tables 43 and 44) increased a maximum of $220 \mathrm{DPH}$ units. The major change occurred at an exposure of $105 \mathrm{MWD} / \mathrm{T}$; further exposure gained only about 5 DPH units. Unirradiated control samples heat treated 6 weeks at various temperatures up ta $500^{\circ} \mathrm{C}$ showed no hardness increases; neither did a control sample heat treated 6 weeks at $400^{\circ} \mathrm{C}$ in $\mathrm{NaK}$. Therefore, increased hardness appears to be entirely a radiation effect. Hardness changes in U-3.8 w/O Si were out of all proportion to those occurring in alpha uranium or gamma-phase uranium alloys (Fig. 10), in which no evidence of phase changes due to radiation was noted.

It is postulated that the volume changes resulting from the disordering of the atomic arrangement in the epsilon phase introduces high internal stresses within the material. The high internal stresses would cause the increased hardness observed. These stresses would also explain the observed brittleness and cracking of the specimens. It has been calculated that the material would be almost entirely disordered after an exposure of 1019 nvt. 18 Since the lowest exposure for any of the specimens examined was $3 \times 1019$ (Spec. 5 of the first experiment), the apparent saturation of hardness increases at low exposures does not contradict this mechanism. 


\section{F. Microstructure}

Metallographs of the imradiated specimens did not reveal any structure; the microsticture was either too fine to permit resolution by optical microscopy, or chemical effects precluded obtaining a suitable etch. However, metallography did reveal that the specimens were physically dense and that void formation had not occurred. Therefore, the density changes were interpreted as true changes in matrix density and not indicative of voìd formation.

If all the displacement spikes occurring within the epsilon matrix were effective in disordering the atomic arrangement, completion of the reaction within $100 \mathrm{MWD} / \mathrm{T}$ exposure is understandable. Even at high exposures ( $1120 \mathrm{MWD} / \mathrm{T}$ ), density decreases to that characteristic of a mixture of alpha and delta $\left(14.65 \mathrm{~g} / \mathrm{cm}^{3}\right)$ were not observed.

\section{G. Corrosion Resistance}

Mid-sections from five samples of the first test together with five control specimens that had been heat treated for 6 weeks at $200^{\circ}, 300^{\circ}$, $400^{\circ}$, and $500^{\circ} \mathrm{C}$ in evacuated Vycor bul'os and at $400^{\circ} \mathrm{C}$ in a NaK-filled capsule were corrosion tested in $650^{\circ} \mathrm{F}$ water for 22 hours. The results are shown in Table 45, together with the corrosion rates of unirradiated, as-epsilonized samples. Three of the isradiated specimens disintegrated during this test period, and the remaining two specimens showed a marked increase in corrosion rates $\left(-6.56\right.$ and $\left.-14.26 \mathrm{mg} / \mathrm{cm}^{2}-\mathrm{hr}\right)$.

The heat-treated control specimens, which were tested in the same autoclave as the irradiated specimens, showed corrosion rates similar to the specimens which were not heat treated for 6 weeks. A comparison of the corrosion rates of two specimens which had received similar heat treatments, one in an evacuated Vycor tube and one in a NaK-filled capsule, indicated that the $\mathrm{NaK}$ environment had little or no effect on the corrosion resistance of this material.

Six sections from three specimens of the second test were corrosion tested in $650^{\circ} \mathrm{F}$ water for 72 hours. During unloading from the test autoclave, three samples broke into pieces. The weight changes of the unbroken samples were quite low (Table 46). However, the broken samples looked oxidized on the fractured surface, indicating that the samples were permeated with oxtde. Thus, the weight changes on corrosion are misleading, and it is believed that the samples from the second test showed corrosion resistance as poor as those from the first test.

\section{DISCUSSION AND CONCLUSIONS}

\section{A. Irradiation Behavion of Single-phase Uranium-base Alloys}

The gamma-phase uranium-molybdenum and uranium-niobium alloys are solid solutions of the alloying element in the body-centered cubic phase of uranium. The UzSi alloy has a slightly distorted face-centered cubic (CuzAu) structure. Each of these alloys was expected to demonstrate a high degree of dimensional stability upon radiation as compared with alpha uranium, which was confirmed in uranium-molybdenum and 
uranium-niobium alloys but was certainly not in U3Si. Although some dimensional instability of UzSi may be attributed to residual alphauranium stringers, gross density and corresponding dimensional changes were noted at very low exposures. Even in the case of gamma-phase alloys, although general behavior was the same, details of the response of uranium-molybdenum and uranium-niobium alloys to radiation were appreciably different. In the former case, electrical resistivity decreased sharply at low exposures and then gradually increased. Similarly radiation did not affect corrosion behavior of bare samples in respect to both corrosion rate and failure time. In U-No alloys, electrical resistivity first increased upon radiation and then decreased sharply with further exposure. Presumably, at longer radiations resistivity would again reverse and show a gradual increase with radiation time. Also, corrosion rates in $650^{\circ} \mathrm{F}$ water were continuously deteriorated by increasing exposure, at least up to $800 \mathrm{MWD} / \mathrm{T}$. An examination of the behavior of these alloys and an attempted explanation of their varying responses to radiation are pertinent.

An explanation has been suggested (in Ref. 9) and has been used in this report to explain radiation behavior. It was found in the cited reference that, in order to explain the difference in the kinetics of crystal structure reversion between uranium-molybdenum alloys and uranium-niobium alloys, it was necessary to assume considerably less homogenization of niobium than molybdenum during a fission event. The explanation was offered that during cooling of the displacement spike the molybdenum atoms remained dispersed through the uranium matrix, whereas the niobium atoms segregated in clusters. This explanation is consistent with the phase diagrams of these systems--the former alloy showing superlattice formation and the latter, segregation of uranium and niobium on transformation of the gamma phase. It is suggested that radiation causes a disordering of the atomic arrangement in epsilonized U3Si. It has been shown that essentially complete disordering would be effected by very low integrated neutron flux exposures (1019 nvt). Observations of density decreases, hardness increases, and reductions in corrosion resistance are consistent with the postulated theory that changes in properties would saturate at low exposures.

In the case of alpha uranium, aside from the dimensional instability effects, radiation in general produced few effects unexplainable by formation of lattice defects and fission atoms. However, in the case of uranium alloys investigated here, the alloying element had an appreciable and, in some cases, major effect on radiation behavior. Thus, alloying to obtain a cubic crystal structure is, in itself, no guarantee of attaining insensitivity to radiation exposure, but rather the specific nature of the alloying addition must be considered.

Mechanical properties of uranium-base alloys were found extremely sensicive to radiation; uranium lost most of its ductility at exposures as low as $65 \mathrm{MWD} / \mathrm{T} .1$ Loss of ductility at such low burnups is unexplainable on the basis of lattice defects and contamination by fission atoms, since the hardness changes observed, though appreciable, are not sufficient to lead to such drastic reductions in ductility. The ductility behavior of uranium-molybdenum alloys indicated that the mechanical 
properties of gamma-phase structure were considerably less subject to radiation damage than were those of alpha uranium. Indeed, burnups of over $300 \mathrm{MWD} / \mathrm{T}$ were required to produce loss of ductility. However, even in alpha uranium appreciable and drastic ductility losses were eventually observed. It is inferred from this that radiation produced structural changes. in addition to the usual lattice defects. Apparently, the occurrence of such changes was sensitive to the crystal structure of the matrix material. Further evidence of these changes was afforded by observations of volume expansion (Section VII-C).

It may be hypothesized from the behavior of the gamma-phase uranium-molybdenum and uranium-niobium alloys that the ideal gammaphase structure is one in which a tendency toward ordering exists. Such a tendency would mitigate the suggested clustering of niobium atoms during radiation and the consequent change in corrosion resistance. Since both zirconium and molybdenum tend to form a superlattice with uranium, it may be highly advantageous to develop ternary or quaternary alloys of uranium-niobium base containing enough molybdenum and/or zirconium to overcome the tendency for clustering in the $\mathrm{U}-\mathrm{Nb}$ base material.

\section{B. Crystal Structure of the Reversion upon Irradiation}

Reversion to the gamma phase of uranium-molybdenum and uraniumniobium solid solution decomposed before radiation to the the rmodynamically stable phases at reactor ambient temperatures was unexpected and unpredicted, even though available theories of radiation damage appear adequate to explain the results. 9 This reversion eases a principal problem in gamma-phase alloy development, namely, the tendency to transform at sufficiently long times at reactor temperatures and heat fluxes to phases of poor corrosion resistance. Because of the transformation tendency, uranium-molybdenum gamma-phase, rather than uranium-niobium, alloys were selected as the principal metallic fuel effort for PWR, since transformation rates of the latter were intolerable at PWR operating temperatures. The lower limit of alloy content at which the gamma phase may still be retained under radiation is unknown. Certainly, results of the Argonne National Laboratory development of alpha-prime uranium alloys containing $1.5 \% \mathrm{Nb}$ and $5 \% \mathrm{Zr}$ indicate that alloying additions insufficient to retain the gamma phase upon quenching have inadequate radiation stability. As little as $6 \%$ molybdenum or niobium might be sufficient to retain the alloys in the gamma phase under reactor radiation. Such alloy contents may be entirely acceptable for power reactor applications.

\section{Volume Expansion}

As noted, whereas dimensional stability of gamma-phase alloys at temperatures of $300^{\circ} \mathrm{C}$ or lower was outstanding, density decreases upon radiation increased continuously with burnup. Not only gamma-phase alloys but also alpha-uranium, zirconium-uranium alloys of high zirconium content, and aluminum-base, aluminum-uranium alloys show density decreases upon radiation. 22 Figure 26 shows volume changes as a function of exposure for bare alpha uraniumll and gamma-phase alloys, for alpha 
uranium and $\mathrm{U}-2 \mathrm{w} / 0 \mathrm{Zr}$ alloys clad in zirconium, and for gamma-phase alloys clad in zirconium. Although, in the case of alpha uranium, volume increases from 3 to $5 \%$ per a/o burnup, gamma-phase alloys show 4 to $6 \%$ per a/o burnup density decrease. Use of a cladding markedly diminishes volume changes (Fig.26). If this observation is correct, much of the volume change, at least in gamma-phase alloys, is probably due to formation of volds which may be suppressed, at least at the surface, by cladding.

Various estimates may be made of the volume expansions in fissionable materials as a result of formation of fission atoms. Such increases would arise because of the large average volume of fission product atoms as compared with that of uranium atoms, as well as the formation of additional atoms. In the U-9 w/o Mo alloy the average atomic volume may be estimated as $12.1 \mathrm{cc}$, whereas the average atomic volume of fission products is $25.2 \mathrm{cc} .23$ If fission atoms leave the uranium lattice and segregate as separate phases, the decrease in density will be given by the additive volumes of uranium and fission products. Thus, in the U-9 w/O Mo at 1 a/O burnup, volume increase will be $3.17 \%$ if the flssion product atoms segregate. However, particularly at low temperatures of exposure, such segregation is not likely. If the fission product atoms are retained as substitutional atoms in the gamma-phase lattice, a volume increase of $1.67 \%$ will occur per atom percent burnup. Here again, it is unlikely that atoms such as iodine and selenium will exist as substitutional atoms; an appreciable fraction of these will prefer to remain in interstitial positions. The volume increase resulting from interstitial placement of fission product atoms will vary greatly, depending on the nature of the atom. Certainly, with its more open structure, the body-centered cubic lattice of the gamma-phase alloys should permit accommodation of interstitial atoms with much less lattice expansion than the close-packed, alpha-uranium lattice. Tucker and Sampson ${ }^{24}$ have estimated that interstitial copper atoms in the copper lattice will cause $1 \%$ lattice parameter expansion for each atom percent interstitial atom--probably a considerable overestimate, since interstitial atoms should be accommodated with less over-all density decrease than substitutional atoms. However, by using the data of Tucker and Sampson again for 1 a/o burmup with half the fission atoms remaining on uranium lattice positions and half on interstitial positions, $3.83 \%$ volume expansion will occur. In any case, none of these estimates equals the volume expansions observed for gamma-phase alloys, namely, 5\% per 1 a/o burnup. It is concluded that such volume changes imply the formation of voids, presumably by segregation and expansion of volatile fission products.

Special attention is directed to the very high volume expansion (6.7\%) exhibited by the sample of gamma uranium-12 w/o Mo irradiated to $0.35 \mathrm{a} / \mathrm{o}$ burnup; while the central temperatures of each of the specimors shown in Fig. 26 varied between $150^{\circ}$ and $400^{\circ} \mathrm{C}$, this par. salar sample was irradiated at a central temperature estimated to se slightly higher than those of most of the other samples shown. On sectioning and hardness testing across the diameter of this sample the hardness as shown in Fig. 26 was found to be very low in the center, lower in fact than the original unirradiated hardness of $307 \mathrm{DPH}$.

Microstructural examination of the interior of this sample revealed some 
ill-defined structural changes which could be interpreted as porosity. Since none of the other unclad samples in Fig. 26 showed this hardness dip at the center, it can be concluded that a sharp temperature limitation exists above. which exaggerated volume expansion is noted. Kittel and Paine 25 have reported a sharp temperature effect on the volume change with burnup for alpha-uranium specimens. At temperatures below about $425^{\circ} \mathrm{C}$, density changes of 2 to $3 \%$ per a/o burnup were observed. As the irradiation temperature was raised above $425^{\circ} \mathrm{C}$, the volume changes increased abruptly to as much as ten times the values observed below this temperature. A similar exaggerated swelling was reported by Pugh 26 for alpha uranium at temperatures above $300^{\circ} \mathrm{C}$; he showed metallographic evidence of voids in specimens irradiated at elevated temperatures.

Thus, any explanation for the volume changes of irradiated fissionable metals must account for two observations: (1) density decreases in the range of 2 to $6 \%$ per a/o burnup at low temperatures and (2) an exaggerated swelling of ten times this order of magnitude occurring at an apparently critical temperature. Lustman 27 suggests that the insoluble noble gas fission fragments are trapped in dislocations present in the metal structure prior to irradiation. However, even with dislocation densities as high as $1012 / \mathrm{cm}^{2}$ only the gas atoms produced by about 0.3 a/o burnup could be condensed on dislocations. Therefore, it is believed most likely that the uncondensed gas atoms are free to seek sites for precipitation as bubbles under high pressure, the uniform distribution of pressure sites causing the volume expansions noted in Fig. 26. The precipitation of gas in local sites at low temperatures with consequent severe local strains is presumed to result from the inability of the matrix to deform generally to relieve such local strains because of the inactivation of dislocations by condensed gas atoms. Lustman further suggests that the deformations encountered in the case of swelling under irradiation at elevated temperatures are relatively slow creep deformations. At temperatures at which the diffusion rate of fission gas atoms is sufficiently high so that the noble gas atoms trapped at dislocations are free to move, the local stresses around the fission gas precipitated as bubbles can be dissipated by gross plastic deformation of the specimen leading to the observation of swelling.

Thus, it is obvious that volume expansions may set the maximum operating conditions and the ultimate life of metallic fuel elements. Fallure of fuel element cladding due to volume expansion has been observed in Zircaloy-1 clad U-2 w/o Zr alloy specimens irradiated to approximately $10,000 \mathrm{MWD} / \mathrm{T}$ (Fig. 27) and in a Zircaloy-2 clad uranium $10.5 \mathrm{w} / 0$ Mo sample exposed to $28,200 \mathrm{MWD} / \mathrm{T}$. Operating temperatures at which gross swelling does not occur may be raised by the development of structures of low dislocation densities. To accomodate the low temperature volume expansions, an expansion space within the fuel element might be provided to extend the ultimate life. Similarly, the use of cladding more ductile than Zircaloy-2 may permit longer exposure without fuel element failure. It is to be noted that no volume expansions have been found in $\mathrm{UO}_{2}$ for exposures well beyond 10,000 $\mathrm{MWD} / \mathrm{T}$; presumably, a void space for the accommodation of fission product atoms is inherent in the crystal lattice of $\mathrm{UO}_{2}$. 
WAPD-127

\section{Corrosion}

Although much of the data in the text of this report cannot be interpreted properly wi.th respect to the effects of radiation on cor-: rosion life because of improper specimen fabrication, certainly no evidence was found within the range of exposure used that would attest to the deterioration of gamma-phase alloys. This conclusion was particularly borne out by the results of in-pile loop tests of defected clad samples of both uranium-molybdenum and uranium-niobium. Certainly the stabilizing effect of radiation on the gamma phase would be expected to lengthen the life of these alloys. Indeed, samples which survived in-pile exposure to hot water for long periods failed on post-irradiation corrosion testing within very short periods. Incipient transformation of gamma-phase alloys should influence corrosion behavior out-of-pile on long-time exposure. In-pile, such transformations should be hindered by radiation; hence, corrosion life should be extended. An interesting. corollary to this observation is that conducting development of corrosionresistant uranium-base alloys by out-of-pile testing may be impossible. The sensitivity of these alloys to radiation exposure is not unexpected. Experiments reported in WAPD-127, Part I, revealed that these alloys are quite tolerant to significant amounts of impurity contamination. Hence, deterioration of corrosion resistance by fission product contamination should not be severe. Iikewise, lattice defect damage would be expected to have a second order effect on corrosion rates of materials that are controlled by formation of an external oxide.

It may be concluded from these observations that, with respect to dimensional stability and corrosion resistance upon radiation, gammaphase alloys show considerable promise for application in water-cooled power reactors. The U3Si alloy, on the other hand, suffered severe deterioration, particularly of corrosion resistance, and its further development as a reactor fuel for high temperature water application awaits identification and solution of the reasons for its instability. 


\section{REFERENCES}

1. M. B. Reynolds and J. N. Frank, "Report of Metallurgy Section," KAPL-985, December 1, 1953.

2. R. E. Hueschen, et al., "The Effects of Irradiation on the Tensile Properties of Uranium," HW-41690, February 9, 1955.

3. P. W. Frank, et al., "Radiochemistry of First PWR Fuel Material Test--X-1 Loop NRX Reactor," WAPD-CPM-I, October 20, 1955.

4. G. O. Bright and F. Schroeder, "Neutron Flux Distribution in the Materials Testing Reactor, Part I," IDO-16047, February 16, 1953.

5. M. L. Bleiberg and L. S. Castleman, "Effects of Neutron Bombardment upon the Properties of Zirconium and of a Zirconium-Tin Alloy," WAPD-78, March 17, 1953.

6. J. D. Eichenberg and R. H. Fillnow, "Equipment for Corrosion Testing and Sectioning of Irradiated Specimens, "WAPD-T-I79, April 7, 1954.

7. H. A. Saller, et al., "The Constitution Diagram of Uranium-Rich Uranium-Molybdenum Alloys," BMI-72, June 1, 1951.

8. Armour Research Foundation, "Research on Uranium-Base Alloys, Part I - Transformation Kinetics of Uraniun-Base Alloys," September 30, 1955.

9. M. L. Bleiberg, et al., "Phase Changes in Pile-Irradiated UrauiunBase Alloys," WAPD-T-300, March 1956.

10. Impurities and Imperfections, (ASM Serninar), American Society for Metals, pp. 162-1.63, 1955.

11. S. H. Paine and J. H. Kittel, "Irradiation Effects in Uranium and Its Ailoys," International Conference on the Peaceful Uses of Atomic Energy, Vol. VII, P/745, p. 445, 1956.

12. S. Greenbers and J. E. Draley, Quarierly Report of the Metallurey Division, Argonne National Laboratory, ANL-5423, Decemider 31, 1954.

13. R. W. Buzzard and H. E. Cleaves, "The Binary Alloys of Uranium;" TID-65, J. Met. Cer. I, p. 25, July, 1948.

14. R. K. McGeary, et al., "Development and Properties of Uranium-Base Alloys Corrosion Resistant in High Temperature Water - Alloys without Protective Cladding," WAPD-127, Part I, April 25, 1955.

15. "Investigation of a Seeded FWR," WAPD-REL(W)-50, January 20, 1955.

16. I. G. Cook and R. L. Cushing, "The Effects of Neutron Irradiation in the NRX Reactor on the Order-Disorder Alloy CuzAu, "Acta Met. I, 5, 539, September 1953. 
WAPD-127

17. G. H. Kinchin and R. S. Pease, "The Displacement of Atoms in Solids by Radiation," Repts. Progr. in Phys. 18, 1955.

18. M. L. Bleiberg and L. J. Jones, "The Effects of Pile Irradiation on U3Si, " WAPD-T-497, April 1957.

19. W. H. Zachariasen, Acta Crystallographica 2, 94 (1949).

20. W. V. Cumming, D. C. Kaulitz, and M. J. Sanderson, Rev.Sci. Instr. 26, 5 (1955).

21. E. K. Halteman, to be published, Acta Crystallographica.

22. L. C. Templeton, et ail., "Quarterly Progress Report," ORNL-693, May 18, 1950.

23. J. P. Howe and C. E. Weber, "Limitations on the Performance of Nuclear Fuels," TID-2012, "Reactor Science and Technology," Vol. 4, No. 1, March 1954.

24. C. W. Tucker and J. B. Sampson, "Interstitial Content of RadiationDamaged Metals from Precision X-Ray Lattice Parameter Measurements," Acta Met. 2, 433, May 1954.

25. J. H. Kittel and S. H. Paine, Nuc. Eng. and Sci. Cong. (1957); $57-N E S C-65$.

26. S. F. Pugh, "Damage Occurring in Uranium During Burnup," International Conference on the Peaceful Uses of Atomic Energy, Vol. VII, P/443, p. 44I, 1956.

27. B. Lustman, "Release of Fission Gases from $\mathrm{UO}_{2}$," WAPD-173, March 1957. 


\section{TABLE I}

\section{Outline of J-Mo Alloy Experiments}

\begin{tabular}{|c|c|c|c|c|c|c|}
\hline $\begin{array}{c}\begin{array}{c}\text { Experiment } \\
\text { No. }\end{array} \\
\end{array}$ & $\begin{array}{r}\text { Type of } \\
\text { Sample } \\
\end{array}$ & $\begin{array}{c}\text { Number } \\
\text { of Samples }\end{array}$ & Composition & Enrichment & Heat Treatment & $\begin{array}{l}\text { Max. Calculated } \\
\text { Exposure (MND/T) }\end{array}$ \\
\hline $1 \mathrm{~B}$ & Unclad & 7 & $\mathrm{U}-12 \mathrm{w} / \mathrm{O} \mathrm{Mo}$ & Natural & $900^{\circ} \mathrm{C}-24 \mathrm{hr}=\mathrm{W} . \mathrm{Q}$. & 2000 \\
\hline $2 B$ & Unclad & $\begin{array}{l}7 \\
7\end{array}$ & $\begin{array}{l}\mathrm{U}-10.5 \mathrm{w} / \mathrm{O} \mathrm{Mo} \\
\mathrm{U}-12 \mathrm{w} / \mathrm{O} \mathrm{Mo}\end{array}$ & $\begin{array}{l}\text { Natural } \\
\text { Natural }\end{array}$ & $750^{\circ} \mathrm{C}-1 / 2 \mathrm{hr}$ Wi.Q. & 1050 \\
\hline $3 B$ & Unclad & $\begin{array}{l}3 \\
3 \\
1\end{array}$ & $\begin{array}{l}\mathrm{U}-12 \mathrm{w} / \mathrm{o} \mathrm{Mo} \\
\mathrm{U}-13.5 \mathrm{w} / \mathrm{o} \mathrm{Mo} \\
\mathrm{U}-13.5 \mathrm{w} / \mathrm{o} \mathrm{Mo}\end{array}$ & $\begin{array}{l}5 \mathrm{w} / 0 \\
5 \mathrm{w} / 0 \\
5 \mathrm{w} / 0\end{array}$ & $\begin{array}{l}n \\
n \\
n\end{array}$ & 3650 \\
\hline $4 B$ & Unclad & $\begin{array}{l}3 \\
3 \\
1\end{array}$ & $\begin{array}{l}\mathrm{U}-12 \mathrm{w} / \mathrm{O} \mathrm{MO} \\
\mathrm{U}-13.5 \mathrm{w} / \mathrm{O} \mathrm{Mc} \\
\mathrm{J}-13.5 \mathrm{w} / \mathrm{O} \mathrm{Mo}\end{array}$ & $\begin{array}{l}5 \mathrm{w} / 0 \\
5 \mathrm{w} / 0 \\
5 \mathrm{w} / 0\end{array}$ & $\begin{array}{rl}750^{\circ} \mathrm{C}-1 / 2 & h r-w_{u} \cdot Q \\
\mathbf{u} & +550^{\circ} \mathrm{C}-2 \text { wk }\end{array}$ & 6100 \\
\hline 58 & Unclad & 7 & $\mathrm{~J}-10.5 \mathrm{w} / \mathrm{o} \mathrm{Mo}$ & $5 w / 0$ & $750^{\circ} \mathrm{C}-1 / 2 \mathrm{hr}-\mathrm{h} \cdot \mathrm{Q}$. & 8800 \\
\hline $6 \mathrm{~B}$ & Unclad & $\begin{array}{l}1 \\
2 \\
1 \\
2 \\
1 \\
6 \\
1 \\
6\end{array}$ & $\begin{array}{l}U-9 \text { w/o Mo } \\
U-9 \text { w/o Mo } \\
U-10.5 \text { w/o Mo } \\
U-10.5 \text { w/o Mo } \\
U-12 \text { w/o Mo } \\
U-12 \text { w/o Mo } \\
U-13.5 \text { w/o Mo } \\
U-13.5 \text { w/o Mo }\end{array}$ & $\begin{array}{l}\text { Natural } \\
\text { Natural } \\
\text { Natural } \\
\text { Natural } \\
\text { Natural } \\
\text { Natural } \\
\text { Natural } \\
\text { Natural }\end{array}$ & $\begin{array}{l}\# 1\left(i . e, 900^{\circ} \mathrm{C}-24 \mathrm{hr}-W \cdot Q_{.}\right) \\
\# 1+525^{\circ} \mathrm{C}-312 \mathrm{hr} \\
\# 1 \\
\# 1+525^{\circ} \mathrm{C}-312 \mathrm{hr} \\
\# I \\
\# 1+525^{\circ} \mathrm{C} \text {-various times } \\
\# I \\
\# I+525^{\circ} \mathrm{C} \text {-various times }\end{array}$ & 790 \\
\hline $1 \mathrm{C}$ & Clad & $\begin{array}{l}8 \\
7\end{array}$ & $\begin{array}{l}\mathrm{U}-10.5 \mathrm{w} / \mathrm{O} \mathrm{Mo} \\
\mathrm{U}-12 \mathrm{w} / \mathrm{O} \mathrm{Mo}\end{array}$ & $\begin{array}{l}\text { Natural } \\
\text { Natural }\end{array}$ & $\begin{array}{l}\text { As Extruded } \\
800^{\circ} \mathrm{C}-4 \text { hr }-W . Q \text {. }\end{array}$ & 1120 \\
\hline $2 \mathrm{C}$ & Clad & $\begin{array}{l}4 \\
5 \\
4 \\
4\end{array}$ & $\begin{array}{l}U-9 \text { w/o Mo } \\
U-10.5 \text { w/o Mo } \\
U-12 \text { w/o Mo } \\
U-13.5 \text { w/o Mo }\end{array}$ & $\begin{array}{l}5 \mathrm{w} / 0 \\
5 \mathrm{w} / 0 \\
5 \mathrm{w} / 0 \\
5 \mathrm{w} / 0\end{array}$ & $\begin{array}{c}750^{\circ} \mathrm{C}-1 / 2 \text { hr }-W . Q . \\
" ~ \\
" ~\end{array}$ & 5610 \\
\hline
\end{tabular}




\section{TABLE I (Contd.)}

\begin{tabular}{|c|c|c|c|c|c|}
\hline $\begin{array}{c}\text { Experiment } \\
\text { No. } \\
\end{array}$ & $\begin{array}{r}\text { Type of } \\
\text { Sample } \\
\end{array}$ & $\begin{array}{c}\text { Number } \\
\text { of Samples }\end{array}$ & Composition & Enrichment & Heat Treatment \\
\hline $3 \mathrm{C}$ & Clad & $\begin{array}{l}4 \\
4 \\
5 \\
4\end{array}$ & $\begin{array}{l}\text { U-9 w/0 Mo } \\
\text { U-10.5 w/0 Mo } \\
\text { U-12 w/o Mo } \\
U-13.5 \text { w/0 Mo }\end{array}$ & $\begin{array}{l}5 \mathrm{w} / 0 \\
5 \mathrm{w} / 0 \\
5 \mathrm{w} / 0 \\
5 \mathrm{w} / 0\end{array}$ & $\begin{array}{rl}750^{\circ} \mathrm{C}-1 / 2 & \mathrm{~m}-\mathrm{H} \cdot \mathrm{Q} . \\
& \mathrm{n} \\
& \end{array}$ \\
\hline $4 c$ & Clad & $\begin{array}{l}5 \\
4 \\
4 \\
4\end{array}$ & $\begin{array}{l}\mathrm{U}-9 \mathrm{w} / \mathrm{O} \mathrm{Mo} \\
\mathrm{U}-10.5 \mathrm{w} / \mathrm{O} \mathrm{Mo} \\
\mathrm{U}-12 \mathrm{w} / \mathrm{O} \mathrm{MO} \\
\mathrm{U}-13.5 \mathrm{w} / \mathrm{O} \mathrm{Ho}\end{array}$ & $\begin{array}{l}5 \mathrm{w} / 0 \\
5 \mathrm{w} / 0 \\
5 \mathrm{w} / 0 \\
5 \mathrm{w} / 0\end{array}$ & $\begin{array}{l}\mathbf{n} \\
\mathbf{n} \\
\mathbf{n}\end{array}$ \\
\hline $5 c$ & Clad & $\frac{4}{4}$ & $\begin{array}{l}\mathrm{U}-9 \mathrm{w} / \mathrm{o} \mathrm{Mo} \\
\mathrm{U}-10.5 \mathrm{w} / \mathrm{O} \mathrm{Mo}\end{array}$ & $\begin{array}{l}5 w / 0 \\
5 \text { w/o }\end{array}$ & $\begin{array}{l}500^{\circ} \mathrm{C}-116 \mathrm{hr}+\mathrm{T} \cdot \mathrm{Q} . \\
475^{\circ} \mathrm{C}-112 \mathrm{hr}+\mathrm{H} \cdot \mathrm{Q}^{\circ}\end{array}$ \\
\hline $6 \mathrm{c}$ & Clad & $\begin{array}{l}6 \\
6 \\
6 \\
6\end{array}$ & $\begin{array}{l}\mathrm{U}-9 \mathrm{w} / \mathrm{o} \mathrm{Mo} \\
\mathrm{U}-10.5 \mathrm{w} / \mathrm{o} \mathrm{Mo} \\
\mathrm{U}-12 \mathrm{w} / \mathrm{o} \mathrm{Mo} \\
\mathrm{U}-13.5 \mathrm{w} / \mathrm{o} \mathrm{Mo}\end{array}$ & $\begin{array}{l}\text { Natural } \\
\text { Natural } \\
\text { Natural } \\
\text { Natural }\end{array}$ & $\begin{array}{c}\text { As Extruded } \\
" \\
" \\
"\end{array}$ \\
\hline $7 \mathrm{C}$ & Clad & $\begin{array}{l}6 \\
6 \\
6 \\
6\end{array}$ & $\begin{array}{l}\mathrm{U}-9 \text { w/o Mo } \\
\mathrm{U}-10.5 \mathrm{w} / \mathrm{O} \mathrm{Mo} \\
\mathrm{U}-12 \mathrm{w} / \mathrm{O} \mathrm{Mo} \\
\mathrm{U}-13.5 \mathrm{w} / \mathrm{O} \mathrm{Mo}\end{array}$ & $\begin{array}{l}5 \mathrm{w} / 0 \\
5 \mathrm{w} / 0 \\
5 \mathrm{w} / 0 \\
5 \mathrm{w} / 0\end{array}$ & $\begin{array}{l}n \\
n \\
n \\
n\end{array}$ \\
\hline $8 \mathrm{C}$ & Clad & $\begin{array}{l}6 \\
6 \\
6 \\
6\end{array}$ & $\begin{array}{l}\mathrm{U}-9 \text { w/o Mo } \\
\mathrm{U}-10.5 \mathrm{w} / \mathrm{O} \mathrm{Mo} \\
\mathrm{U}-12 \mathrm{w} / \mathrm{O} \mathrm{Mo} \\
\mathrm{U}-13.5 \mathrm{w} / \mathrm{O} \mathrm{Mo}\end{array}$ & $\begin{array}{l}5 \mathrm{w} / 0 \\
5 \mathrm{w} / 0 \\
5 \mathrm{w} / 0 \\
5 \mathrm{w} / 0\end{array}$ & $\begin{array}{l}\text { n } \\
4 \\
n \\
n\end{array}$ \\
\hline $1 \mathrm{~L}$ & Clad & $\begin{array}{r}4 \\
10\end{array}$ & $\begin{array}{l}\mathrm{U}-12 \mathrm{w} / \mathrm{O} \text { Mo } \\
\mathrm{U}-10.5 \mathrm{w} / \mathrm{O} \mathrm{MO}\end{array}$ & $\begin{array}{l}3.6 \mathrm{w} / \mathrm{o} \\
3.6 \mathrm{w} / \mathrm{o}\end{array}$ & " \\
\hline $\begin{array}{c}1 \mathrm{I} \\
\text { Control }\end{array}$ & Clad & $\begin{array}{r}2 \\
12\end{array}$ & $\begin{array}{l}\mathrm{U}-12 \mathrm{w} / \mathrm{o} \mathrm{Mo} \\
\mathrm{U}-10.5 \mathrm{w} / \mathrm{O} \mathrm{Mo}\end{array}$ & $\begin{array}{l}3.6 \mathrm{w} / \mathrm{o} \\
3.6 \mathrm{w} / \mathrm{o}\end{array}$ & $"$ \\
\hline
\end{tabular}

Max. Calculated Exposure (MWD/T)

10,500

28,200

2100

860

5860

10,500

1545

5370 
PABLE I (Contd.)

\begin{tabular}{|c|c|c|c|c|c|c|}
\hline $\begin{array}{c}\begin{array}{c}\text { Experiment } \\
\text { No. }\end{array} \\
\end{array}$ & $\begin{array}{l}\text { Type of } \\
\text { Sample } \\
\end{array}$ & $\begin{array}{c}\text { Number } \\
\text { of Samples }\end{array}$ & Composition & Enrichment & Heat Treatment & $\begin{array}{l}\text { Max. Calculated } \\
\text { Exposure (MW/T) }\end{array}$ \\
\hline $2 I$ & Clad & $\begin{array}{l}6 \\
7\end{array}$ & $\begin{array}{l}\mathrm{U}-11.1 \mathrm{w} / \mathrm{O} \mathrm{Mo} \\
\mathrm{U}-12.1 \mathrm{w} / \mathrm{O} \mathrm{Mo}\end{array}$ & $\begin{array}{l}3.6 w / 0 \\
3.6 \mathrm{w} / 0\end{array}$ & $\begin{array}{c}\text { As Extruded } \\
" 1\end{array}$ & 4000 \\
\hline $\begin{array}{c}2 \mathrm{I} \\
\text { Control }\end{array}$ & Clad & $\frac{1}{6}$ & $\begin{array}{l}U-11.1 \text { w/o Mo } \\
U-12.1 \text { w/o Mo }\end{array}$ & $\begin{array}{l}3.6 w / 0 \\
3.6 \mathrm{w} / 0\end{array}$ & " & 6450 \\
\hline $3 I$ & Clad & 1 & $\mathrm{U}-12 \mathrm{w} / \mathrm{O} \mathrm{Mo}$ & $3.6 \mathrm{w} / 0$ & " & 1200 \\
\hline
\end{tabular}




\section{TABLE 2}

Exposure Data for Experiment 1B, U-12 w/o Mo Samples

\begin{tabular}{|c|c|c|c|c|c|c|}
\hline $\begin{array}{c}\text { Sample } \\
\text { No. }\end{array}$ & $\begin{array}{l}\text { Thermal Flux } \\
\left(\mathrm{nv} \times 10^{-14}\right)\end{array}$ & $\begin{array}{l}\text { Int. Thermal Flux } \\
\text { (nvt } \times 10-20 \text { ) }\end{array}$ & $\begin{array}{l}\text { Exposure } \\
(\text { WWD } / T) \\
\end{array}$ & $\begin{array}{l}\text { Total Atoms } \\
\text { Fissioned (\%) }\end{array}$ & $\frac{\text { Max. } \mathrm{Ca}}{\underline{\text { Surface }}}$ & $\frac{\text { D. }\left({ }^{\circ} \mathrm{C}\right)}{\text { Center }}$ \\
\hline 40 & 0.42 & 2.20 & 650 & 0.06 & 68 & 82 \\
\hline 51 & 1.23 & 6.50 & 1690 & 0.17 & 122 & 164 \\
\hline 61 & 0.55 & 2.90 & 835 & 0.08 & 77 & 96 \\
\hline 80 & 0.86 & 4.55 & 1250 & 0.12 & 98 & 127 \\
\hline 81 & $0.1 / 4$ & 0.75 & 230 & 0.02 & 49 & 54 \\
\hline 90 & 1.51 & 8.00 & 2000 & 0.20 & 141 & 193 \\
\hline 00 & 1.13 & 6.00 & 1575 & 0.16 & 116 & 154 \\
\hline
\end{tabular}




\section{TABLE 3}

Exposure Data for Experiment 2B, U-10.5 and -12 w/o Mo Samples

\begin{tabular}{|c|c|c|c|c|c|c|}
\hline $\begin{array}{c}\text { Sample } \\
\text { Noe }\end{array}$ & $\begin{array}{l}\text { Thermal Flux } \\
\text { (nv } \times 10-14 \text { ) }\end{array}$ & $\begin{array}{l}\text { Int. Thermal Fivx } \\
\left(\text { nvt } \times 10^{-20}\right)\end{array}$ & $\begin{array}{r}\text { Exposure } \\
(\mathrm{NWD} / \mathrm{T}) \\
\end{array}$ & $\begin{array}{l}\text { Total Atoms } \\
\text { Fissioned (\%) }\end{array}$ & $\frac{\text { Max. Calc. }}{\text { Surface }}$ & $\frac{\text { Temp. }\left({ }^{\circ} \mathrm{C}\right)}{\text { Center }}$ \\
\hline $1 \& 21$ & 0.13 & 0.35 & 115 & 0.01 & 77 & 96 \\
\hline $2 \& 22$ & 0.40 & 1.20 & 375 & 0.04 & 98 & 127 \\
\hline $3 \& 23$ & 0.80 & 2.35 & 700 & 0.07 & 133 & 179 \\
\hline $4 \& 24$ & 1.10 & 3.25 & 940 & 0.10 & 159 & 218 \\
\hline $11 \& 25$ & 1.25 & 3.70 & 1050 & 0.10 & 172 & 239 \\
\hline $12 \& 26$ & 1.05 & 3.10 & 900 & 0.09 & 155 & 213 \\
\hline $13 \& 27$ & 1.00 & 1.45 & 445 & 0.05 & 107 & U1 \\
\hline
\end{tabular}




\section{TABLE 4}

Exposure Data for Experiments 38, 4B, and SB

\begin{tabular}{|c|c|c|c|c|c|c|}
\hline Sample & Composition & $\begin{array}{l}\text { Thermal FIux } \\
\left(\mathrm{nv} \times 10^{-13}\right)\end{array}$ & $\begin{array}{c}\text { Int. Thermal Flux } \\
\left.\text { (nvt } \times 10^{-20}\right)\end{array}$ & $\begin{array}{r}\text { Exposure } \\
(M W D / T)\end{array}$ & $\begin{array}{l}\text { Total Atoms } \\
\text { Fissioned (\%) }\end{array}$ & $\frac{\text { Max. Calc. Temp. }\left({ }^{\circ} \mathrm{C}\right)}{\underline{\text { Surface }} \quad \text { Center }}$ \\
\hline
\end{tabular}

Experiment $3 \mathrm{~B}$

\begin{tabular}{|c|c|c|c|c|c|c|c|}
\hline $\begin{array}{l}81 \\
83 \\
84 \\
89 \\
61 \\
63 \\
64\end{array}$ & $\begin{array}{c}\mathrm{U}-13.5 \mathrm{w} / \mathrm{O} \mathrm{MO} \\
\mathrm{u} \\
\mathrm{U}-13.5 \mathrm{w} / \mathrm{O} \mathrm{Mo} \\
\mathrm{U}-12 \mathrm{w} / \mathrm{O} \mathrm{Mo} \\
\mathrm{u}\end{array}$ & $\begin{array}{l}0.85 \\
1.6 \\
2.0 \\
2.4 \\
2.3 \\
1.5 \\
0.75\end{array}$ & $\begin{array}{l}0.54 \\
1.02 \\
1.28 \\
1.54 \\
1.47 \\
0.96 \\
0.48\end{array}$ & $\begin{array}{l}1350 \\
2250 \\
3200 \\
3650 \\
3500 \\
2450 \\
1200\end{array}$ & $\begin{array}{l}0.13 \\
0.22 \\
0.32 \\
0.36 \\
0.35 \\
0.25 \\
0.12\end{array}$ & $\begin{array}{l}114 \\
166 \\
193 \\
217 \\
207 \\
156 \\
106\end{array}$ & $\begin{array}{l}152 \\
231 . \\
273 \\
309 \\
296 \\
218 \\
1117\end{array}$ \\
\hline
\end{tabular}

Experiment $4 \mathrm{~B}$

\begin{tabular}{|c|c|c|c|c|c|c|c|}
\hline $\begin{array}{l}85 \\
86 \\
87 \\
90 \\
65 \\
62 \\
67\end{array}$ & $\begin{array}{c}\mathrm{U}-13.5 \mathrm{w} / \mathrm{O} \text {. Mo } \\
n \\
\mathrm{U}-13.5 \mathrm{w} / \mathrm{O} \mathrm{MO} \\
\mathrm{U}-12 \mathrm{w} / \mathrm{O} \mathrm{Mo} \\
\mathrm{n}\end{array}$ & $\begin{array}{l}0.35 \\
0.65 \\
1.0 \\
1.3 \\
1.4 \\
1.2 \\
0.90\end{array}$ & $\begin{array}{l}0.65 \\
1.20 \\
1.85 \\
2.41 \\
2.59 \\
2.22 \\
1.67\end{array}$ & $\begin{array}{l}2050 \\
2900 \\
4700 \\
5700 \\
6100 \\
5250 \\
3950\end{array}$ & $\begin{array}{l}0.20 \\
0.29 \\
0.47 \\
0.57 \\
0.61 \\
0.53 \\
0.40\end{array}$ & $\begin{array}{r}80 \\
99 \\
128 \\
145 \\
151 \\
138 \\
117\end{array}$ & $\begin{array}{l}101 \\
130 \\
174 \\
200 \\
209 \\
189 \\
157\end{array}$ \\
\hline
\end{tabular}

Experiment SB

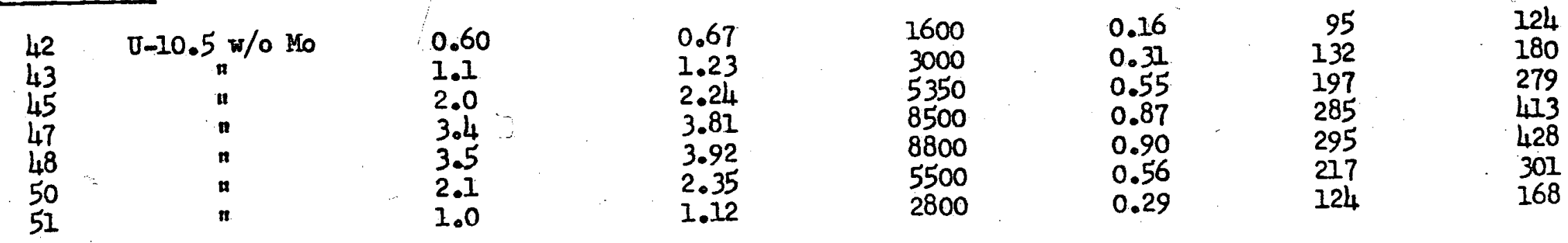

* Specimens partially transformed $+550^{\circ} \mathrm{C}$ for -2 wk after garma quenching. 


\section{TABLE 5}

Exposure Data for Experiment 6B

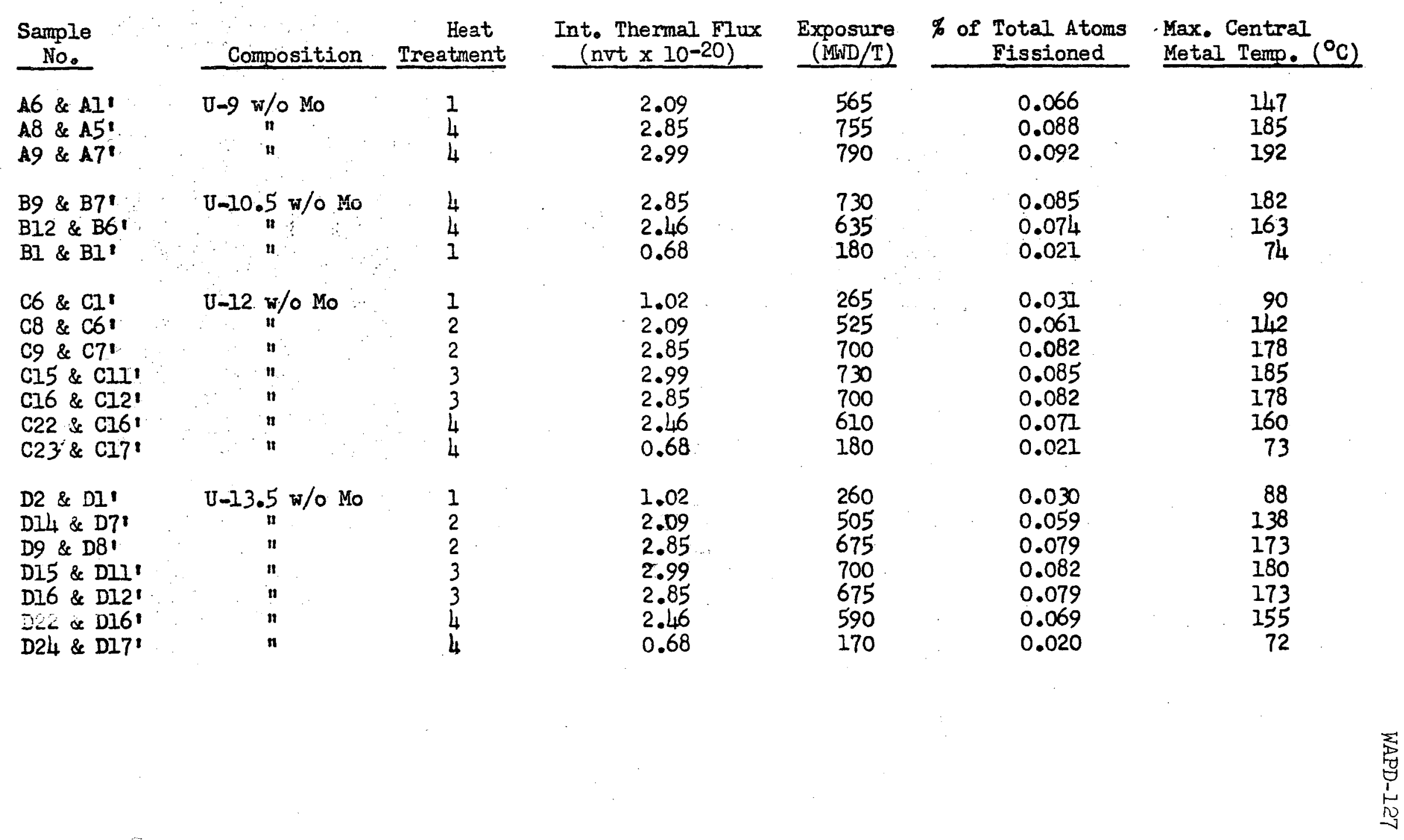


TABLE 6

\section{Exposure Data for Experiment IC}

\begin{tabular}{|c|c|c|c|c|c|c|c|c|}
\hline $\begin{array}{l}\text { Sample* } \\
\text { No. }\end{array}$ & $\begin{array}{l}\text { Thermal Flux } \\
\text { (nv } \times 10-14)\end{array}$ & $\begin{array}{l}\text { Int. Thermal } \\
\text { FIux } \\
\left.\text { (nv } \times 10^{-20}\right) \\
\end{array}$ & $\begin{array}{l}\text { \% Burrup } \\
\text { of Total } \\
\text { Atoms } \\
\end{array}$ & $\begin{array}{c}\% \text { of Total } \\
\text { Atoms } \\
\text { Fissioned } \\
\end{array}$ & $\begin{array}{l}\text { Exposure } \\
(\text { M }\end{array}$ & $\begin{array}{l}\text { Max. Calc } \\
\text { Surface }\end{array}$ & $\frac{\text { Spec. Temp }}{\text { Interface }}$ & Central $\quad\left({ }^{\circ} \mathrm{C}\right)$ \\
\hline $\begin{array}{ll}\text { B } & 1 \\
\text { B } & 2 \\
\text { B } & 3 \\
\text { B } & 4 \\
\text { B } & 7 \\
\text { B } & 8 \\
\text { B } & 9 \\
\text { B } & 10\end{array}$ & $\begin{array}{l}1.20 \\
1.45 \\
1.50 \\
1.45 \\
1.25 \\
0.80 \\
1.05 \\
0.80\end{array}$ & $\begin{array}{l}3.22 \\
3.90 \\
4.02 \\
3.90 \\
3.35 \\
2.15 \\
2.80 \\
2.15\end{array}$ & $\begin{array}{l}0.10 \\
0.13 \\
0.13 \\
0.13 \\
0.11 \\
0.07 \\
0.10 \\
0.07\end{array}$ & $\begin{array}{l}0.10 \\
0.11 \\
0.12 \\
0.11 \\
0.10 \\
0.07 \\
0.08 \\
0.07\end{array}$ & $\begin{array}{r}920 \\
1090 \\
1120 \\
1090 \\
950 \\
630 \\
810 \\
630\end{array}$ & $\begin{array}{l}57 \\
61 \\
62 \\
61 \\
58 \\
52 \\
55 \\
52\end{array}$ & $\begin{array}{l}87 \\
97 \\
98 \\
97 \\
88 \\
71 \\
81 \\
71\end{array}$ & $\begin{array}{l}183 \\
212 \\
217 \\
212 \\
188 \\
135 \\
164 \\
135\end{array}$ \\
\hline $\begin{array}{ll}\text { C } & 1 \\
\text { C } & 2 \\
\text { C } & 3 \\
\text { C } & 4 \\
\text { C } & 5 \\
\text { B } & 5 \\
\text { B } & 6\end{array}$ & $\begin{array}{l}1.50 \\
1.45 \\
1.25 \\
0.34 \\
0.34 \\
1.20 \\
1.45\end{array}$ & $\begin{array}{l}4.02 \\
3.90 \\
3.35 \\
0.90 \\
0.90 \\
3.22 \\
3.90\end{array}$ & $\begin{array}{l}0.13 \\
0.13 \\
0.11 \\
0.03 \\
0.03 \\
0.10 \\
0.13\end{array}$ & $\begin{array}{l}0.11 \\
0.11 \\
0.09 \\
0.03 \\
0.03 \\
0.09 \\
0.11\end{array}$ & $\begin{array}{r}1120 \\
1090 \\
950 \\
275 \\
275 \\
920 \\
1090\end{array}$ & $\begin{array}{l}61 \\
60 \\
57 \\
45 \\
45 \\
57 \\
60\end{array}$ & $\begin{array}{l}96 \\
94 \\
87 \\
53 \\
53 \\
85 \\
94\end{array}$ & $\begin{array}{r}213 \\
207 \\
184 \\
80 \\
80 \\
178 \\
207\end{array}$ \\
\hline $\begin{array}{ll}\text { D } & 1 \\
\text { D } & 4 \\
\text { D } & 5\end{array}$ & $\begin{array}{l}1.50 \\
1.50 \\
1.40\end{array}$ & $\begin{array}{l}4.02 \\
4.02 \\
3.75\end{array}$ & $\begin{array}{l}0.12 \\
0.12 \\
0.11\end{array}$ & $\begin{array}{l}0.11 \\
0.11 \\
0.10\end{array}$ & $\begin{array}{l}1120 \\
1120 \\
1050\end{array}$ & $\begin{array}{l}60 \\
60 \\
59\end{array}$ & $\begin{array}{l}95 \\
95 \\
91\end{array}$ & $\begin{array}{l}207 \\
207 \\
196\end{array}$ \\
\hline
\end{tabular}

* Samples with prefix "B": U-10.5 w/0 Mo

Samples with prefix "C" and samples B 5 and B 6: U-12 w/o Mo Samples with prefix "D": U-13.5 w/O Mo 
TABLE 7

Exposure Data for Experiment 2C

\begin{tabular}{|c|c|c|c|c|c|c|c|c|c|c|}
\hline $\begin{array}{r}\text { Sample* } \\
\text { No.: } \\
\end{array}$ & $\begin{array}{l}\text { Ave Thermal } \\
\left.\text { (nv } \times 10^{-13}\right) \\
\end{array}$ & $\begin{array}{l}\text { Int. } \\
\text { (nvt }\end{array}$ & $\begin{array}{l}\text { Thermal } \\
\text { Flux } \\
\times 10^{-20)}\end{array}$ & $\begin{array}{l}\text { \% Eurnup } \\
\text { of Total } \\
\text { Atoms } \\
\end{array}$ & $\begin{array}{c}\text { \% of Total } \\
\text { Atoms } \\
\text { Fissioned } \\
\end{array}$ & $\begin{array}{r}\text { Exposure } \\
(\mathrm{MWD} / \mathrm{T}) \\
\end{array}$ & $\frac{\text { Max. C }}{\text { Surface }}$ & $\frac{\text { Calc. }}{\text { e }}$ & $\begin{array}{c}\text { Spec. T } \\
\text { Interface }\end{array}$ & $\frac{\text { Temp. }\left({ }^{\circ} \mathrm{C}\right)}{\text { Central }}$ \\
\hline $\begin{array}{l}\text { A } 21 \\
\text { A } 22 \\
\text { A } 23 \\
\text { A } 24\end{array}$ & $\begin{array}{l}3.95 \\
5.10 \\
5.65 \\
4.55\end{array}$ & & $\begin{array}{l}1.61 \\
2.07 \\
2.30 \\
1.85\end{array}$ & $\begin{array}{l}0.46 \\
0.59 \\
0.64 \\
0.53\end{array}$ & $\begin{array}{l}0.41 \\
0.57 \\
0.56 \\
0.46\end{array}$ & $\begin{array}{l}3900 \\
4930 \\
5400 \\
4410\end{array}$ & $\begin{array}{r}84 \\
97 \\
102 \\
91\end{array}$ & & $\begin{array}{l}160 \\
194 \\
210 \\
178\end{array}$ & $\begin{array}{l}406 \\
512 \\
563 \\
462\end{array}$ \\
\hline $\begin{array}{l}\text { C } 21 \\
\text { C } 22 \\
\text { C } 23 \\
\text { C } 24\end{array}$ & $\begin{array}{l}5.85 \\
5.50 \\
5.85 \\
5.65\end{array}$ & & $\begin{array}{l}2.38 \\
2.24 \\
2.38 \\
2.30\end{array}$ & $\begin{array}{l}0.64 \\
0.60 \\
0.64 \\
0.62\end{array}$ & $\begin{array}{l}0.56 \\
0.53 \\
0.56 \\
0.54\end{array}$ & $\begin{array}{l}5610 \\
5310 \\
5610 \\
5400\end{array}$ & $\begin{array}{r}103 \\
99 \\
103 \\
101\end{array}$ & & $\begin{array}{l}210 \\
200 \\
210 \\
205\end{array}$ & $\begin{array}{l}562 \\
531 \\
562 \\
545\end{array}$ \\
\hline
\end{tabular}

* Samples with prefix "A": U-9 w/0 Mo Samples with prefix "B": U-10.5 w/O Mo Samples with prefix "C": U-12 w/o Mo Samples with prefix "D": U-13.5 w/o Mo 
TABLE 8

Exposure Data for Experiment 3C

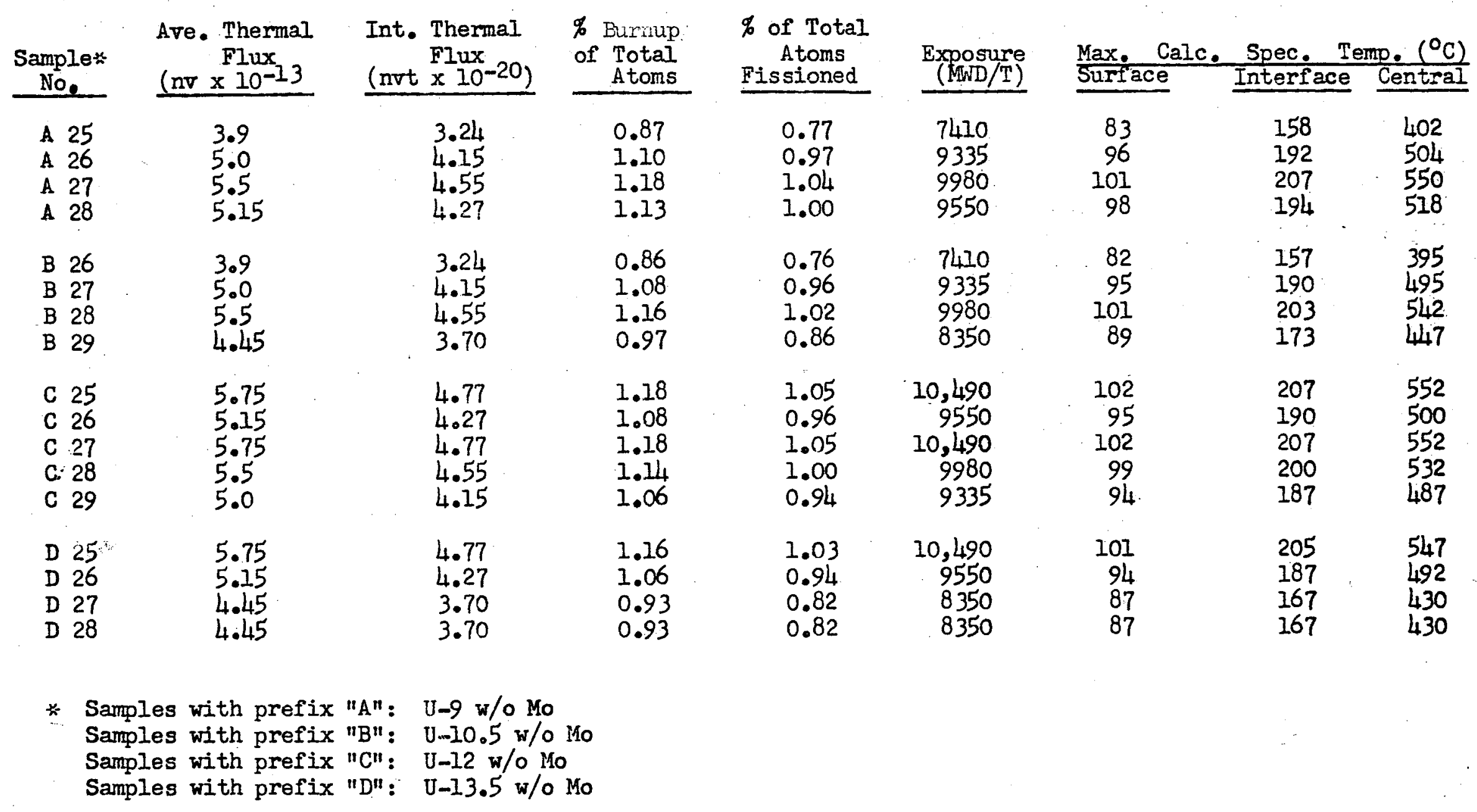


TABLE 9

Exposure Data for Experiment $4 \mathrm{C}$

\begin{tabular}{|c|c|c|c|c|c|c|c|c|c|c|c|}
\hline $\begin{array}{c}\text { Samplex } \\
\text { No. }\end{array}$ & $\begin{array}{l}\text { Ave. } \\
\text { (nv }\end{array}$ & $\begin{array}{l}\text { Thermal } \\
\text { Flux } \\
\left.\times 10^{-13}\right)\end{array}$ & $\begin{array}{l}\text { Int. } \\
\text { (nvt }\end{array}$ & $\begin{array}{l}\text { Thermal } \\
\text { Flux } \\
\left.\times 10^{-20}\right)\end{array}$ & $\begin{array}{l}\% \text { Burnux } \\
\text { of Total } \\
\text { Atoms }\end{array}$ & $\begin{array}{c}\% \text { of Total } \\
\text { Atoms } \\
\text { Fissioned }\end{array}$ & $\begin{array}{r}\text { Exposure } \\
(\mathrm{MWD} / \mathrm{T}) \\
\end{array}$ & $\frac{\text { Max. }}{\text { Surface }}$ & $\frac{\text { Calc. }}{e}$ & $\begin{array}{l}\text { Spec. T } \\
\text { Interface }\end{array}$ & $\frac{\text { me. } \quad\left({ }^{\circ} \mathrm{C}\right)}{\text { Central }}$ \\
\hline $\begin{array}{l}\text { A } 29 \\
\text { A } 30 \\
\text { A } 31 \\
\text { A } 32 \\
\text { A } 33\end{array}$ & & $\begin{array}{l}4.60 \\
5.90 \\
6.55 \\
5.25 \\
5.25\end{array}$ & 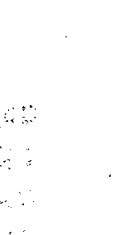 & $\begin{array}{l}12.40 \\
15.95 \\
17.70 \\
14.20 \\
14.20\end{array}$ & $\begin{array}{l}2.54 \\
2.95 \\
3.12 \\
2.75 \\
2.75\end{array}$ & $\begin{array}{l}2.31 \\
2.72 \\
2.90 \\
2.53 \\
2.53\end{array}$ & $\begin{array}{l}22,200 \\
26,100 \\
27,800 \\
24,200 \\
24,200\end{array}$ & $\begin{array}{r}91 \\
105 \\
112 \\
98 \\
98\end{array}$ & & $\begin{array}{l}179 . \\
218 \\
238 \\
198 . \\
198\end{array}$ & $\begin{array}{l}465 \\
585 \\
647 \\
527 \\
527\end{array}$ \\
\hline $\begin{array}{ll}\text { B } & 30 \\
\text { B } & 31 \\
\text { B } & 32 \\
\text { B } & 33\end{array}$ & $\cdots$ & $\begin{array}{l}4.60 \\
5.90 \\
6.75 \\
6.55\end{array}$ & 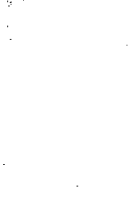 & $\begin{array}{l}12.40 \\
15.95 \\
18.25 \\
16.45\end{array}$ & $\begin{array}{l}2.49 \\
2.89 \\
3.10 \\
2.94\end{array}$ & $\begin{array}{l}2.27 \\
2.66 \\
2.89 \\
2.72\end{array}$ & $\begin{array}{l}22,200 \\
26,100 \\
28,200 \\
26,600\end{array}$ & $\begin{array}{r}90 \\
105 \\
113 \\
106\end{array}$ & & $\begin{array}{l}177 \\
215 \\
240 \\
221\end{array}$ & $\begin{array}{l}460 \\
577 \\
654 \\
595\end{array}$ \\
\hline $\begin{array}{ll}\text { C } & 30 \\
\text { C } & 32 \\
\text { c } & 33 \\
\text { c } & 34\end{array}$ & & $\begin{array}{l}6.10 \\
6.75 \\
6.55 \\
5.90\end{array}$ & & $\begin{array}{l}16.45 \\
18.25 \\
17.70 \\
15.95\end{array}$ & $\begin{array}{l}2.88 \\
3.04 \\
3.00 \\
2.84\end{array}$ & $\begin{array}{l}2.67 \\
2.83 \\
2.79 \\
2.62\end{array}$ & $\begin{array}{l}26,600 \\
28,200 \\
27,800 \\
26,100\end{array}$ & $\begin{array}{l}105 \\
172 \\
110 \\
104\end{array}$ & & $\begin{array}{l}219 \\
238 \\
232 \\
214\end{array}$ & $\begin{array}{l}585 \\
643 \\
627 \\
566\end{array}$ \\
\hline $\begin{array}{ll}\text { D } & 29 \\
\text { D } & 30 \\
\text { D } & 31 \\
\text { D } & 32\end{array}$ & 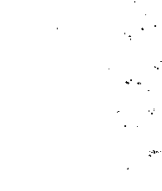 & $\begin{array}{l}6.55 \\
6.75 \\
6.10 \\
5.25\end{array}$ & & $\begin{array}{l}17.70 \\
18.25 \\
16.45 \\
14.20\end{array}$ & $\begin{array}{l}2.94 \\
2.99 \\
2.83 \\
2.60\end{array}$ & $\begin{array}{l}2.73 \\
2.78 \\
2.62 \\
2.39\end{array}$ & $\begin{array}{l}27,800 \\
28,200 \\
26,600 \\
24,200\end{array}$ & $\begin{array}{r}109 \\
117 \\
105 \\
96\end{array}$ & & $\begin{array}{l}228 \\
2.35 \\
216 \\
192\end{array}$ & $\begin{array}{l}616 \\
634 \\
577 \\
502\end{array}$ \\
\hline
\end{tabular}

* Samples with prefix "A": U-9 w/o Mo Samples with prefix "B": $U-10.5 \mathrm{w} / 0$ Mo Samples with prefix "C": U-12 w/o Mo Samples with prefix "D": U-13.5 \%/0 Mo 


\section{TABLE 10}

Changes in Dimensions and Density of Gamma-quenched U-Mo Alloys

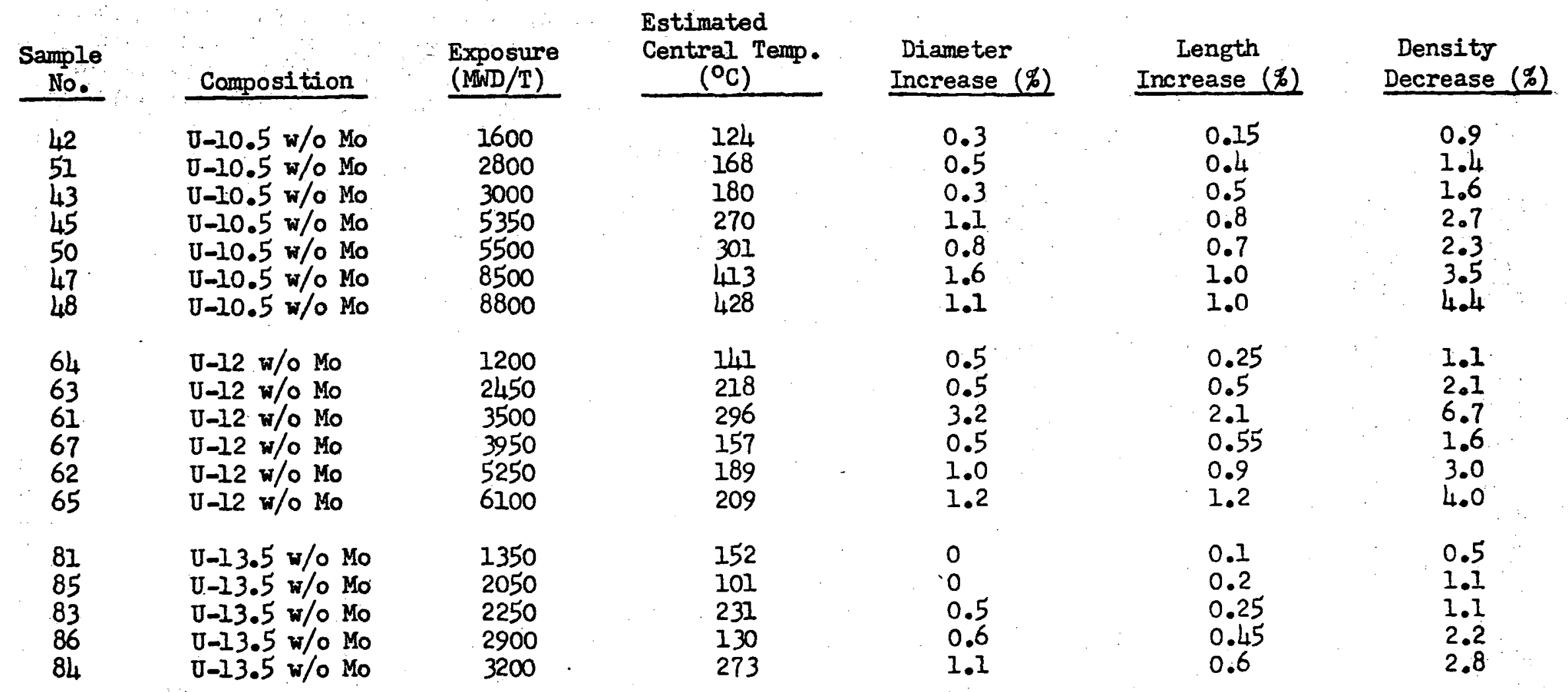




\section{TABLE 11}

Changes in Dimensions and Density of Transformed U-Mo Alloys

\begin{tabular}{|c|c|c|c|c|c|c|c|}
\hline Sample & & Heat & Exposure & Diameter & Densi & $\left(\mathrm{g} / \mathrm{cm}^{3}\right)$ & Density \\
\hline No. & Composition & Treatment: & $(\mathrm{MWD} / \mathrm{T})$ & Increase & Pre-irradiation & Post-irradiation & Change $(\%)$ \\
\hline A 6 & U-9 w/0 Mo & No. 1 & 4565 & n.s.** & $17.35 \pm 0.01$ & 17.34 & 0 \\
\hline 18 & U-9 w/o Mo & No. 4 & 755 & $0.6 \%$ & $17.47 \pm 0.01$ & 17.29 & -1.0 \\
\hline A. 9 & $\mathrm{U}-9$ - $/ \mathrm{O} \mathrm{MO}$ & No. 4 & 790 & $0.7 \%$ & & 17.24 & $-1 \cdot 3$ \\
\hline B 1 & $\mathrm{U}-10.5 \mathrm{w} / \mathrm{o} \mathrm{Mo}$ & No. 1 & 180 & n.s. & $17.15 \pm 0.01$ & 17.16 & 0 \\
\hline B 12 & $\mathrm{U}-10.5 \mathrm{w} / \mathrm{O} \mathrm{Mo}$ & No. 4 & 635 & n.s. & $17 . .18 \pm 0.01$ & 17.16 & -- \\
\hline B 9 & $\mathrm{U}-10.5 \mathrm{w} / \mathrm{O} \mathrm{Mo}$ & No. 4 & 730 & n.s. & & 17.11 & -0.4 \\
\hline
\end{tabular}

All specimens of $U-12 \mathrm{w} / 0$ Mo and U-13.5 w/o Mo, having heat treatments No. 1 to No. 4 , respectively, showed no change in dimensions or density.

* Heat Treatments

No. I - $900^{\circ} \mathrm{C}-24 \cdot \mathrm{hr}-\mathrm{W} . \mathrm{Q}$.

No. $2-1+525^{\circ} \mathrm{C}-8 \mathrm{hr}-\mathrm{Wl} . \mathrm{Q}$.

No. $3-1+525^{\circ} \mathrm{C}-48 \mathrm{hr}-\mathrm{N} . Q$.

No. $4-1+525^{\circ} \mathrm{C}-312 \mathrm{hr}-\mathrm{N} \cdot \mathrm{Q}$.

n.s. - indicates no significant change. 
TABLE 12

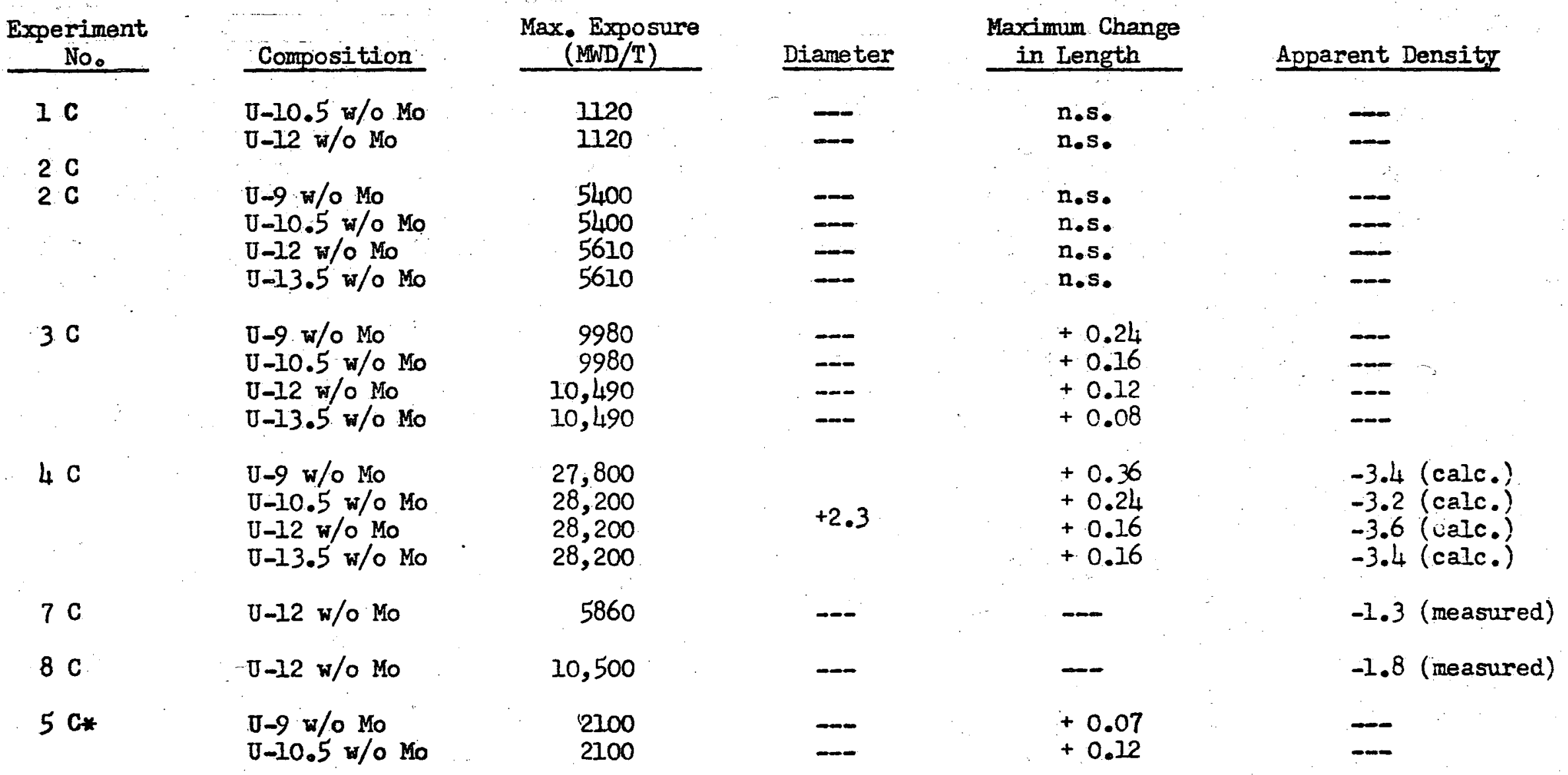

* Specimens partially transformed to alpha plus epsilon; all other specimens in the gama-quenched condition. 
TABLE 13

Electrical Resistivity Changes of Irradiated U-12 w/o Mo (Gamma-quenched) at $-196^{\circ} \mathrm{C}$

\section{Irradiated Sample Data}

\begin{tabular}{cc}
$\begin{array}{c}\text { Sample } \\
\text { No. }\end{array}$ & $\begin{array}{r}\text { Exposure } \\
(\mathrm{MWD} / \mathrm{T})\end{array}$ \\
\hline 51 & 1690 \\
40 & 650 \\
90 & 2000 \\
80 & 230 \\
61 & 835
\end{tabular}

Bulk $\left.{ }^{\circ} \mathrm{C}\right)$
164
82
193
54
96

$\begin{array}{cc}\frac{\text { Resistivity }}{\text { Pre-irradiation }} & \frac{\text { Post-irradiation }}{\mathrm{cm})} \\ 75.6 \pm 0.2 & 74.8 \pm 0.2 \\ 75.7 \pm 0.2 & 73.5 \pm 0.2 \\ 75.3 \pm 0.2 & 74.3 \pm 0.2 \\ 75.8 \pm 0.2 & 73.4 \pm 0.2 \\ 75.6 \pm 0.2 & 73.4 \pm 0.2\end{array}$

Resistivity Change (\%)$$
-1.1 \pm 0.5
$$$$
-2.8 \pm 0.5
$$$$
-1.3 \pm 0.5
$$$$
-3.2 \pm 0.5
$$$$
-2.9 \pm 0.5
$$ 
TABTE 14

Electrical Resistivity Changes of Irradiated U-Mo Alloys (Gamma-quenched) at $-196^{\circ} \mathrm{C}$

Exposure Butk

Sample

No.

1

2

3

4

11

12

13

21

22

-3:

24

25

26

27
Composition

U-10.5 w/O No

$n$

n

n

n

n

$\mathrm{U}-12$ w/O Mo

n

(MND/T)

115

375

700

940

1050

900

445

115

375

700

940

1050

900

445

\begin{tabular}{c} 
Bulk \\
Tomp. (o) \\
\hline 96 \\
127 \\
179 \\
218 \\
239 \\
213 \\
141 \\
96 \\
127 \\
179 \\
218 \\
239 \\
213 \\
141 \\
\hline
\end{tabular}

Resistivity (microlm/cm)

Pre Post

73.26

73.19

73.32

73.34

73.36

73.35

73.49

75.36

75.37

75.30

75.35

75.37

75.32

75.35
7.4

7.9

72.2

72.2

72.2

72.0

71.6

73.3

73.9

74.0

74.3

73.5

73.4

73.3
Resistivity

Change (f)

$-2.6$

$-1.8$

$-1.5$

$-1=5$

$-1.6$

$-1.9$

$-2.6$

$-2.8$

$-2.0$

$-1.7$

$-1.5$

$-2.5$

$-2.5$

$-2.8$

Standard deviations: Resistivity - 0.09 microhm-cm

Resistivity chango - $0.2 \%$ 
TABLE 15

Electrical Resistivity Changes of Unirradiated U-12 w/0 Ko (Gamma-quenched) at $-196^{\circ} \mathrm{C}$

\section{Unirradiated Control Data}

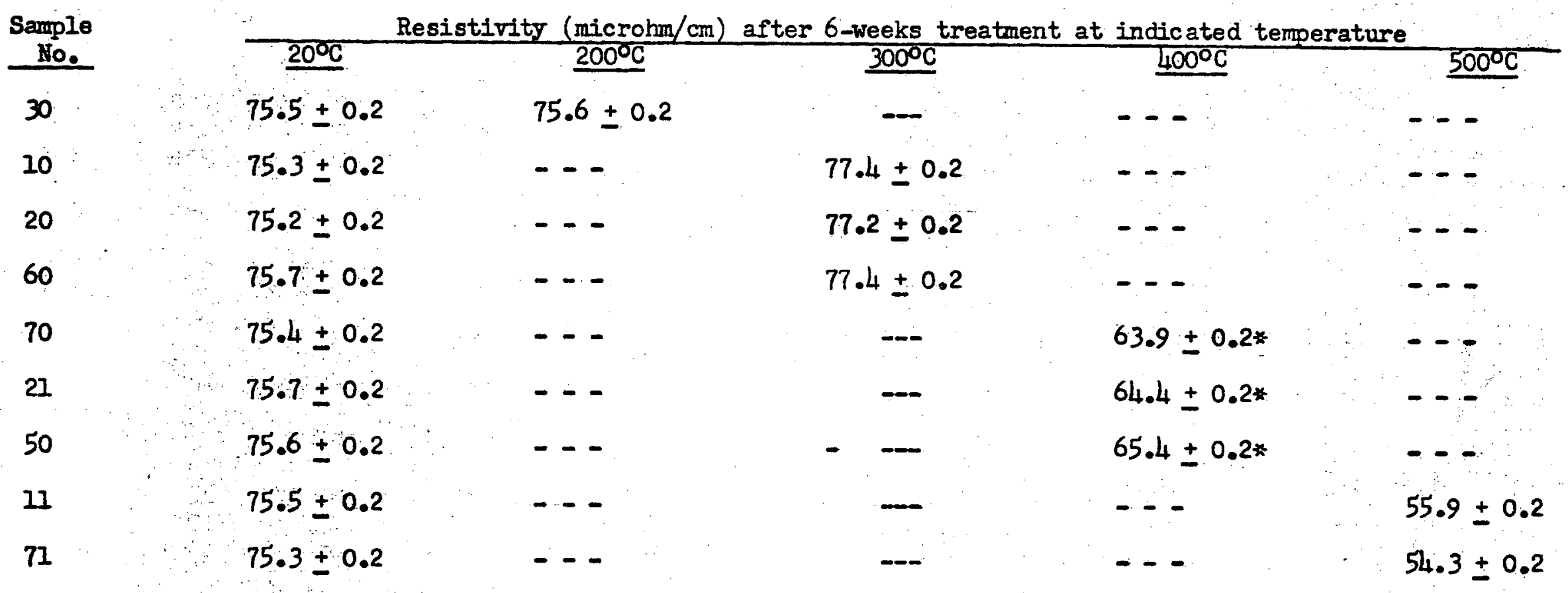

* The sharp drop in resistivity is an indication of the transformation from the gama to the epsilon phase in the material.

NOTE: Prior to annealing treatments indicated above, all specimens were heat treated for 24 hours at $900^{\circ} \mathrm{C}$ and water quenched. 
TABLE 16

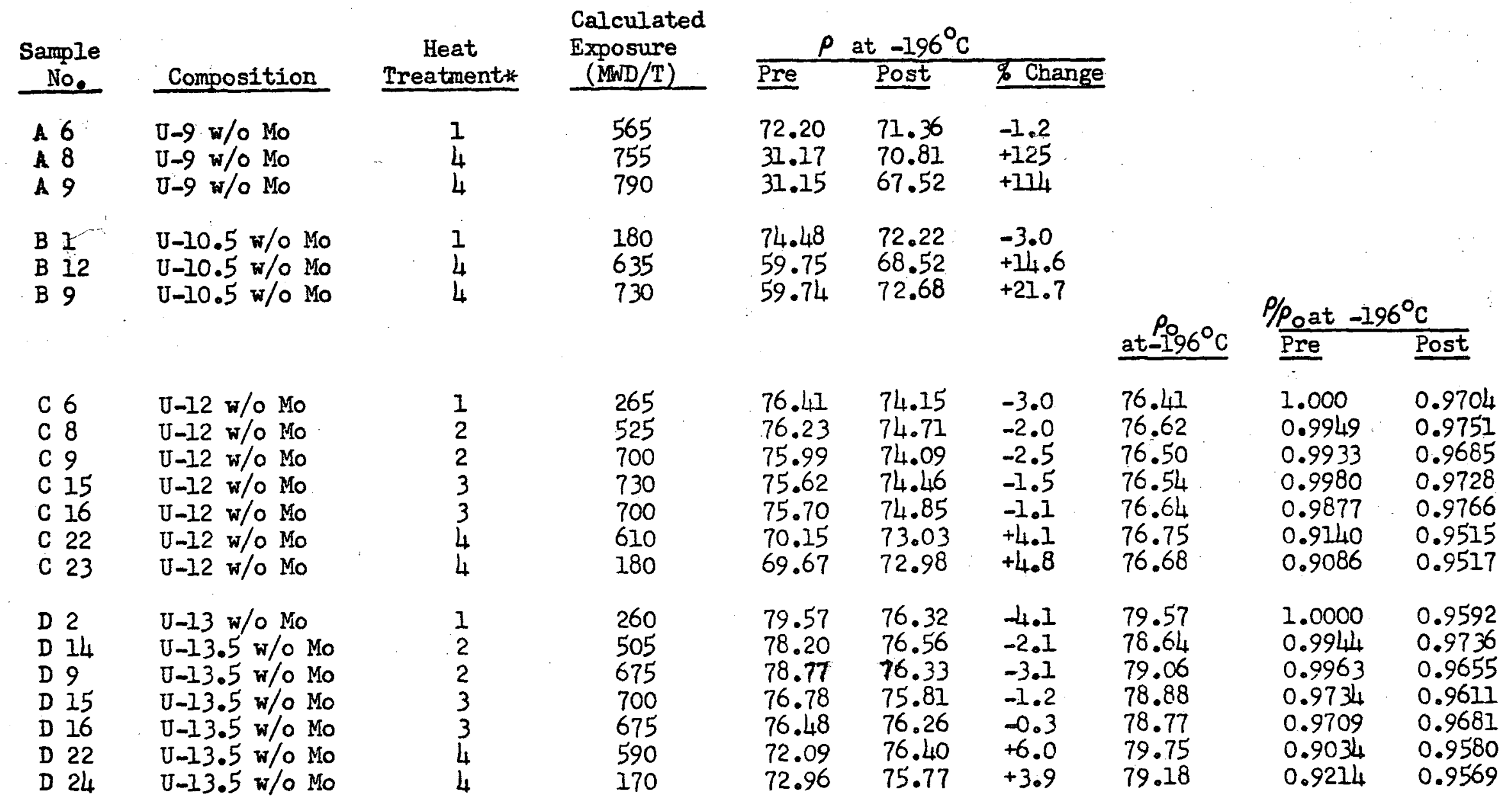

\section{* Heat Treatments}
1 - $900^{\circ} \mathrm{C}$ in kinetic vacuum for $24 \mathrm{hr}$, W.Q.
$2=1+525^{\circ} \mathrm{C}$ in evacuated Vycor tubes for $8 \mathrm{hr}$, W.Q.
$3-1+525^{\circ} \mathrm{C}$ in evacuated Vycor tubes for $48 \mathrm{hr}$, W.Q.
$4-1+525^{\circ} \mathrm{C}$ in evacuated Vycor tubes for $312 \mathrm{hr}$, W.Q. 
TABLE 17

Microhardness of Irradiated Gamma-quenched U-10.5 w/o Mo Bare Samples

(Extruded Material)

\begin{tabular}{cc}
$\begin{array}{c}\text { Sample } \\
\text { No. }\end{array}$ & $\begin{array}{c}\text { Exposure } \\
\text { (MNO/T) }\end{array}$ \\
\hline 1 & 115 \\
2 & 375 \\
13 & 445 \\
3 & 700 \\
12 & 900 \\
4 & 940 \\
11 & 1050 \\
42 & 1600 \\
51 & 2800 \\
43 & 3000 \\
45 & 5350 \\
50 & 5500 \\
47 & 8500 \\
48 & 8800
\end{tabular}

$\mathrm{DPH}$ at $5-\mathrm{kg}$ Load

\begin{tabular}{lll}
\hline Pre & Post & Increase \\
$299 \pm 3$ & $24 \pm 8$ \\
$323 \pm 8$ & $48 \pm 13$ \\
$285 \pm 9$ & $10 \pm 14$ \\
$275 \pm 5$ & $305 \pm 4$ & $31 \pm 9$ \\
$310 \pm 7$ & $35 \pm 12$ \\
$317 \pm 4$ & $42 \pm 9$ \\
$318 \pm 5$ & $43 \pm 10$ \\
$315 \pm 2$ & $40 \pm 7$ \\
$329 \pm 2$ & $54 \pm 7$ \\
$330 \pm 4$ & $55 \pm 9$ \\
$355 \pm 3$ & $80 \pm 8$ \\
$369 \pm 4$ & $94 \pm 9$ \\
$360 \pm 5$ & $85 \pm 10$ \\
$366 \pm 2$ & $91 \pm 7$
\end{tabular}




\section{TABLE 18}

\begin{tabular}{|c|c|c|c|c|}
\hline $\begin{array}{c}\text { Sample } \\
\text { No. } \\
\end{array}$ & $\begin{array}{l}\text { Exposure } \\
(\mathrm{MWD} / \mathrm{T})\end{array}$ & Pre & Post & Increase \\
\hline \multicolumn{5}{|c|}{ Experiment IB (Cast Button Material) } \\
\hline $\begin{array}{l}81 \\
40 \\
61 \\
80 \\
00 \\
51 \\
90\end{array}$ & $\begin{array}{r}230 \\
650 \\
835 \\
1250 \\
1575 \\
1690 \\
2000\end{array}$ & $\begin{array}{l}324 \pm 5 \\
329 \pm 6 \\
327 \pm 2 \\
324 \pm 5 \\
325 \pm 2 \\
327 \pm 5 \\
329 \pm 4\end{array}$ & $\begin{array}{l}330 \pm 6 \\
334 \pm 4 \\
350 \pm 74 \\
343 \pm 6 \\
353 \pm 7 \\
348 \pm 4 \\
364 \pm 4\end{array}$ & $\begin{array}{r}6 \pm 11 \\
5 \pm 10 \\
23 \pm 16 \\
19 \pm 11 \\
28 \pm 9 \\
21 \pm 9 \\
35 \pm 8\end{array}$ \\
\hline \multicolumn{5}{|c|}{ Experiments 2B, 3B, and $4 \mathrm{~B}$ (Extruded Material) } \\
\hline $\begin{array}{l}21 \\
22 \\
27 \\
23 \\
26 \\
24 \\
25 \\
64 \\
63 \\
61 \\
67 \\
62 \\
65\end{array}$ & $\begin{array}{l}175 \\
375 \\
445 \\
700 \\
900 \\
940 \\
1050 \\
1200 \\
2450 \\
3500 \\
3950 \\
5250 \\
6100\end{array}$ & $307 \pm 3$ & $\begin{array}{l}332 \pm 12 \\
358 \pm 11 \\
323 \pm 4 \\
344 \pm 6 \\
319 \pm 8 \\
336 \pm 10 \\
359 \pm 15 \\
365 \pm 7 \\
390 \pm 6 \\
277 \text { t5 } 386 \% \\
367 \pm 15 \\
406 \pm 4 \\
387 \pm 8\end{array}$ & $\begin{array}{l}25 \pm 15 \\
51 \pm 14 \\
16 \pm 7 \\
37 \pm 9 \\
12 \pm 11 \\
29 \pm 13 \\
52 \pm 18 \\
58 \pm 10 \\
83 \pm 9 \\
-30 \pm 0+79 \\
60 \pm 8 \\
99 \pm 7 \\
80 \pm 11\end{array}$ \\
\hline
\end{tabular}

* Sample showed a variation in hardness across the diameter - softer in the center of the specimen than at the surface. 
TABIE 19

Milcrohardness of Irradiated Gamma-quenched $0-13.5$ w/0 Mo Bare Samples

(Extruded Material)

Sample Exposure

No.

81

85

83

86
$\operatorname{Lim} / T)$

1350

2050

2250

2900
DPH at 5-kg Load

\begin{tabular}{ccc}
\hline Pre & $\frac{\text { Post }}{413 \pm 47 *}$ & Increase \\
$322 \pm 4$ & $91 \pm 51$ \\
& $371 \pm 7$ & $49 \pm 17$ \\
& $412 \pm 5$ & $90 \pm 9$ \\
& $400 \pm 7$ & $78 \pm 11$
\end{tabular}

* Sample showed a variation in hardness across the diameter - softer in the center of the specimen than at the surface. 


\section{TABLE 20}

Haxdness Changes for Trangformed Irradiated U-Mo AIloy

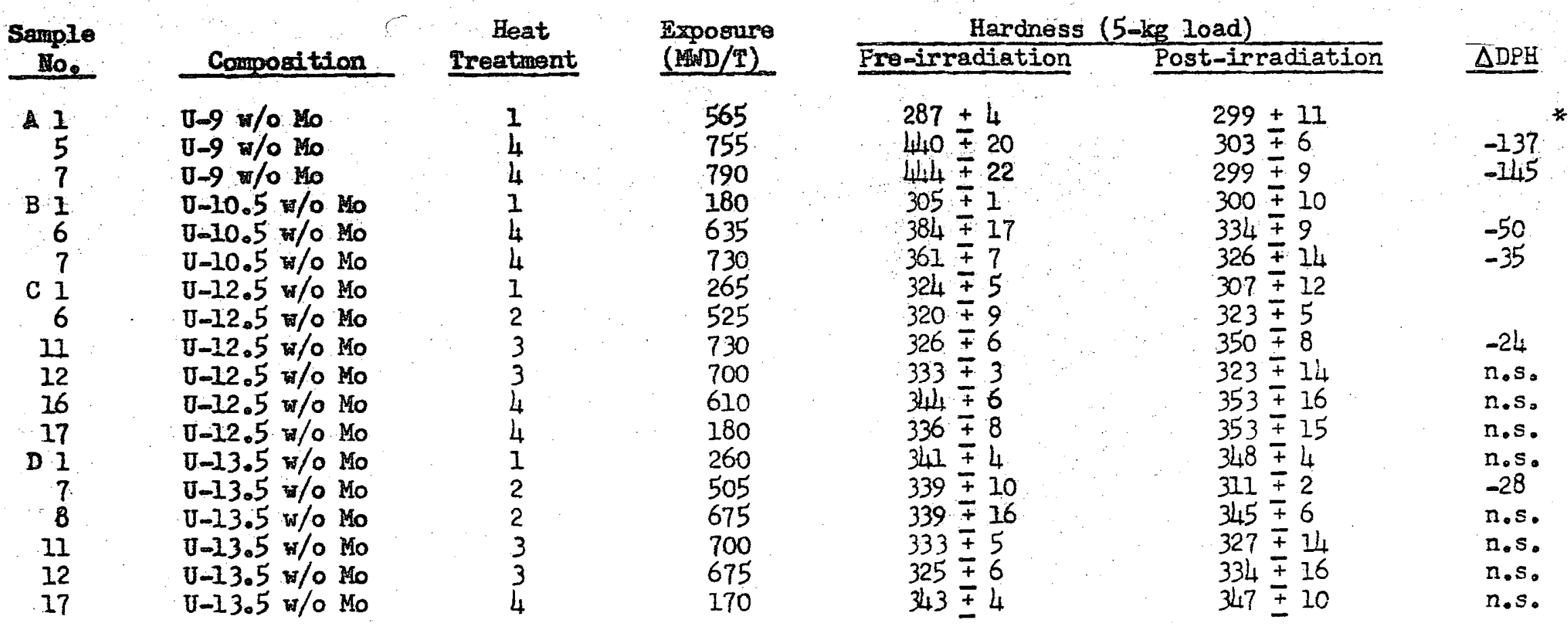

* - Not Significant

Heat Treatments:

1 - $900^{\circ} \mathrm{C}$ for $24 \mathrm{hr}$ W.Q. ( $\gamma$ Quench)

2 - y-Quench $+525^{\circ} \mathrm{C}$ for $8 \mathrm{hr}$, water-quenched

3 - y-Quench $+525^{\circ} \mathrm{C}$ for $48 \mathrm{hr}$, water-quenched

$4-\gamma$-Quench $+525^{\circ} \mathrm{C}$ for 13 days, water-quenched 
TABLE 21

Corrosion Rates of Non-irradiated and Irradiated (Gamma-quenched) Unclad U-Mo Samples

(Experiment $1 \mathrm{~B}$ tested at $575^{\circ} \mathrm{F}$, Experiment $2 \mathrm{~B}$ at $650^{\circ} \mathrm{F}$

\begin{tabular}{|c|c|c|c|c|}
\hline $\begin{array}{c}\text { Experiment } \\
\text { No. }\end{array}$ & $\begin{array}{c}\text { Sample } \\
\text { No. } \\
\end{array}$ & Composition & Heat Treatment & $\begin{array}{l}\text { Exposure } \\
\text { (MWD/T) }\end{array}$ \\
\hline IB & $\begin{array}{l}30 \mathrm{C} \\
80 \mathrm{C} \\
30 \mathrm{H} \\
20 \mathrm{H} \\
50 \mathrm{H} \\
21 \mathrm{H} \\
11 \mathrm{H} \\
81 \\
40 \\
61 \\
8 \\
0 \\
51 \\
90\end{array}$ & U-12 w/o Mo & $\begin{array}{l}\text { Control } \\
\text { Control } \\
6 \text { wk, } 200^{\circ} \mathrm{C} \\
6 \text { wk, } 300^{\circ} \mathrm{C} \\
6 \text { wk, } @ 400^{\circ} \mathrm{C} \\
6 \text { wk } @ 400^{\circ} \mathrm{C} \\
6 \text { wk } @ 500^{\circ} \mathrm{C} \\
--- \\
--- \\
-- \\
-- \\
-- \\
--\end{array}$ & $\begin{array}{r}\ldots- \\
-\ldots \\
-\ldots \\
-\ldots \\
-\ldots \\
\cdots- \\
230 \\
650 \\
835 \\
1250 \\
1575 \\
1690 \\
2000\end{array}$ \\
\hline $2 B$ & $\begin{array}{l}6 \\
5 \\
9 \\
14 \\
15 \\
19 \\
11 \\
12 \\
13\end{array}$ & J-10.5 w/o Mo & 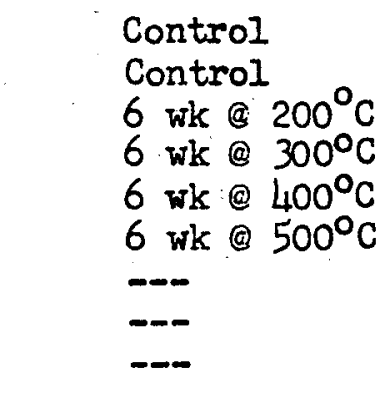 & $\begin{array}{r}-.- \\
-- \\
-- \\
-- \\
1050 \\
900 \\
445\end{array}$ \\
\hline $2 B$ & $\begin{array}{l}30 \\
29\end{array}$ & U-12 w/o Mo & $\begin{array}{l}\text { Control } \\
\text { Control }\end{array}$ & $-\infty$ \\
\hline
\end{tabular}

Ave. Corrosion

Rate before Failure Days to $\left(\mathrm{mg} / \mathrm{cm}^{2}-\mathrm{hr}\right) \quad$ Failure

$0.09 \quad 52-66$

$0.11 \quad 45-52$

$0.07 \quad 49-56$

$0.07 \quad 49-56$

$0.04 \quad 49-56$

$0.08 \quad 49-56$

$--0-1$

$0.05 \quad 11-21$

0.05 7-14

$0.01 \quad 14-21$

$0.05 \quad 1-7$

$0.05 \quad 7-14$

$0.04 \quad 1-7$

$0.04 \quad 1-7$

$0.24 \quad 21-35$

$0.25 \quad 21-35$

$\begin{array}{lr}0.28 & 7-14 \\ 0.23 & 14-28\end{array}$

$1.3 \quad 7-14$

$-\cdots \quad 0-1$

$0.30 \quad 22-28$

$0.20 \quad 35-42$

$0.26 \quad 22-28$

$0.25 \quad 21-35$

$0.20 \quad 21-35$




$\begin{array}{ccc}\begin{array}{c}\text { Experiment } \\ \text { No. }\end{array} & \begin{array}{c}\text { Sample } \\ \text { No. }\end{array} \\ & & \\ & 36 \\ & & \\ & & \\ & & \\ & 24 \\ & & \end{array}$

\begin{tabular}{|c|c|}
\hline Heat Treatment & $\begin{array}{l}\text { Exposure } \\
(\mathrm{MWD} / \mathrm{T})\end{array}$ \\
\hline 6 wk@300 ${ }^{\circ} \mathrm{C}$ & $-\cdots$ \\
\hline 6 wk@400 $\mathrm{C}$ & \\
\hline-- & 445 \\
\hline-- & 940 \\
\hline$=-$ & 900 \\
\hline
\end{tabular}

Ave. Corrosion

Rate before Fâilure (mg/ $\mathrm{cm}^{2}-\mathrm{hr}$ )

\subsection{0}

0.18

0.30

0.13

0.11
Days to

Failure.

$14-28$

$14-28$

20-22

$35-42$

22-28 
TABLE 22

Effect of Irradiation on the Corrosion Resistance of Transformed U-Mo Alloys

(Expariment 6B: All samples tested in $650^{\circ} \mathrm{F}\left(343^{\circ} \mathrm{C}\right)$ water at saturation pressure)

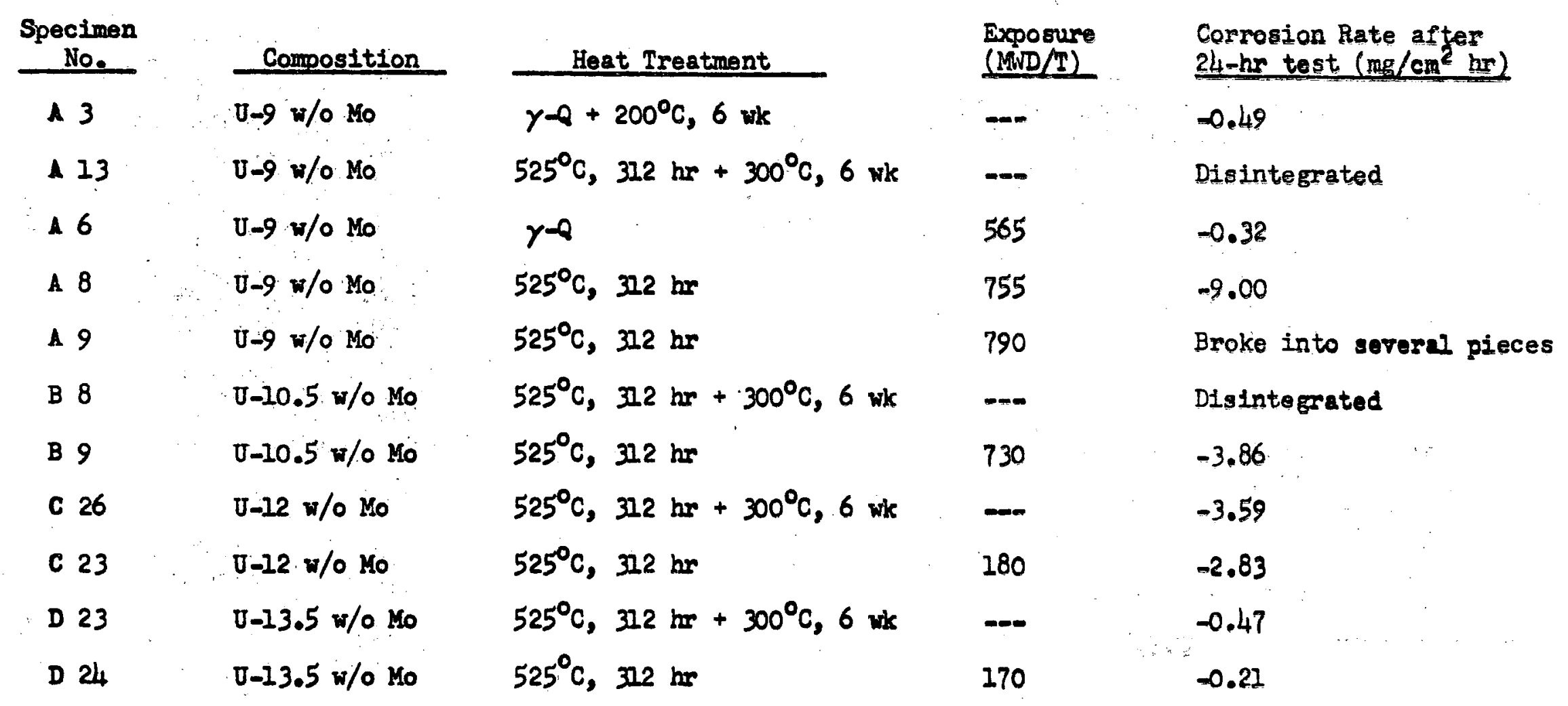


TABLE 23

Corrosion Results of Clad U-10.5 w/o Mo Samples

(Experiment 1C)

\begin{tabular}{|c|c|c|c|}
\hline $\begin{array}{c}\text { Sample } \\
\text { No. }\end{array}$ & $\begin{array}{c}\text { Heat } \\
\text { Treatment } \\
\end{array}$ & $\begin{array}{l}\text { Exposure } \\
\text { (MWD/T) }\end{array}$ & $\begin{array}{l}\text { Days to } \\
\text { Failure }\end{array}$ \\
\hline $\begin{array}{ll}\text { B } & \text { I } \\
\text { B } & 2 \\
\text { B } & 3 \\
\text { B } & 4 \\
\text { B } & 7 \\
\text { B } & 8 \\
\text { B } & 9 \\
\text { B } & 10\end{array}$ & $\begin{array}{l}\text { None after } \\
\text { extrusion } \\
\text { " } \\
\text { " } \\
\text { " } \\
\text { " } \\
\text { " }\end{array}$ & $\begin{array}{r}920 \\
1020 \\
1120 \\
1090 \\
950 \\
630 \\
810 \\
630\end{array}$ & $\begin{array}{r}45-57 \\
23-32 \\
15-22 \\
15-22 \\
45-57 \\
8-14 \\
45-57 \\
45-57\end{array}$ \\
\hline $\begin{array}{ll}\text { BC } & 1 \\
\text { BC } & 2 \\
\text { BC } & 3 \\
\text { BC } & 4 \\
B C & 5\end{array}$ & $\begin{array}{c}750^{\circ} \mathrm{C} \text { for } \\
40 \text { minutes } \\
" 1 \\
\text { " }\end{array}$ & $\begin{array}{c}\text { None } \\
\text { None } \\
" \\
n \\
"\end{array}$ & $\begin{array}{l}45-57 \\
75-88 \\
75-88 \\
45-57 \\
23-32\end{array}$ \\
\hline $\begin{array}{ll}\mathrm{BC} & 6 \\
\mathrm{BC} & 7 \\
\mathrm{BC} & 8 \\
\mathrm{BC} & 9 \\
\mathrm{BC} & 10\end{array}$ & $\begin{array}{c}\text { None after } \\
\text { extrusion } \\
\text { " } \\
n \\
n\end{array}$ & $\begin{array}{l}" 1 \\
" 1 \\
" 1 \\
"\end{array}$ & $\begin{array}{l}33-44 \\
145-158 \\
33 \text { - } 44 \\
0 . K \text {. after } \\
366 \text { days }\end{array}$ \\
\hline
\end{tabular}

Remarks

Failure by splitting of clad near defect

Failure caused by corrosion of contaminated welc metal Failure caused by corrosion of contaminated weld metal Failure caused by corrosion of contaminated weld metal Failure by splitting of clad near defect

Failure caused by corrosion of contaminated weld metal Failure by splitting of clad near defect Failure by splitting of clad near defect

Failure by splitting of clad near defect Failure by splitting of clad near defect Failure by splitting of clad near defect Failure by splitting of clad near defect Specimen bulged at defect

Failure by splitting of clad near defect Failure by splitting of clad near defect Failure by splitting of clad near defect 


\section{TABLE 24}

Corrosion Life of Irrediated Clad U-Mo Alloys

(Pre-irradiation Heat Treatment: $750^{\circ} \mathrm{C}$ for $1 / 2 \mathrm{mr}$ )

\begin{tabular}{|c|c|c|c|}
\hline $\begin{array}{c}\text { Sample } \\
\text { No. } \\
\end{array}$ & Composition & $\begin{array}{l}\text { Exposure } \\
(\mathrm{MWD} / \mathrm{T}) \\
\end{array}$ & $\begin{array}{l}\text { Test Days in } 650^{\circ} \mathrm{F} \\
\text { Water to Failure }\end{array}$ \\
\hline $\begin{array}{l}\text { A } 21 \\
\text { A } 22 \\
A 23 \\
A 24 \\
A 25 \\
A 26 \\
A 27\end{array}$ & U-9 w/o Mo & $\begin{array}{l}3900 \\
4930 \\
5400 \\
4410 \\
7410 \\
9335 \\
9980\end{array}$ & $\begin{aligned} 21 & =28 \\
14 & =21 \\
6 & =9 \\
14 & =21 \\
14 & =21 \\
3 & =6 \\
0 & =7\end{aligned}$ \\
\hline $\begin{array}{ll}\text { B } & 21 \\
\text { B } 22 \\
\text { B } 23 \\
\text { B } 24 \\
\text { B } 25 \\
\text { B } 26 \\
\text { B } 27 \\
\text { B } 28\end{array}$ & $U-10.5 \mathrm{w} / \mathrm{O} \mathrm{Mo}$ & $\begin{array}{l}3900 \\
4930 \\
5400 \\
5100 \\
4410 \\
7410 \\
9335 \\
9980\end{array}$ & $\begin{array}{c}28-35 \\
35-42 \\
14-21 \\
26-33 \\
21=28 \\
15-16 \\
0=3 \\
0-7\end{array}$ \\
\hline $\begin{array}{l}\text { C } 21 \\
\text { c } 22 \\
\text { C } 23 \\
\text { C } 24 \\
\text { C } 26 \\
\text { C } 27 \\
\text { C } 28 \\
\text { C } 29\end{array}$ & $\mathrm{U}-12 \mathrm{w} / \mathrm{o} \mathrm{Mo}$ & $\begin{array}{r}5610 \\
5310 \\
5610 \\
5400 \\
9550 \\
10,490 \\
9980 \\
9335\end{array}$ & $\begin{array}{c}6-9 \\
6-9 \\
u_{4}-21 \\
9-u_{4} \\
0-3 \\
0-3 \\
0-7 \\
0-7\end{array}$ \\
\hline
\end{tabular}


TABLE 24 (Contd)

\&

Exposure

Sample No.

D 21

D. 22

D 23

D 24

D 25

D 26

D 27

\section{Composition}

U-13.5 w/० Mo
(MWD/T)

5610

5100

4410

4930

10,490

9550

8350
Test Days in $650^{\circ} \mathrm{F}$ Water to Failure

$$
\begin{array}{r}
6-9 \\
6-9 \\
9-14 \\
74=21 \\
9=7 \\
0=7 \\
3-6
\end{array}
$$




\section{TABLE 25}

\section{Corrosion Life of Unirradiated Clad U-Mo Alloys}

(Control Samples for Experiments $2 \mathrm{C}$ and $3 \mathrm{C}$ )

\begin{tabular}{c} 
Sample \\
No. \\
\hline $12-1$ \\
$12-2$ \\
$12-3$ \\
$12-7$ \\
$12-8$ \\
$12-9$ \\
$2-1$ \\
$2-2$ \\
$2-3$ \\
$2-7$ \\
$2-8$ \\
$2-9$ \\
$3-2$ \\
$3-3$ \\
$3-4$ \\
$3-9$ \\
$3-10$
\end{tabular}

Heat

Treatment

$750^{\circ} \mathrm{C}-1 / 2 \mathrm{hr}$

$750 \mathrm{C}-1 / 2 \mathrm{hr}$

$750^{\circ} \mathrm{C}-1 / 2 \mathrm{hr}$

As-extruded:

As-extruded

As-extruded

$750^{\circ} \mathrm{C}-1 / 2 \mathrm{hr}$

$750^{\circ} \mathrm{C}-1 / 2 \mathrm{hr}$

$750^{\circ} \mathrm{C}-1 / 2 \mathrm{hr}$

As-extruded

As-extruded

As-extruded

$750^{\circ} \mathrm{C}-1 / 2 \mathrm{hr}$

$750^{\circ} \mathrm{C}-1 / 2 \mathrm{hr}$

$750^{\circ} \mathrm{C}-1 / 2 \mathrm{hr}$

As-extruded

As-extruded

$750^{\circ} \mathrm{C}-1 / 2 \mathrm{br}$

$750^{\circ} \mathrm{C}-1 / 2 \mathrm{hr}$

$750^{\circ} \mathrm{C}-1 / 2 \mathrm{hr}$

As-extruded

As-extruded

As-extruded
Test Days in $650^{\circ} \mathrm{F}$

Water to Failure

$$
\begin{aligned}
& 14-28 \\
& 14-28 \\
& 21-28 \\
& 42-56 \\
& 28-42 \\
& 28-35 \\
& 42-56 \\
& 56-70 \\
& 35-42 \\
& 0 . K . \text { after } 168 \text { days } \\
& 84-98 \\
& 56-63 \\
& 56-70 \\
& 42-56 \\
& 35-42 \\
& 112-126 \\
& 70-77 \\
& 28-42 \\
& 28-42 \\
& 28-35 \\
& 0 . K . \text { after } 168 \text { days } \\
& 0, K . \text { after } 168 \text { days } \\
& 63-70
\end{aligned}
$$




\begin{tabular}{|c|c|c|c|c|c|c|}
\hline $\begin{array}{c}\text { Specimen } \\
\text { No. }\end{array}$ & Composition 5 & $\begin{array}{l}\text { Enrichment } \\
\left(\mathrm{w} / 0 \mathrm{U}^{2} 35\right)\end{array}$ & $\begin{array}{l}\text { Type of End } \\
\text { Closurel } \\
\end{array}$ & $\begin{array}{l}\text { Diam. of } \\
\text { Defect }\end{array}$ & $\begin{array}{c}\text { Calculated } \\
\text { Exposure } 3 \text { (MwD/T) }\end{array}$ & $\begin{array}{l}\text { Calc. Max. Temp } \\
\text { at Base of Defect }(O)\end{array}$ \\
\hline 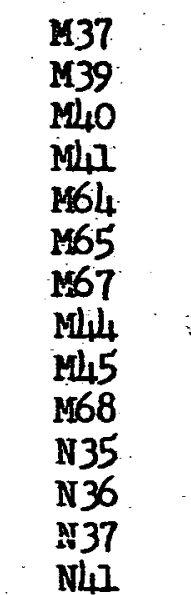 & $\begin{array}{l}\text { U-10.5 w/o Mo } \\
\text { U-12 w/0 Mo }\end{array}$ & $\begin{array}{l}3.6 \\
3.6 \\
3.6 \\
3.6 \\
3.6 \\
3.6 \\
3.6 \\
3.6 \\
3.6 \\
3.6 \\
3.6 \\
3.6 \\
3.6 \\
3.6\end{array}$ & $\begin{array}{l}\text { Bonded } \\
\text { Unbonded }\end{array}$ & $\begin{array}{l}\text { Not defected } \\
\text { Not defected } \\
0.020 \text { in. } \\
0.012 \text { in. } \\
\text { Not defected } \\
\text { Not defected } \\
0.007 \text { in. } \\
\text { Not defected } \\
0.008 \text { in. } \\
0.015 \text { in. } \\
0.007 \text { in. } \\
\text { Not defected } \\
0.009 \text { in. } \\
\text { Not defected }\end{array}$ & $\begin{array}{r}1350 \\
1145 \\
1290 \\
1510 \\
1050 \\
950 \\
1510 \\
1225 \\
1430 \\
1225 \\
1545 \\
1290 \\
1430 \\
1050\end{array}$ & $\begin{array}{l}- \\
\overline{629} \\
647 \\
\overline{-} \\
647 \\
\overline{647} \\
624 \\
650 \\
\overline{647} \\
--\end{array}$ \\
\hline
\end{tabular}

(1) "Bonded" - end plugs pressure welded to core and clad. "Unbonded" - end plugs arc-welded to clad only.

(2) Defect drilled through clad with a $0.040 \mathrm{in.} \mathrm{diam} \mathrm{drill.} \mathrm{Diameter} \mathrm{of} \mathrm{defect} \mathrm{into} \mathrm{core} \mathrm{measured.}$

(3) Exposure based on heat generation data from WAPD-CPM-1.

(4) Exposed to water for 6 weeks. Specinens at maximum temperatures approximately 2 days and at temperatures $30^{\circ}$ lower for about 40 days.

(5) Fabrication history: All single melted in $1 \mathrm{MgO}$ crucibles. Poured into $1-1 / 4$ in. ID copper molds at $1400^{\circ} \mathrm{C}$. Extruded to 0.314 -in. diam at $1750^{\circ}$ to $1950^{\circ} \mathrm{F}$. 
ABLE 27

Corrosion Life of CIEd U-Mo Alloys after Exposure in a Hot Water Loo?

(Corrosion test conditions: $650^{\circ} \mathrm{F}$ static water at saturation pressure)

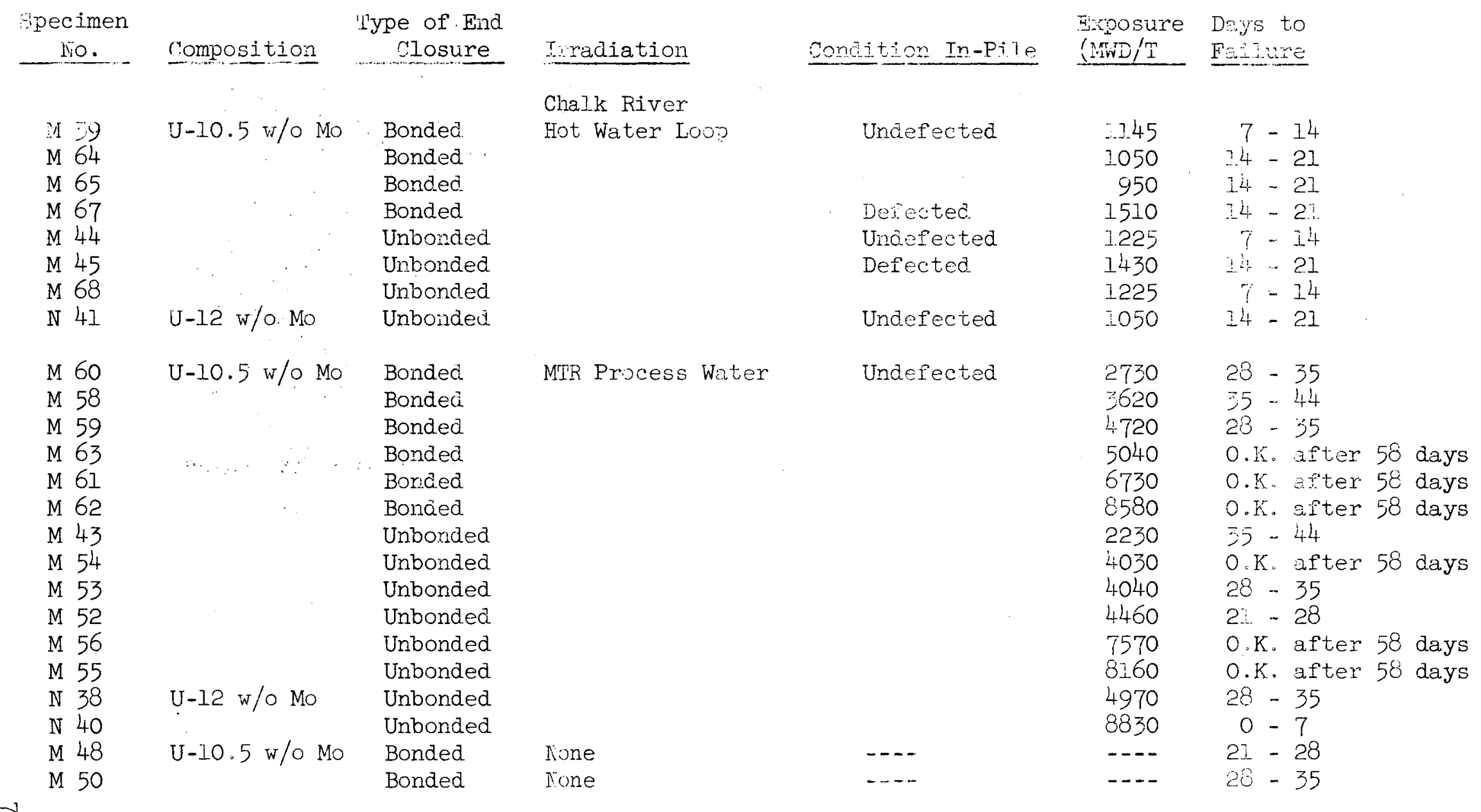


TABLE 27 (Contd)

\begin{tabular}{|c|c|c|c|c|c|c|}
\hline $\begin{array}{c}\text { Specimen } \\
\text { No. }\end{array}$ & Composition & $\begin{array}{r}\text { Type of End } \\
\text { Closure }\end{array}$ & Irradiation & Condition In-Pile & $\begin{array}{l}\text { Exposure } \\
(\mathrm{MND} / \mathrm{T}) \\
\end{array}$ & $\begin{array}{l}\text { Days } \\
\text { Failure }\end{array}$ \\
\hline $\begin{array}{l}\text { N } 51 \\
\text { N } 34 \\
\text { N } 47\end{array}$ & $\mathrm{U}-12 \approx / 0 \mathrm{Mo}$ & $\begin{array}{l}\text { Unbonded } \\
\text { Bonded } \\
\text { Unbonded }\end{array}$ & $\begin{array}{l}\text { None } \\
\text { None } \\
\text { None }\end{array}$ & $-\infty$ & $-\overline{-}$ & $\begin{array}{l}28-35 \\
28-35 \\
28-35\end{array}$ \\
\hline
\end{tabular}

NOTE: AIl samples were as - extruded. No heat treatment was given. 
TABLE 28

\section{Corrosion Life of Clad U-Mo Alloys after Exposure in the X-3 Hot Water Loop}

\section{(Corrosion Test Condition: $650 \mathrm{~F}$ static water at saturation pressure)}

\begin{tabular}{|c|c|}
\hline $\begin{array}{l}\text { Specimen } \\
\text { No. }\end{array}$ & Comosition ${ }^{2}$ \\
\hline $\begin{array}{l}\text { N50 } \\
\text { N51 } \\
\text { N52 } \\
\text { N53 } \\
\text { N54 } \\
\text { N55 }\end{array}$ & $\begin{array}{l}\text { U-12.1 w/o Mo } \\
\text { U-12.1 w/o Mo } \\
\text { U-12.1 w/o Mo } \\
\text { U-12.1 w/o Mo } \\
\text { U-12.1 w/o Mo } \\
\text { U-12.1 w/o Mo }\end{array}$ \\
\hline $\begin{array}{l}\text { N56 } \\
\text { N60 } \\
N 61 \\
N 62 \\
N 63 \\
N 64 \\
N 65\end{array}$ & 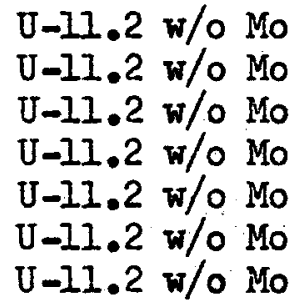 \\
\hline $\begin{array}{l}N 70 \\
N 71 \\
N 72 \\
N 73 \\
N 74 \\
N 75 \\
N 76\end{array}$ & 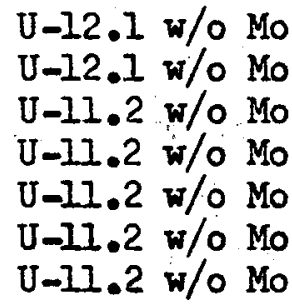 \\
\hline $\begin{array}{l}\mathrm{M} 49 \\
\mathrm{~N} 49\end{array}$ & $\begin{array}{l}U-11.2 \text { w/o Mo } \\
U-12.1 \text { w/o Mo }\end{array}$ \\
\hline
\end{tabular}

Irradiation 3
Chalk River
X-3 Hot Water Loop
X-3 Hot Water Loop
"
"
"
"
"
"
"

MTR Process Water MTR Process Water MTR Process Water MTR Process Water MTR Process Water MTR Process Water MTR Process Water

\section{None}

None

\begin{tabular}{l} 
Condition In-Pile \\
\hline Undefected \\
Undefected \\
Undefected \\
Undefected \\
Undefected \\
Defected, 0.40 in. \\
fuel exposed \\
Undefected \\
Undefected \\
Undefected \\
Undefected \\
Undefected \\
Undefected \\
Undefected \\
Undefected \\
Undefected \\
Undefected \\
Undefected \\
Undefected \\
Undefected \\
Undefected \\
- \\
-
\end{tabular}

\begin{tabular}{|c|c|}
\hline $\begin{array}{l}\text { Exposure } \\
\text { (MWD/T) }\end{array}$ & Days to Failure \\
\hline $\begin{array}{l}2770 \\
3060 \\
3280 \\
3420 \\
3520 \\
3660\end{array}$ & $\begin{array}{c}16-23 \\
0-9 \\
\text { Not tested } \\
16-23 \\
0-9 \\
\text { Not tested }\end{array}$ \\
\hline $\begin{array}{l}3630 \\
3630 \\
3520 \\
3420 \\
3280 \\
3060 \\
2770\end{array}$ & $\begin{array}{c}16-23 \\
0-9 \\
16-23 \\
0-9 \\
\text { Not tested } \\
0-9 \\
0-9\end{array}$ \\
\hline $\begin{array}{l}2870 \\
4870 \\
6070 \\
6440 \\
6070 \\
5180 \\
3360\end{array}$ & $\begin{array}{l}16-23 \\
0 . K . \text { after } 23 \text { days } \\
0-9 \\
0-9 \\
0 . K . \text { after } 23 \text { days } \\
16-23 \\
0 . K \text {. after } 23 \text { days }\end{array}$ \\
\hline - & $\begin{array}{l}0-9 \\
0-9\end{array}$ \\
\hline
\end{tabular}


(I) Exposure of samples in Chalk River X-3 Loop based on heat generation data supplied by P. Frank. Exposure of samples in MTR Process Water based on maximum flux value and flux distribution supplied by MTR personmel.

(2) Fabrication Conditions: All single melted in MgO crucibles. Poured into 1-1/4 in. ID copper molds at $1400^{\circ} \mathrm{C}$. Extruded to 0.314 -in. diam at $1750^{\circ}$ to $1950^{\circ} \mathrm{F}$.

(3) Irradiation time of samples in hot water loop:

$$
\begin{array}{ll}
\text { Time in test } & -2365 \mathrm{hr} \\
\text { Time at } 40 \mathrm{mr} \text { (full power) } & -1803 \mathrm{hr} \\
\% \text { time at } 40 \mathrm{mw} & -76.2
\end{array}
$$




\section{TABLE 29}

Effect of Irradiation on the Bend Ductility of Gamma-quenched U-Mo Alloys

\begin{tabular}{|c|c|c|c|}
\hline $\begin{array}{c}\text { Sample } \\
\text { No. }\end{array}$ & Cormosition & $\begin{array}{l}\text { Exposure } \\
\text { (MWD/T) }\end{array}$ & Strain at Fracture (in./in.) \\
\hline 1 & $\mathrm{U}-10.5 \mathrm{w} / \mathrm{O} \mathrm{Mo}$ & 115 & Did not fracture at 0.15 in. \\
\hline 2 & $\therefore$ & 375 & Did not fracture at 0.17 \\
\hline 3 & & 700 & 0.10 \\
\hline 4 & $3 \ldots$ & 940 & 0.03 \\
\hline 21 & $\mathrm{U}-12 \mathrm{w} / 0 \mathrm{Mo}$ & 115 & Did not fracture at 0.16 \\
\hline 22 & & 375 & Did not fracture at 0.16 \\
\hline 23 & & 700 & 0.01 \\
\hline 25 . & & 1050 & 0.01 \\
\hline
\end{tabular}


Test Temperature - Room Temperature

$\begin{array}{ll}\text { Composition } & \text { Heat Treatment } \\ \text { J-10.5 w/0 Mo } & \gamma-Q+200^{\circ} \mathrm{C}-6 \text { wk } \\ & \gamma-Q+300^{\circ} \mathrm{C}-6 \text { wk } \\ & \gamma-Q+400^{\circ} \mathrm{C}-6 \mathrm{wk} \\ & \gamma-Q+500^{\circ} \mathrm{C}-6 \text { wk } \\ \text { U-12 w/0 Mo } & \gamma-Q+200^{\circ} \mathrm{C}-6 \text { wk } \\ & \gamma-Q+300^{\circ} \mathrm{C}-6 \text { wk } \\ & \gamma-Q+400^{\circ} \mathrm{C}-6 \text { wk } \\ & \gamma-Q+500^{\circ} \mathrm{C}-6 \text { wk }\end{array}$

Strain at Fracture (in./in.)

Did not fracture at 0.37 in.

Did not fracture at 0.36

0.04

0.07

Did not fracture at 0.36

Did not fracture at 0.37

0.03

0.07 


\section{TABLE 31}

Exposure and Temperature Data for Unclad U-10 w/0 Nb Experiment

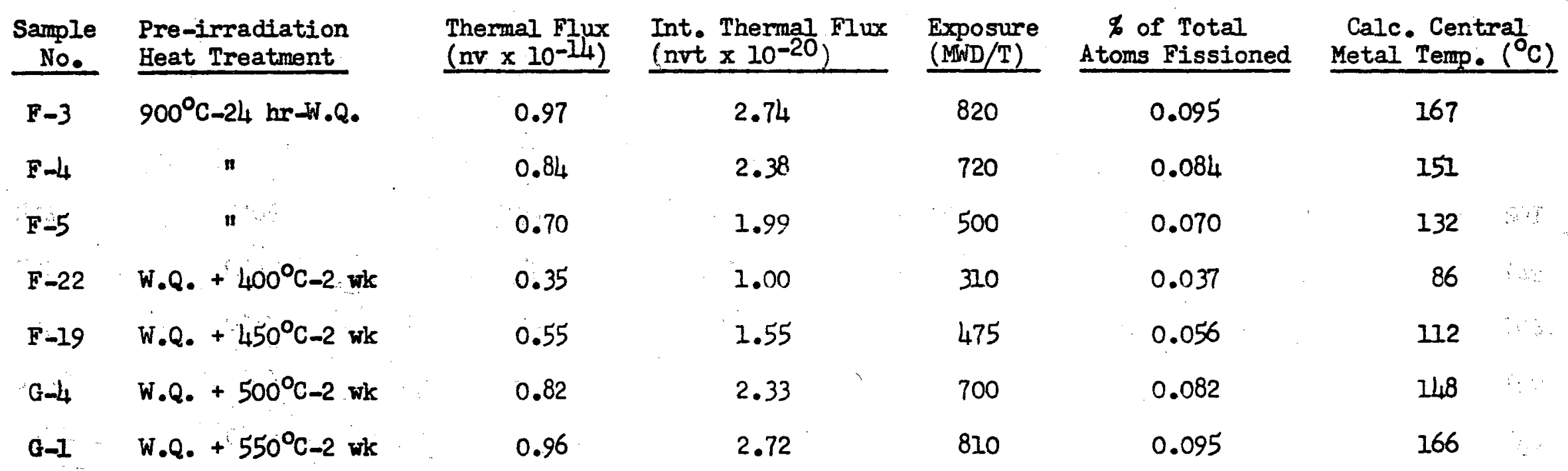


TABLE 32

\begin{tabular}{|c|c|c|c|c|c|c|c|}
\hline \multirow{2}{*}{$\begin{array}{c}\text { Sample } \\
\text { No. } \\
\end{array}$} & \multirow{2}{*}{$\begin{array}{l}\text { Thermal Fipx } \\
\left(\mathrm{nv} \times 10^{-14}\right)\end{array}$} & \multirow{2}{*}{$\begin{array}{l}\text { Integrated } \\
\text { Thermal Fluxx } \\
\text { (nvt } \times 10^{-20} \text { ) }\end{array}$} & \multirow{2}{*}{$\begin{array}{l}\text { Exposure } \\
(\mathrm{MWD} / \mathrm{T}) \\
\end{array}$} & \multirow{2}{*}{$\begin{array}{l}\% \text { of Total } \\
\text { Atoms } \\
\text { Fissioned }\end{array}$} & \multicolumn{3}{|c|}{ Calc. Specimen Temp. $\left({ }^{\circ} \mathrm{C}\right)$} \\
\hline & & & & & Surface & Interface & Central \\
\hline F-7 & 0.61 & 1.67 & 500 & 0.050 & 49 & 71 & 123 \\
\hline$F-9$ & 1.05 & 2.89 & 840 & 0.086 & 55 & 94 & 180 \\
\hline F-12 & 1.05 & 2.89 & 840 & 0.086 & 55 & 94 & 180 \\
\hline F-14 & 0.90 & 2.46 & 730 & 0.074 & 53 & 86 & 160 \\
\hline$G-18$ & 0.59 & 1.62 & 495 & 0.050 & 48 & 70 & 120 \\
\hline$G-19$ & 0.88 & 2.412 & 720 & 0.073 & 53 & 85 & 158 \\
\hline$G-20$ & 1.05 & 2.89 & 840 & 0.086 & 55 & 94 & 180 \\
\hline $\mathrm{G}-21$ & 0.91 & 2.48 & 740 & 0.075 & 53 & 87 & 162 \\
\hline $\mathrm{H}-\mathrm{I}$ & 0.90 & 2.46 & 730 & 0.074 & 57 & 95 & 178 \\
\hline $\mathrm{H}-7$ & 1.05 & 2.89 & 840 & 0.086 & 60 & 104 & 201 \\
\hline
\end{tabular}


TABLE 33

Exposure and Temperature Data for Second Clad U-10 w/0 Nb Experiment

\begin{tabular}{|c|c|c|c|c|c|c|c|}
\hline \multirow{2}{*}{$\begin{array}{c}\text { Sample } \\
\text { No. } \\
\end{array}$} & \multirow{2}{*}{$\begin{array}{l}\text { Thermal F7px } \\
\left(\mathrm{nv} \times 10^{-14}\right)\end{array}$} & \multirow{2}{*}{$\begin{array}{l}\text { Integrated } \\
\text { Thermal Flux } \\
\left.\text { (nvt } \times 10^{-20}\right) \\
\end{array}$} & \multirow{2}{*}{$\begin{array}{l}\text { Exposure } \\
(\text { MWD/T) }\end{array}$} & \multirow{2}{*}{$\begin{array}{c}\% \text { of Total } \\
\text { Atoms } \\
\text { Fissioned } \\
\end{array}$} & \multicolumn{3}{|c|}{ Calc. Specimen Temp. $\left({ }^{\circ} \mathrm{C}\right)$} \\
\hline & & & & & Surface & Interface & Central \\
\hline$G-6$ & 0.54 & 1.46 & 448 & 0.046 & 48 & 68 & 213 \\
\hline$G-7$ & 1.15 & 3.12 & 913 & 0.093 & 56 & 91 & 193 \\
\hline$G-9$ & 0.92 & 2.48 & 740 & 0.075 & 53 & 87 & 163 \\
\hline$G-10$ & 0.98 & 2.65 & 783 & 0.080 & 54 & 90 & 171 \\
\hline G-12 & 1.12 & 3.02 & 886 & 0.090 & 54 & 92 & 189 \\
\hline$G-13$ & $\therefore \quad 0.67$ & 1.81 & 556 & 0.057 & 50 & 74 & 130 \\
\hline$G-30$ & $\therefore \quad 0.54$ & 1.46 & 48 & 0.046 & 48 & 68 & 113 \\
\hline$G-31$ & 1.15 & 3.12 & 913 & 0.093 & 56 & 91 & 193 \\
\hline$G-33$ & 0.92 & 2.48 & 740 & 0.075 & 53 & 87 & 163 \\
\hline$G-34$ & 0.98 & 2.65 & 783 & 0.080 & 54 & 90 & 171 \\
\hline$G-36$ & 1.12 & 3.02 & 886 & 0.090 & 54 & 92 & 189 \\
\hline G-37 & 0.67 & 1.81 & 556 & 0.057 & 50 & 74 & 130 \\
\hline
\end{tabular}


TABLE 34

Length and Density Changes of Irradiated Unclad U-10 w/O Nb AIloys

$\begin{array}{ll}\frac{\text { Specimen }}{\text { No. }} & \frac{\text { Pre-irradiation }}{\text { Condition }} \\ \text { F-3 } & 900^{\circ} \mathrm{C}-24 \mathrm{hr}-\text { W.Q. }(\gamma-Q) \\ \text { F-4 } & 900^{\circ} \mathrm{C}-24 \mathrm{hr}-\text { W.Q. }(\gamma-Q) \\ \text { F-5 } & 900^{\circ} \mathrm{C}-24 \mathrm{hr}-\text { W.Q. }(\gamma-Q) \\ \text { F-22 } & \gamma-Q+400^{\circ} \mathrm{C}-2 \mathrm{wk} \\ \text { F-19 } & \gamma-Q+450^{\circ} \mathrm{C}-2 \mathrm{wk} \\ \text { G-4 } & \gamma-Q+500^{\circ} \mathrm{C}-2 \mathrm{wk} \\ \text { G-1 } & \gamma-Q+550^{\circ} \mathrm{C}-2 \mathrm{wk}\end{array}$

\begin{tabular}{|c|c|c|c|c|}
\hline $\begin{array}{l}\text { Exposure } \\
\text { (NWD/T) }\end{array}$ & $\frac{\text { Length }}{\mathrm{Pre}}$ & $\frac{(\text { in.) }}{\text { Post }}$ & $\frac{\text { b Length }}{\text { Change }}$ & Pre \\
\hline 820 & 1.992 & 1.995 & +0.2 & 16.51 \\
\hline 720 & 1.993 & 1.995 & +0.1 & 16.49 \\
\hline 500 & 1.995 & 1.996 & +0.1 & 16.49 \\
\hline 310 & 1.983 & 1.995 & +0.6 & 16.71 \\
\hline 475 & 1.983 & 1.993 & +0.5 & 16.76 \\
\hline 700 & 1.984 & 2.014 & +1.5 & 16.79 \\
\hline 810 & 1.984 & 2.052 & +3.4 & 16.82 \\
\hline
\end{tabular}
$\frac{\text { Density }\left(\mathrm{g} / \mathrm{sm}^{3}\right)}{\underline{\text { Post }}} \frac{\text { D Density }}{\underline{\text { Change }}} \frac{\stackrel{1}{1}}{\sim}$ $16.49-0.1$

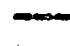

16.50

$+0.1$

16.55

$-1.0$

16.58

$-1.1$

16.53

$-1.6$

16.47

$-2.1$ 
TABIE 35

Dimensional Changes of Irradiated Clad U-10 w/O Nb

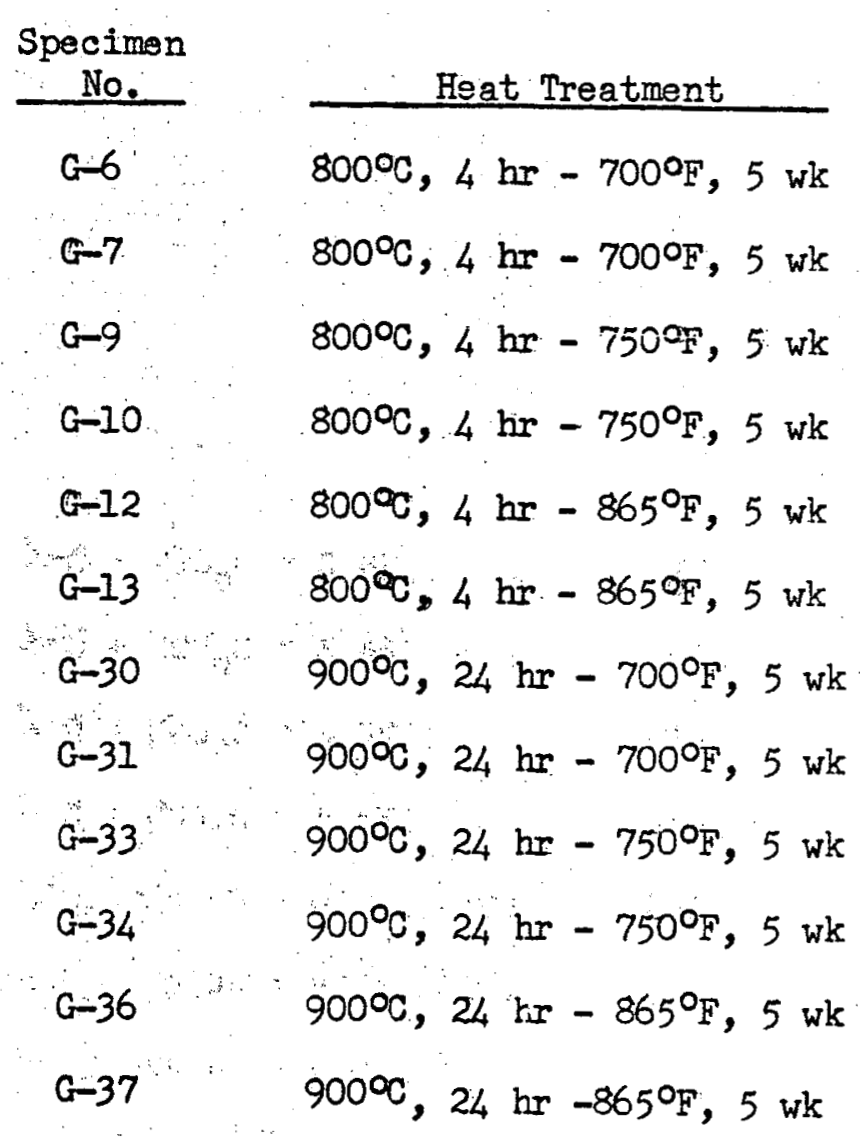

\begin{tabular}{l} 
Exposure \\
$(\mathrm{ND} / \mathrm{T})$ \\
\hline 448 \\
913 \\
740 \\
783 \\
886 \\
556 \\
448 \\
913 \\
740 \\
783 \\
886 \\
556
\end{tabular}

\begin{tabular}{|c|c|c|}
\hline \multicolumn{2}{|c|}{ Iength (in.) } & t Lengt \\
\hline Pre & Post & Ghange \\
\hline 4.239 & 4.238 & -0.04 \\
\hline 4.241 & 4.241 & - \\
\hline 4.236 & 4.239 & +0.12 \\
\hline 4.249 & 4.249 & - \\
\hline 4.237 & 4.237 & - \\
\hline 4.239 & 4.231 & -0.32 \\
\hline 4.236 & 4.219 & -0.68 \\
\hline 4.229 & 4.230 & +0.04 \\
\hline 4.241 & 4.241 & - \\
\hline 4.237 & 4.237 & $\cdots$ \\
\hline 4.228 & 4.227 & -0.04 \\
\hline 4.230 & 4.205 & -1.00 \\
\hline
\end{tabular}


TABLE 36

\begin{tabular}{|c|c|c|c|c|c|c|c|c|}
\hline \multirow[b]{2}{*}{$\begin{array}{c}\text { Specimen } \\
\text { No. } \\
\end{array}$} & \multirow[b]{2}{*}{$\begin{array}{c}\begin{array}{c}\text { Pre-irradiation } \\
\text { Condition }\end{array} \\
\end{array}$} & \multirow[b]{2}{*}{$\begin{array}{l}\text { Exposure } \\
(\mathrm{MND} / \mathrm{T})\end{array}$} & \multicolumn{6}{|c|}{ Resistivity } \\
\hline & & & at & $\begin{array}{l}196^{\circ} \mathrm{C} \\
\text { Post }\end{array}$ & $\frac{\text { engm) }}{\text { o Change }}$ & $\frac{\text { at Room }}{\text { Pre }}$ & $\begin{array}{l}\text { Tempera } \\
\text { Post }\end{array}$ & $\begin{array}{l}\mathrm{re}(\mu \sqrt{\mathrm{cm})}) \\
\text { o Change }\end{array}$ \\
\hline$F-3$ & $900^{\circ} \mathrm{C}-24 \mathrm{hr}-\mathrm{W}_{0} Q_{0}(\gamma-Q)$ & 820 & 71.19 & 61.55 & -13.5 & 65.59 & 63.87 & -2.6 \\
\hline$F-4$ & $900^{\circ} \mathrm{C}-24 \mathrm{hr}-W_{0} Q_{0}(\gamma-Q)$ & $720^{\circ}$ & 71.22 & 69.96 & -1.8 & 65.76 & 66.12 & +0.6 \\
\hline$F-5$ & $900^{\circ} \mathrm{C}-24 \mathrm{hr}-$ W.Q. $(\gamma-Q)$ & 500 & 71.19 & 72.64 & +2.0 & 65.66 & 68.54 & +4.4 \\
\hline$F-22$ & $\gamma-Q+400^{\circ} \mathrm{c}-2$ wk & 310 & 35.71 & 58.99 & +65.2 & 52.22 & 63.67 & +21.9 \\
\hline$F-19$ & $\gamma-Q+450^{\circ} \mathrm{C}-2$ wik & 475 & 21.73 & 41.58 & +91.4 & 44.24 & 58.26 & +31.7 \\
\hline$G-4$ & $\gamma-Q+500^{\circ} \mathrm{C}-2$ wk & 700 & 18.04 & 34.20 & +89.6 & 47.56 & 53.44 & +28.6 \\
\hline$F-1$ & $\gamma-Q+550^{\circ} \mathrm{C}-2$ wk & 810 & 16.57 & 27.76 & +67.5 & 40.14 & 50.27 & +25.2 \\
\hline
\end{tabular}




\section{TABLE 37}

Microhardness of Irradiated Unclad U-10 w/O ND AIloy

$\begin{array}{ll}\frac{\text { Specimen }}{\text { Ho. }} & \frac{\text { Heat Treatment }}{900^{\circ} \mathrm{C}-24 \mathrm{hr}-\text { W.Q. }(\gamma-Q)} \\ \text { F-3 } & 900^{\circ} \mathrm{C}-24 \mathrm{hr}-\text { W.Q. }(\gamma-Q) \\ \text { F-4 } & 900^{\circ} \mathrm{C}-24 \mathrm{hr}-\text { W.Q. }(\gamma-Q) \\ \text { F-5 } & \gamma-Q+400^{\circ} \mathrm{C}-2 \text { wk } \\ \text { F-22 } & \gamma-Q+450^{\circ} \mathrm{C}-2 \text { wk } \\ \text { F-19 } & \gamma-Q+500^{\circ} \mathrm{C}-2 \text { wk } \\ \text { G-4 } & \gamma-Q+550^{\circ} \mathrm{C}-2 \text { wk } \\ \text { G-1 } & \end{array}$

\begin{tabular}{c}
$\begin{array}{c}\text { Exposure } \\
\text { (MWD/T) }\end{array}$ \\
\hline 820 \\
720 \\
500 \\
310 \\
475 \\
700 \\
810
\end{tabular}

DPH at 5-kg Load

\begin{tabular}{lcc} 
& DPH at 5-kg Load & \\
\hline Pre & $\frac{\text { Post }}{347 \pm 13}$ & Change \\
$((286 \pm 16)$ & $347 \pm 61$ \\
$(\quad)$ & $325 \pm 11$ & +39 \\
$558 \pm 23$ & $309 \pm 6$ & +23 \\
$460 \pm 7$ & $367 \pm 11$ & -191 \\
$396 \pm 1$ & $369 \pm 10$ & -91 \\
$355 \pm 1$ & $311 \pm 22$ & -85 \\
& $338 \pm 25$ & -17
\end{tabular}


TABLE 38

Corrosion Properties of Unirradiated and Irradiated Unclad U-10 w/O No Alloy

Unirradiated Data

Sample

No.

M०3A9-I B

$\mathrm{F}-25$

F -23

F -20

G-5

G-2

\section{Condition}

As-extruded

$\underline{24 \mathrm{hr}}$

$900^{\circ} \mathrm{C}-24 \mathrm{hr}-\mathrm{W} . \mathrm{Q}$. $\gamma^{Q}+400^{\circ} \mathrm{C}-2$ wk $\gamma \mathrm{Q}+450^{\circ} \mathrm{C}-2 \mathrm{wk}$ $\gamma Q+500^{\circ} \mathrm{C}-2 \cdot \mathrm{wk}$ $\gamma \mathrm{Q}+550^{\circ} \mathrm{C}-2$ wk
Corrosion Rate in $650 \mathrm{~F}$ Water $\left(\mathrm{mg} / \mathrm{cm}^{2}-\mathrm{hr}\right)$

\begin{tabular}{|c|c|c|c|c|c|}
\hline $72 \mathrm{hr}$ & $168 \mathrm{hr}$ & $336 \mathrm{hr}$ & $672 \mathrm{hr}$ & $1008 \mathrm{hr}$ & $1680 \mathrm{hr}$ \\
\hline-0.008 & -0.007 & -0.015 & -0.033 & -0.043 & disint. \\
\hline $24 \mathrm{hr}$ & $96 \mathrm{hr}$ & $168 \mathrm{hr}$ & $336 \mathrm{hr}$ & $504 \mathrm{hr}$ & $672 \mathrm{hr}$ 8LO hr \\
\hline $\begin{array}{l}+0.037 \\
\text { disint. } \\
\text { disint. } \\
\text { disint. } \\
\text { disint. }\end{array}$ & +0.006 & -0.012 & -0.12 & -0.25 & -1.33 disint. \\
\hline
\end{tabular}

\section{Irradiated Data}

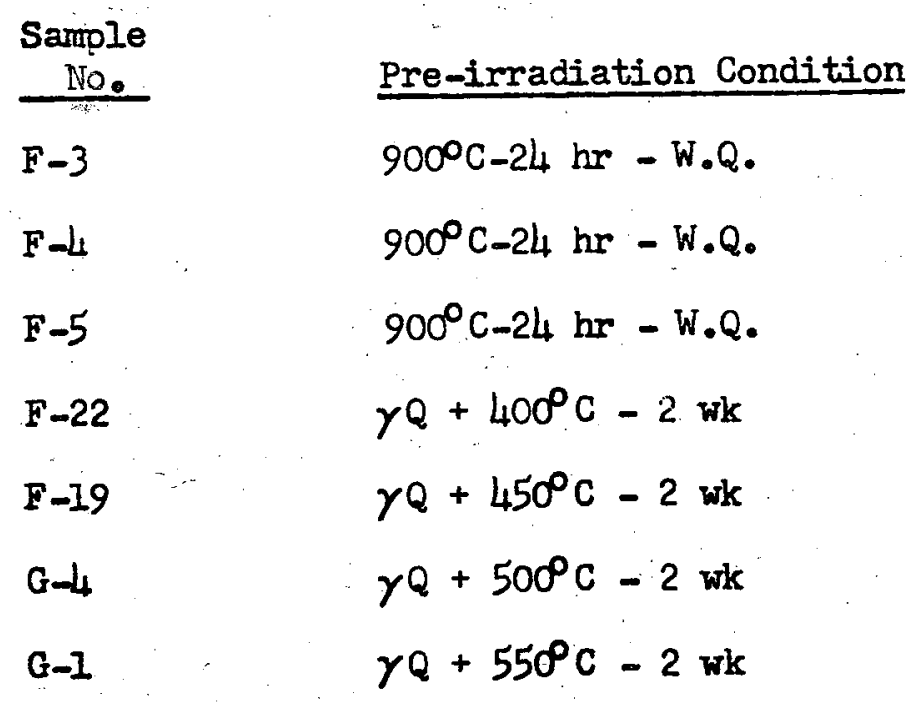

Exposure $(\mathrm{MWD} / \mathrm{T})$

820

720

500

310

475

700

810

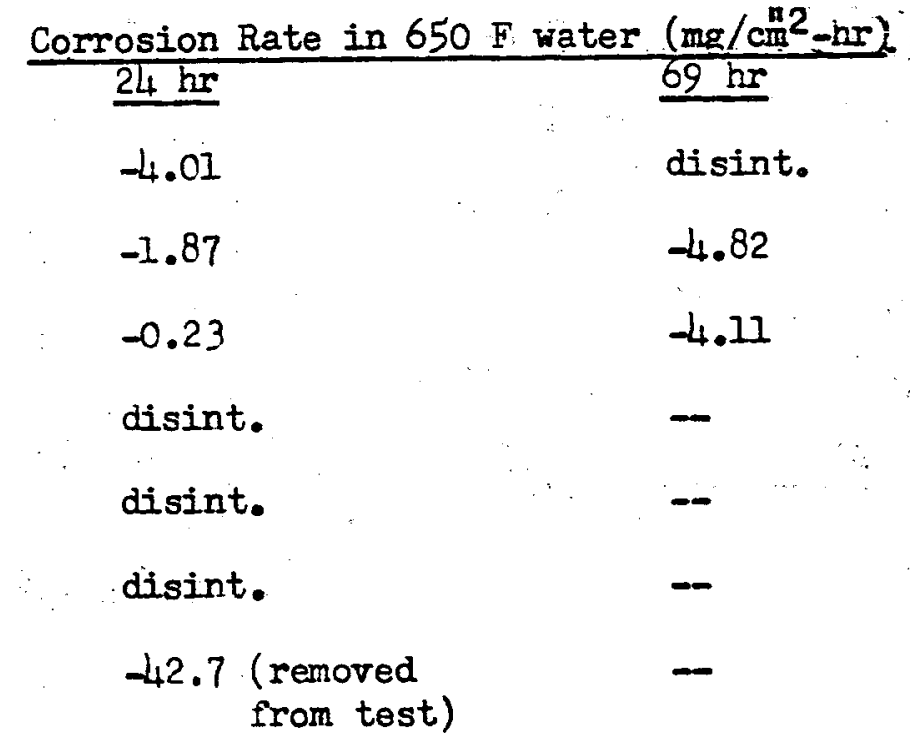




\section{TABLE 39}

Exposure Data for First प-3.8 w/O Si Experiment:

\begin{tabular}{|c|c|c|c|c|c|c|c|}
\hline Sample & Ave. Thermal Flux & Int. Thermal Flux & \% Burn-up & $\%$ of To & Alloy & $\begin{array}{c}\text { Max. CaI } \\
0 \\
\end{array}$ & Spec. Temp. \\
\hline No. & $\left(n v \times 10^{-13}\right)$ & (nvt $\left.\times 10^{-6} \mathrm{co}\right)$ & of Total Atoms & Atoms Fissioned & $(\operatorname{MND} / \mathrm{T})$ & Surface & Central. \\
\hline 5 & 1.12 & 0.31 & 0.011 & 0.010 & 105 & 51 & 57 \\
\hline 8 & 4.17 & 1.16 & 0.041 & 0.036 & 390 & 79 & 100 \\
\hline 10 & 7.30 & 2.03 & 0.069 & 0.061 & 660 & 107 & 144 \\
\hline 11 & 8.5 & 2.36 & 0.079 & 0.070 & 755 & 178 & 161 \\
\hline 16 & 7.54 & 2.10 & 0.071 & 0.063 & 680 & 110 & 148 \\
\hline 17 & 5.21 & 1.45 & 0.050 & 0.044 & 470 & 89 & 175 \\
\hline 18 & 2.418 & 6.70 & 0.024 & 0.021 & 220 & 63 & 76 \\
\hline
\end{tabular}


TABLE 40

Exposure Data for Second $\mathrm{U}-3.8 \mathrm{w} / 0$ Si Experiment

\begin{tabular}{|c|c|c|c|c|c|c|c|}
\hline $\begin{array}{l}\text { Sample } \\
\text { No. } \\
\end{array}$ & $\begin{array}{c}\text { Ave. Thermal Ftpx } \\
\text { nv } \times 10^{-14} \\
\end{array}$ & $\begin{array}{l}\text { Int. Thermal Flux } \\
\left(\text { nvt } \times 10^{-20}\right)\end{array}$ & $\begin{array}{l}\text { \% Burn-up } \\
\text { of Total Atoms } \\
\end{array}$ & $\begin{array}{c}\% \text { of Total } \\
\text { Atoms Fissioned }\end{array}$ & $\begin{array}{l}\text { Alloy } \\
(\mathrm{MWD} / \mathrm{T})\end{array}$ & $\frac{\text { Max.Calc }}{\text { Surface }}$ & $\frac{\text { Temp.o }}{\text { Centra }}$ \\
\hline$I$ & 0.37 & 0.91 & 0.032 & 0.028 & 300 & 74 & 94 \\
\hline 4 & 0.75 & 1.87 & 0.064 & 0.056 & 610 & 109 & 247 \\
\hline 7 & 1.16 & 2.89 & 0.096 & 0.084 & 910 & 147 & 205 \\
\hline 10 & 1.42 & 3.55 & 0.115 & 0.102 & 1100 & 170 & 242 \\
\hline 13 & 1.47 & 3.66 & 0.118 & 0.104 & 1120 & 174 & 249 \\
\hline 16 & 1.17 & 2.91 & 0.097 & 0.085 & 920 & 147 & 207 \\
\hline 19 & 0.78 & 1.93 & 0.066 & 0.058 & 630 & 112 & 151 \\
\hline
\end{tabular}


TABLE 4I

Dimension:l Changes and Density of Irradiated U-3.8 w/O Si Alloy (First Experiment

\begin{tabular}{|c|c|c|c|c|c|c|}
\hline Specimen & Exposure & Dimensional & Changes (in.) & Densit & $\left(\mathrm{cm}^{3}\right)$ & Density \\
\hline No. & $(\mathrm{MWD} / \mathrm{T})$ & Diameter & Length & Pre-irradiation: & Post-irradiation & Decrease 8 \\
\hline 5 & 105 & +0.0022 & +0.003. & 15.54 & 14.97 & 3.8 \\
\hline 8 & 390 & +0.0025 & - & 15.54 & 15.31 & $0.2 * *$ \\
\hline 10 & 660 & +0.0028 & - & 15.54 & 14.99 & 3.5 \\
\hline 11 & 755 & +0.0053 & - & 15.52 & 14.92 & 3.9 \\
\hline 16 & 680 & +0.0051 & -0.013 & 15.53 & 14.96 & 3.7 \\
\hline 17 & 470 & +0.0023 & - & 15.53 & $I_{4} .96$ & 3.7 \\
\hline 18 & 220 & +0.0033 & - & 15.52 & 14.96 & 3.6 \\
\hline
\end{tabular}

"As-extruded" density, measured on four control samples $-15.34 \pm 0.01$

* Heat treated at $800^{\circ} \mathrm{C}$ for $91 \mathrm{hr}$ in evacuated vycor tubes.

* Sample cracked during a sectioning operation; density measurenent may be invalid. 
TABLE 42

Dimensional Changes and Density of Irradiated U-3.8 w/0 Si Alloy (Second Experiment)

\begin{tabular}{|c|c|c|c|c|c|c|}
\hline Specimen & Exposure & Dimensional $\mathrm{C}$ & nges (in.) & Dens & $\left(\mathrm{cm}^{3}\right)$ & Density \\
\hline No. & $(\mathrm{NWD} / \mathrm{T})$ & Diameter (I) & Length & Pre-irradiation & Post-irradiation & Decrease \% \\
\hline 1 & 300 & +0.0046 & +0.022 & 15.45 & 14.87 & 3.8 \\
\hline 4 & 610 & $\$ 0.0041$ & $--(2)$ & 15.45 & 14.82. & 4.1 \\
\hline 7 & 910 & +0.0073 & -0.035 & 15.44 & 14.83 & 4.0 \\
\hline 10 & 1100 & +0.0042 & -0.001 & 15.43 & 14.99 & 2.9 \\
\hline 13 & 1120 & +0.0046 & +0.004 & 15.53 & 14.90 & 4.1 \\
\hline 16 & 920 & +0.0052 & +0.021 & 15.45 & 14.85 & 3.9 \\
\hline 19 & 630 & +0.0046 & +0.014 & 15.46 & 14.92 & 3.5 \\
\hline
\end{tabular}

(1) Average diameter over length of specimen.

(2) Sample bent too much to obtain length. 
TABLE 43

Microhardness of Irradiated U $-3.8 \mathrm{w} / 0 \mathrm{Si}$ Alloy (First Experiment)

\section{Irradiated Specimens}

\begin{tabular}{cc}
$\begin{array}{c}\text { Sample } \\
\text { No. }\end{array}$ & $\begin{array}{c}\text { Exposure } \\
(\mathrm{MWD} / \mathrm{T})\end{array}$ \\
\hline 5 & 105 \\
8 & 390 \\
10 & 660 \\
11 & 755 \\
16 & 680 \\
17 & 470 \\
18 & 220
\end{tabular}

Unirradiated Controls

\section{Heat Treatment}

6

13

15

14

19

\begin{tabular}{llr} 
& Hardness $(\mathrm{DPH}$ at 1-kg Load) & $\Delta \mathrm{DPH}$ \\
\hline Pre & $\frac{\text { Post }}{442 \pm 10}$ & +215 \\
$227 \pm 6$ & -15 & - \\
$227 \pm 6$ & $442 \pm 10$ & +215 \\
$227 \pm 6$ & $447 \pm 12$ & +220 \\
$227 \pm 6$ & $446 \pm 8$ & +219 \\
$227 \pm 6$ & $443 \pm 11$ & +216 \\
$227 \pm 6$ & $440 \pm 9$ & +213 \\
$227 \pm 6$ & 40 &
\end{tabular}

Hardiess (DPH at 1-kg Ioad)

6 wk at $200^{\circ} \mathrm{C}$ in vacuum

6 wh at $300^{\circ} \mathrm{C}$ in vacuum

6 wh at $400^{\circ} \mathrm{C}$ in vacuum

6 wk at $400^{\circ} \mathrm{C}$ in $\mathrm{NaK}$

6 wk at $500^{\circ} \mathrm{C}$ in vacuum
$229 \pm 8$

$223 \pm 6$

$226 \pm 3$

$230 \pm 3$

$233 \pm 8$ 
TABLE 44

Microhardness of Irradiated U-3.8 w/O Si Alloy (Second Experiment)

\begin{tabular}{cc}
$\begin{array}{c}\text { Sample } \\
\text { Noe }\end{array}$ & $\begin{array}{c}\text { Exposure } \\
(\mathrm{MWD} / \mathrm{T})\end{array}$ \\
\cline { 2 - 2 } & 610 \\
7 & 910 \\
13 & 1120 \\
16 & 920
\end{tabular}

\begin{tabular}{llr} 
& Hardness $(\mathrm{DPH}$ at $5-\mathrm{kg}$ Load) & $\Delta \underline{\text { DPH }}$ \\
\hline Pre & $\frac{\text { Post }}{480 \pm 18}$ & +137 \\
$343 \pm 5$ & $468 \pm 5$ & +125 \\
$343 \pm 5$ & $482 \pm 6$ & +139 \\
$343 \pm 5$ & $483 \pm 6$ & +140 \\
$343 \pm 5$ & &
\end{tabular}


TABLE 45

Corrosion Behavior of U-3.8 w/O Si Alloy (First Experiment)

\section{Unirradiated Samples}

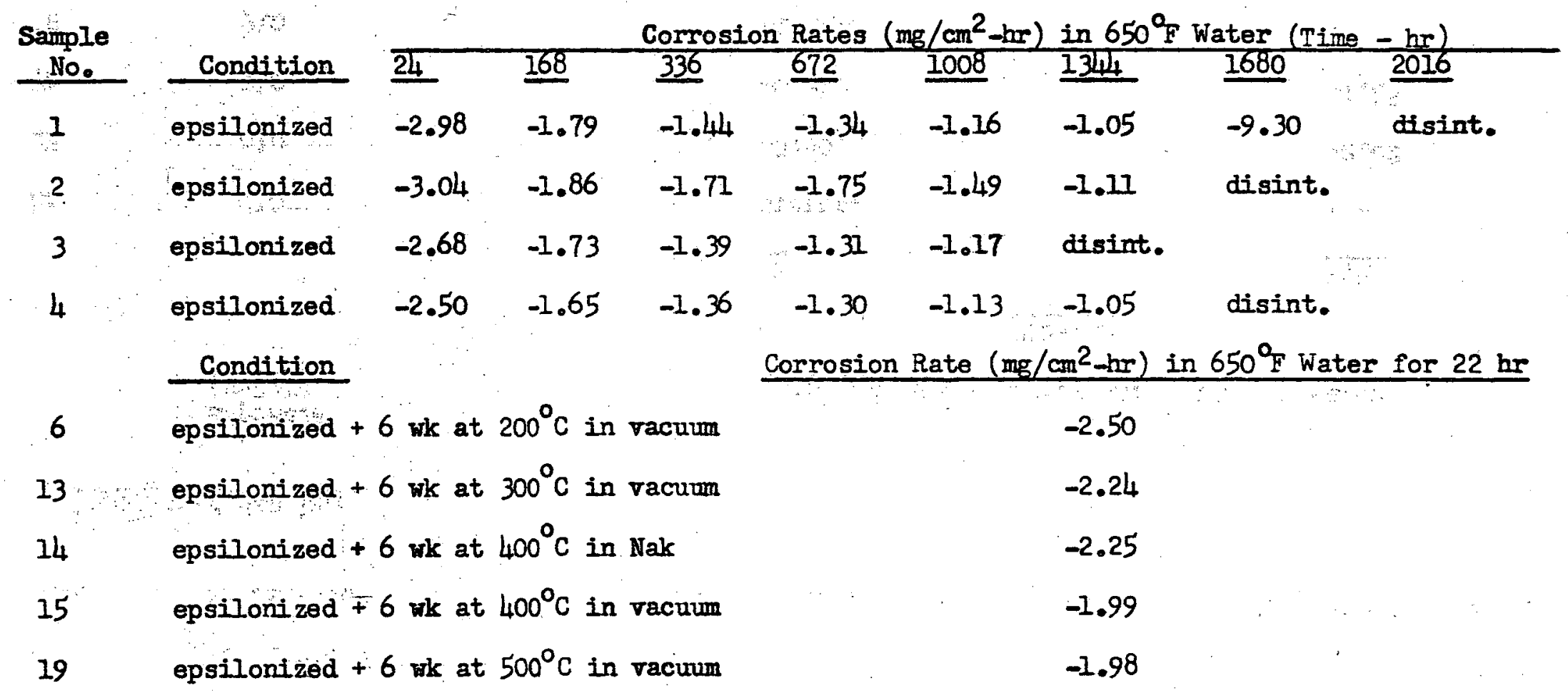

Irradiated Samples

Exposure (MWD/T)

Corrosion Rate (mg/cm -hr) in 650 F Water for $22 \mathrm{hr}$

$\begin{array}{rr}8 & 390 \\ 10 & 660 \\ 11 & 755 \\ 17 & 470 \\ 18 & 220\end{array}$

$$
\begin{aligned}
& \text { disint. } \\
& \text { disint. } \\
& \text { disint. } \\
& -6.56 \\
& -14.26
\end{aligned}
$$


TABLE 46

Corrosion Behavior of $0-3.8 \mathrm{w} / 0$ Si Alloy (Second Experiment)

Unirradiated Semples

Sample

No.

14-1

$14-2$
Condition

As-extruded

As-extruded

\begin{tabular}{lllllll}
\multicolumn{8}{c}{ Corrosion Rates $\left(\mathrm{mg} / \mathrm{cm}^{2}-\mathrm{hr}\right)$} & in $650^{\circ} \mathrm{F}$ Water (Time $-\mathrm{hr}$ ) \\
\hline 12 & 168 & $\underline{36}$ & $\underline{504}$ & $\underline{672}$ & $\underline{1008}$ & $\underline{1176}$ \\
-1.76 & -1.47 & -1.19 & -0.93 & -0.92 & -0.87 & -0.86 \\
-1.20 & -1.37 & -1.13 & -0.94 & -0.95 & -0.95 & -0.95
\end{tabular}

\section{Irradiated Samples}

Escposure $(\operatorname{MND} / T)$

$\begin{array}{cc}4 A & 610 \\ 4 B & 610 \\ 7 A & 910 \\ 7 B & 910 \\ 16 A & 920 \\ 16 B & 920\end{array}$

Corrosion Rates (mg/cm ${ }^{2}-\mathrm{hr}$ ) in $650^{\circ} \mathrm{F}$ water

\section{Time-br}

$\underline{72}$

$\underline{144}$

Disint.

$-0.50$

$-2.62$

$-0.31$

$-1.48$

Disint.

$-0.35$

$-0.35$

Disint. 


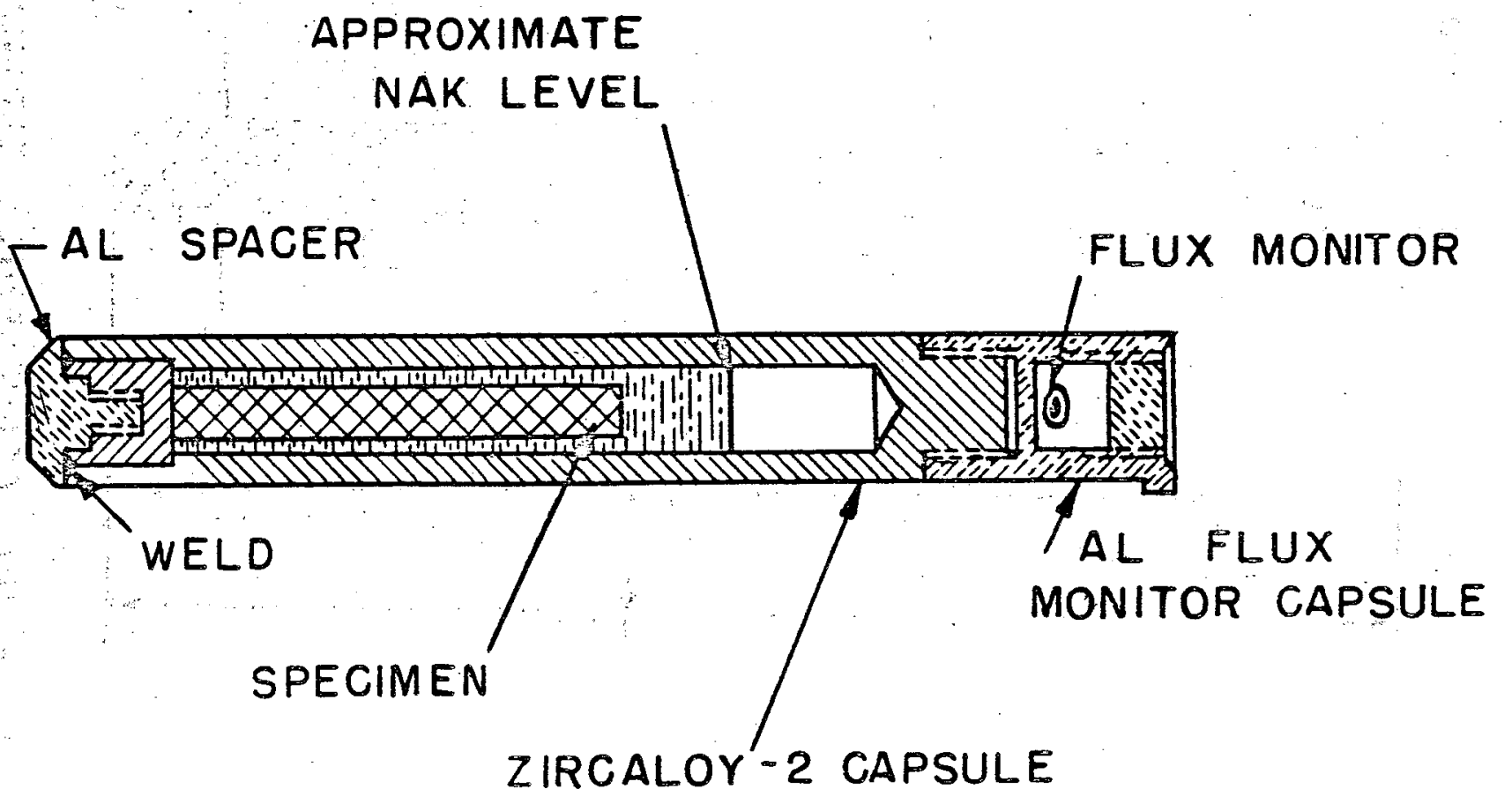

Fig. 1 Cross-section of Capsule Used for the Irradiation of Unclad Uranium Alloys 
WAPD-127

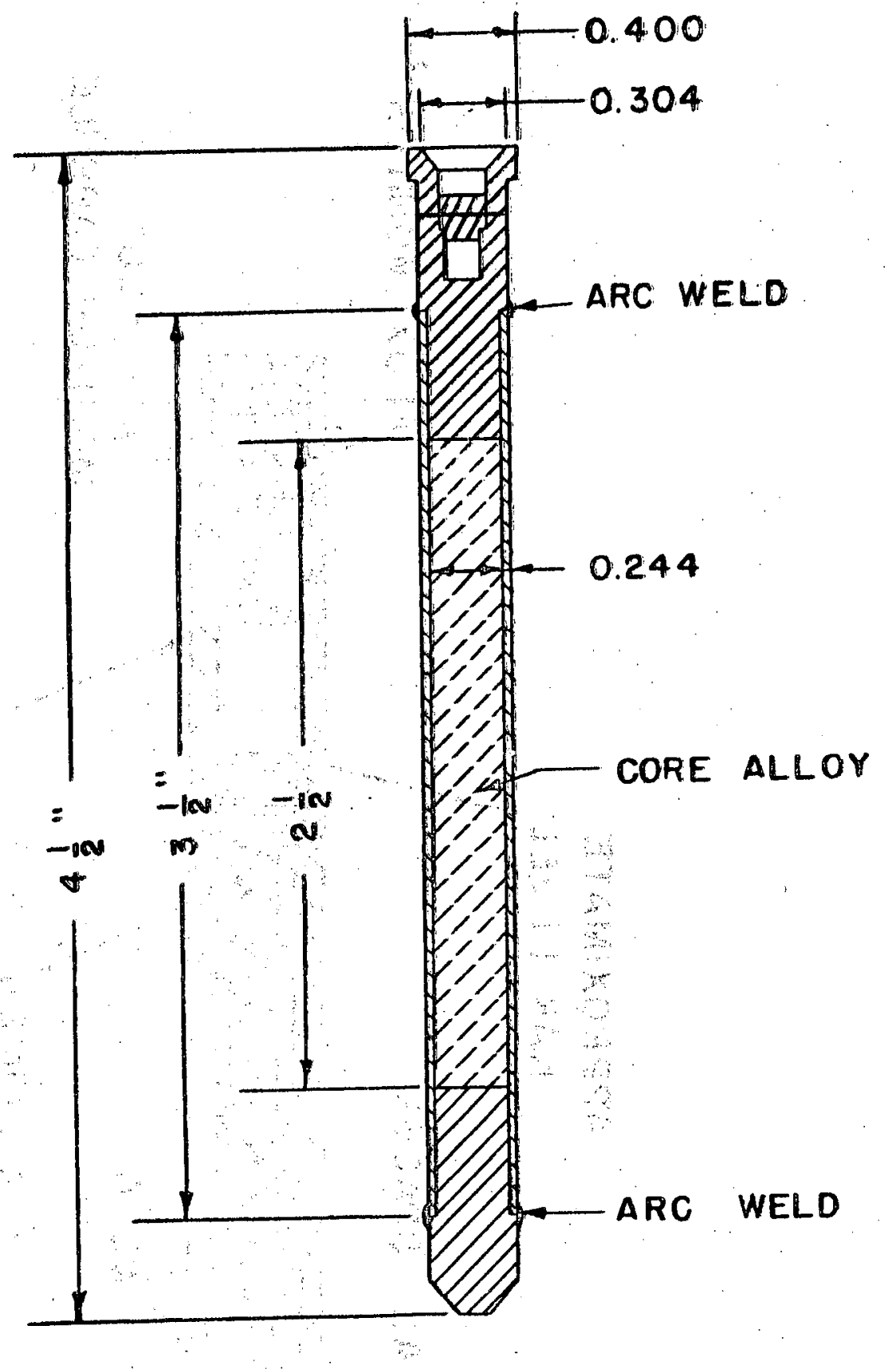

NOTE: ALL COMPONENTS ZIRCALOY 2 EXCEPT WHERE. NOTED.

Fig. 2 Cross-section of Clad Uranium Alloy Specimens Irradiated in Reactor Process. Water

(Neg 10766) 


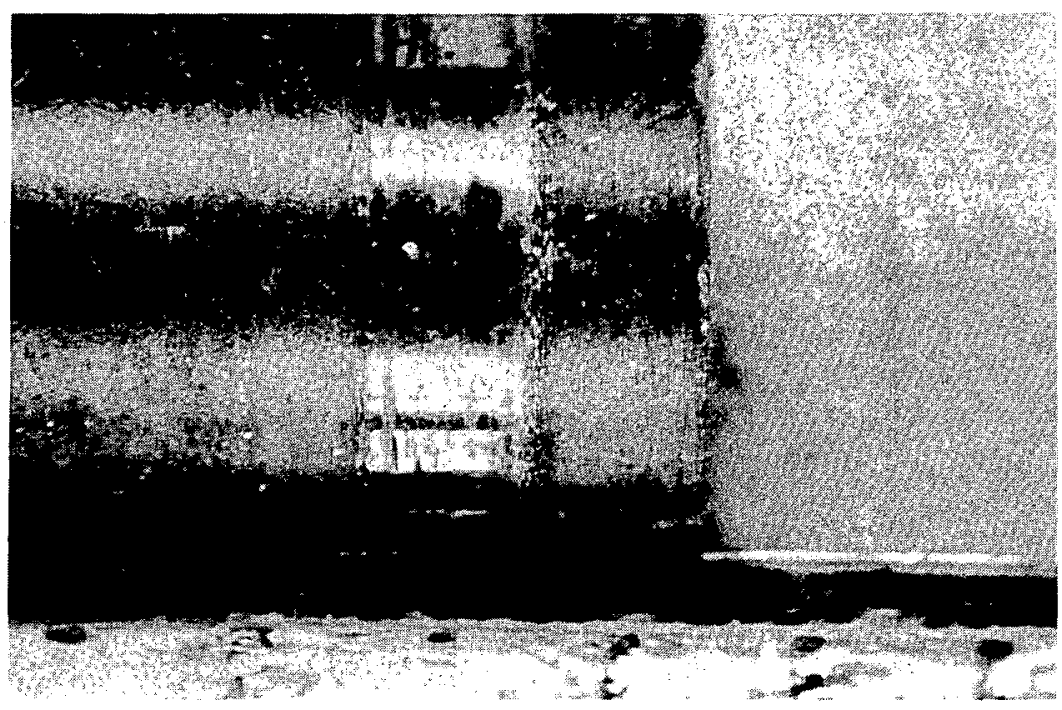

Fig. 3 Photograph of Gamma-quenched U-13.5 w/O Mo (Spec. No. 84), Irradiated to $3200 \mathrm{MWD} / \mathrm{T}$, Showing Typical "Banding" near End (approx. 12X)

(Neg 21955-7) 


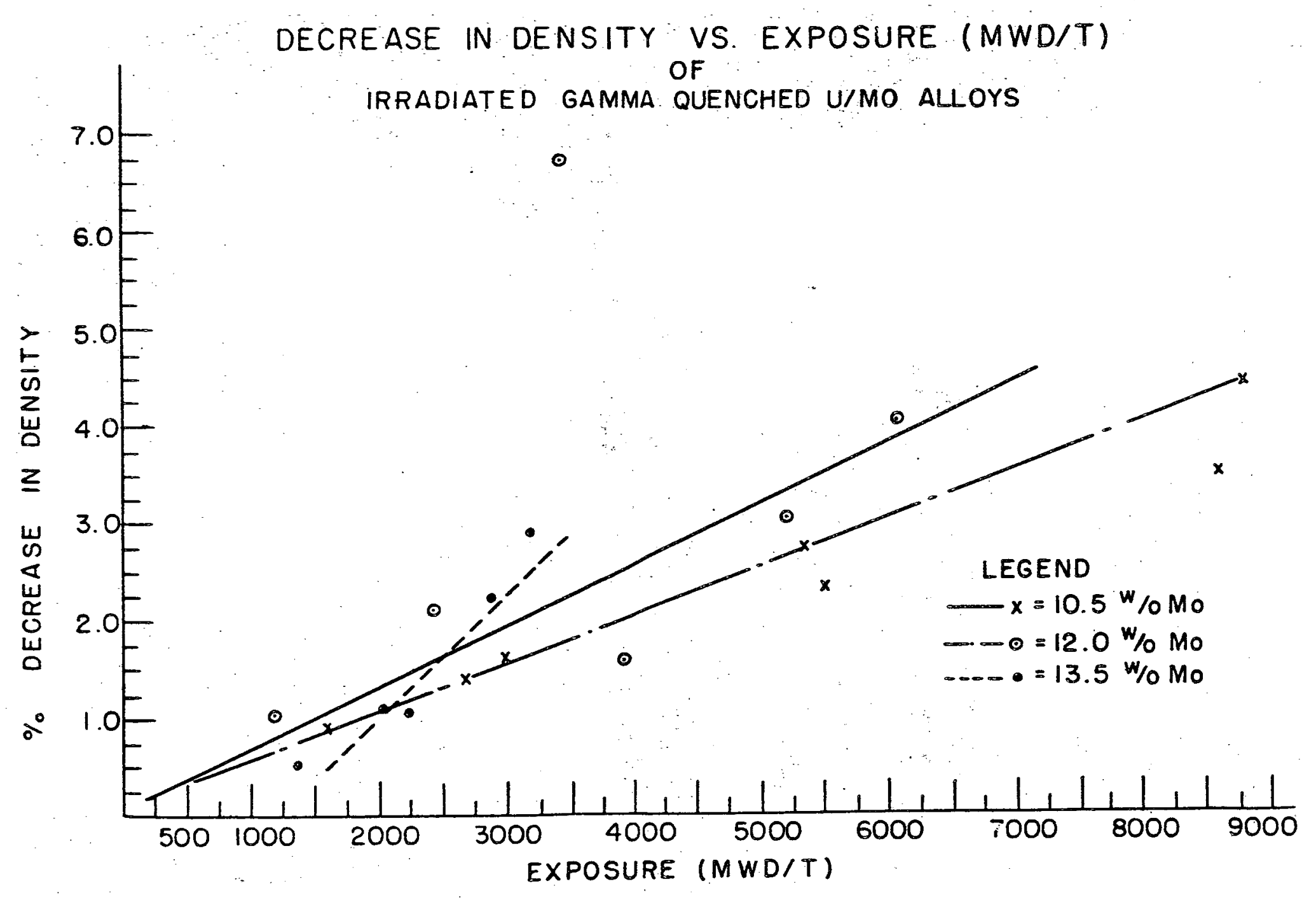

Figure 4

(Neg 16009) 


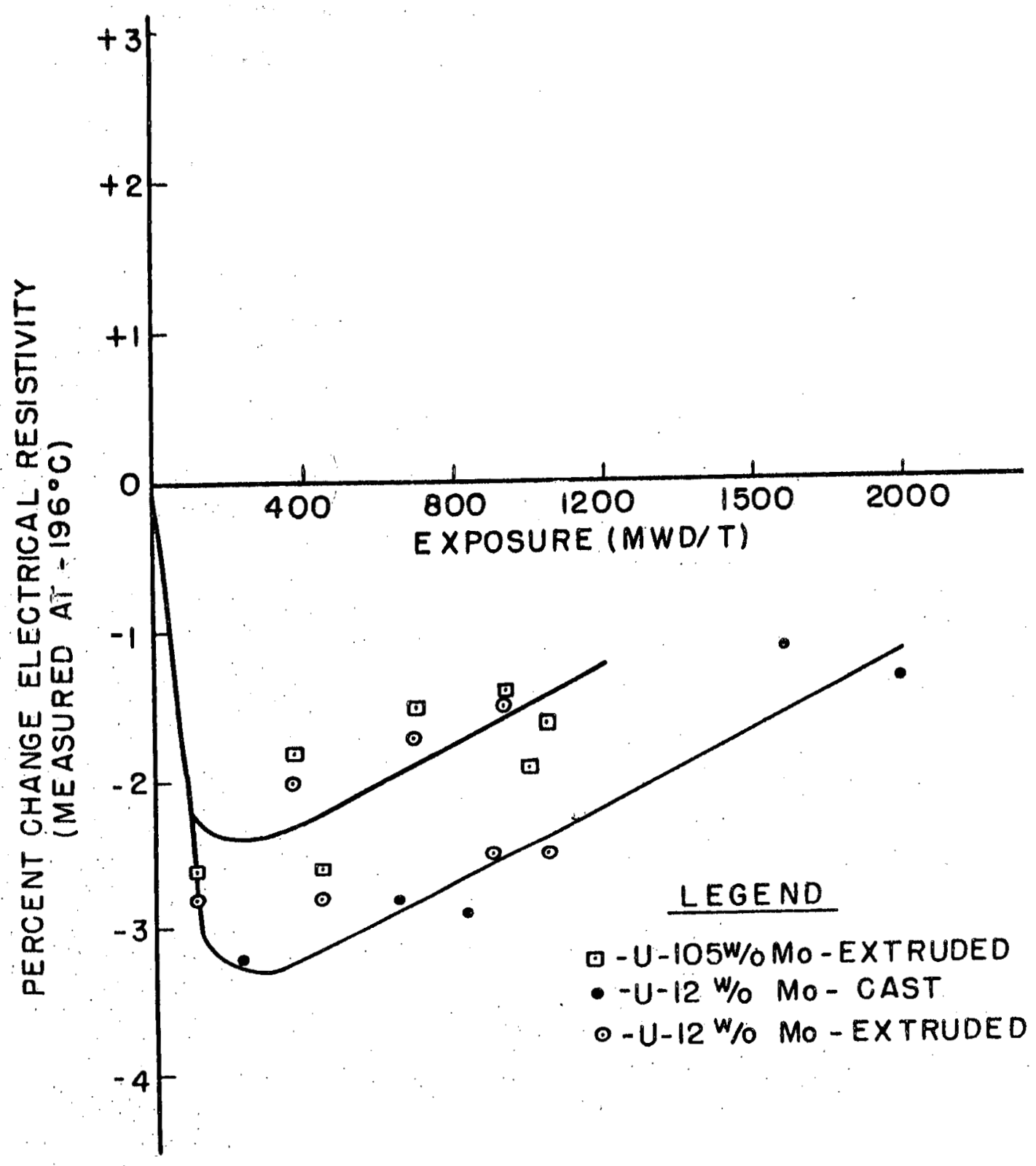

Fig. 5 Change in Electrical Resistivity of

Gamma-quenched U-Mo Alloys vs. Exposure

(Neg 20903-1) 


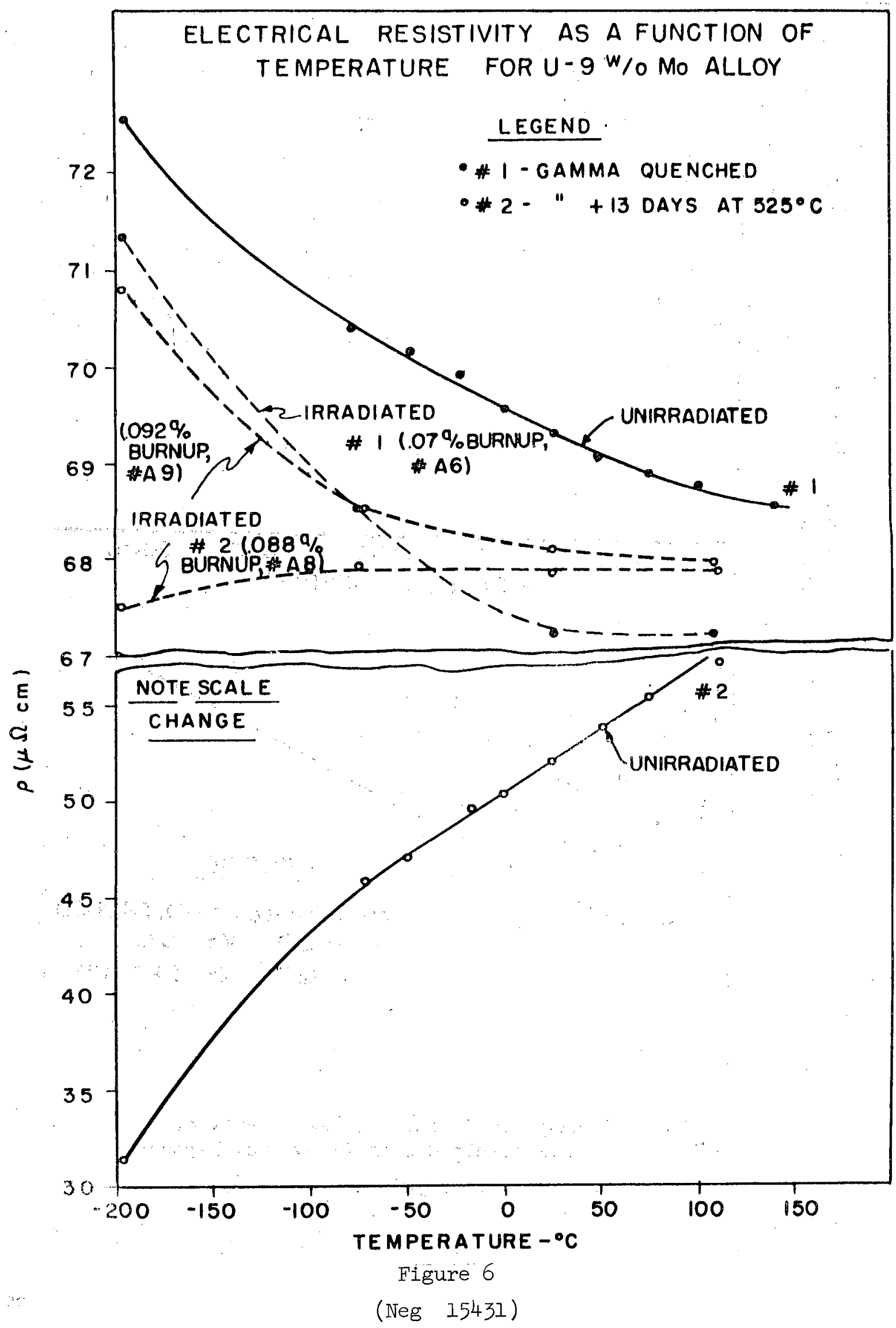


ELECTRICAL RESISTIVITY AS A FUNCTION OF TEMPERATURE FOR U-10.5 W/ MO ALLOY

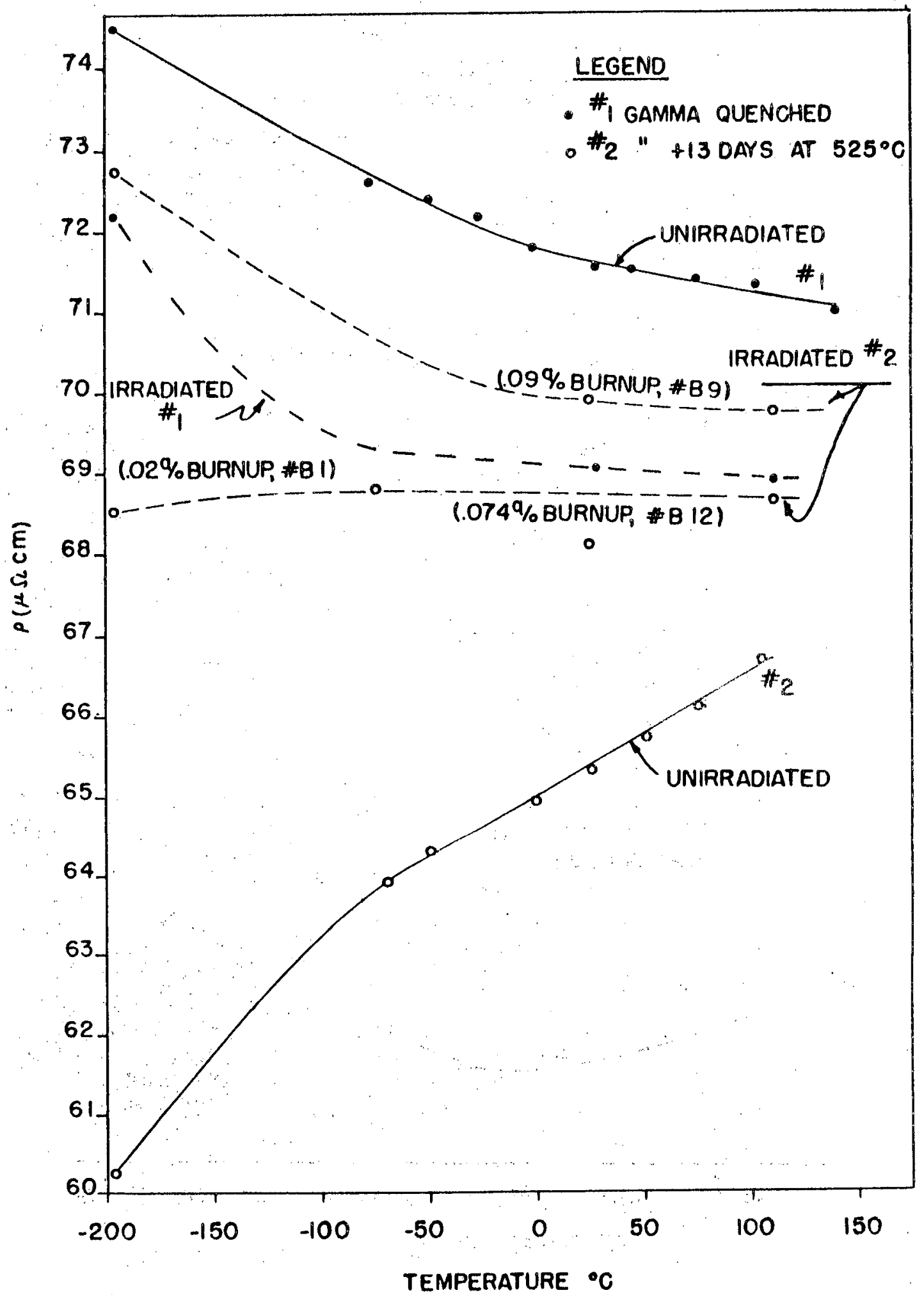

Figure 7

(Neg 15432) 


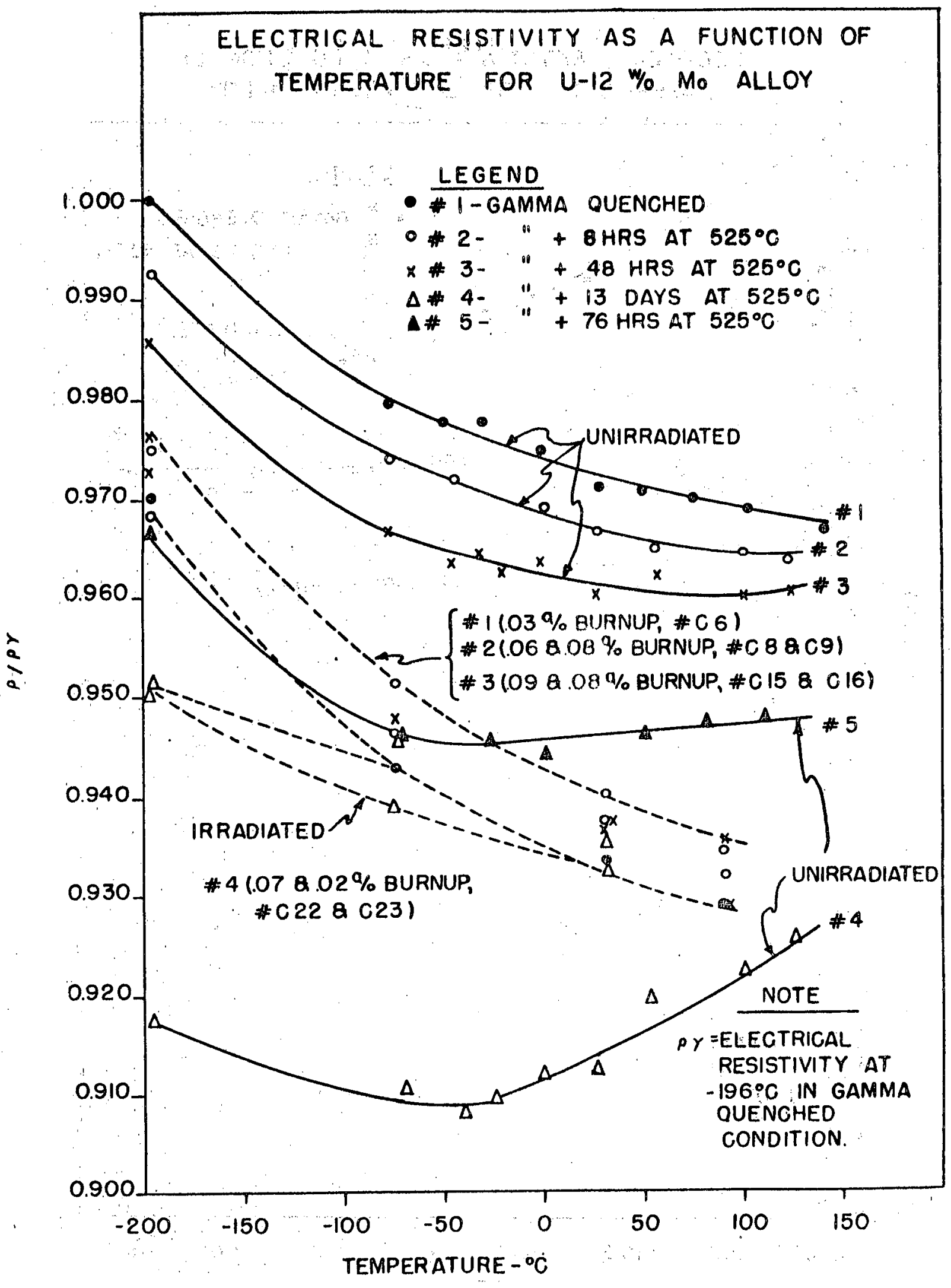

Figure 8

(Neg 15433) 


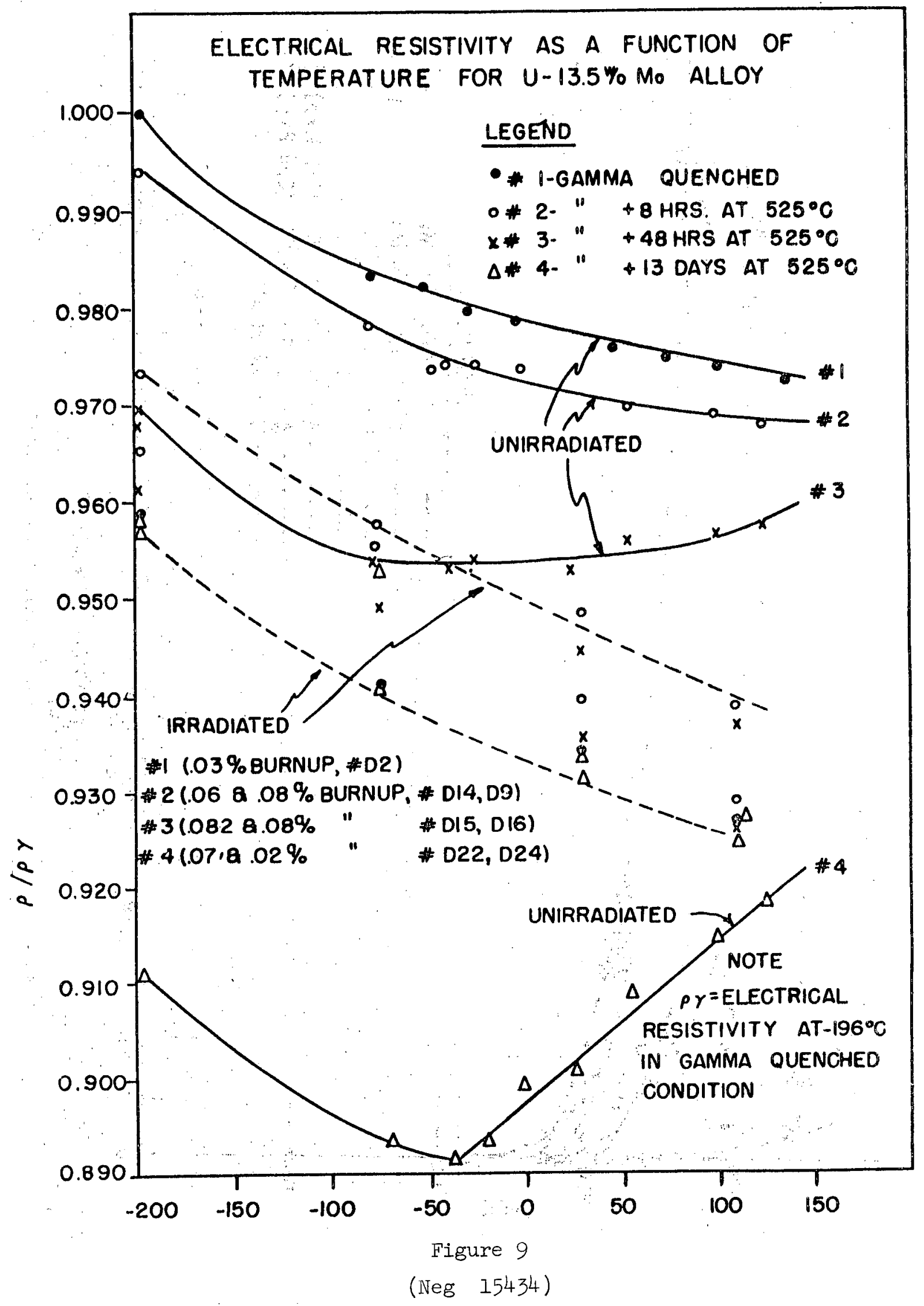




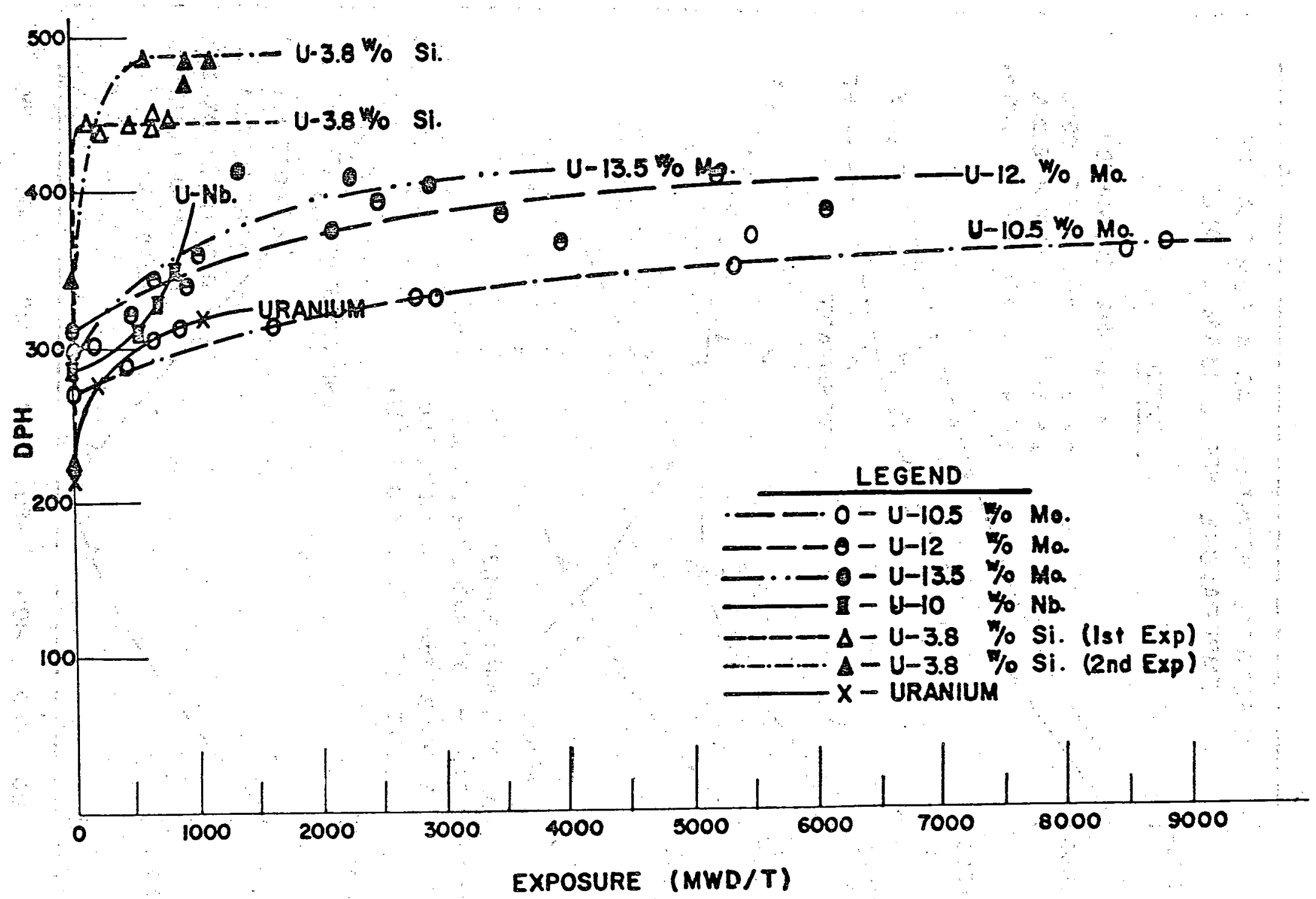

Fig. 10 Hardness of Uranium anā Uranium Alloys vs. Exposure

(Neg 20903-6) 


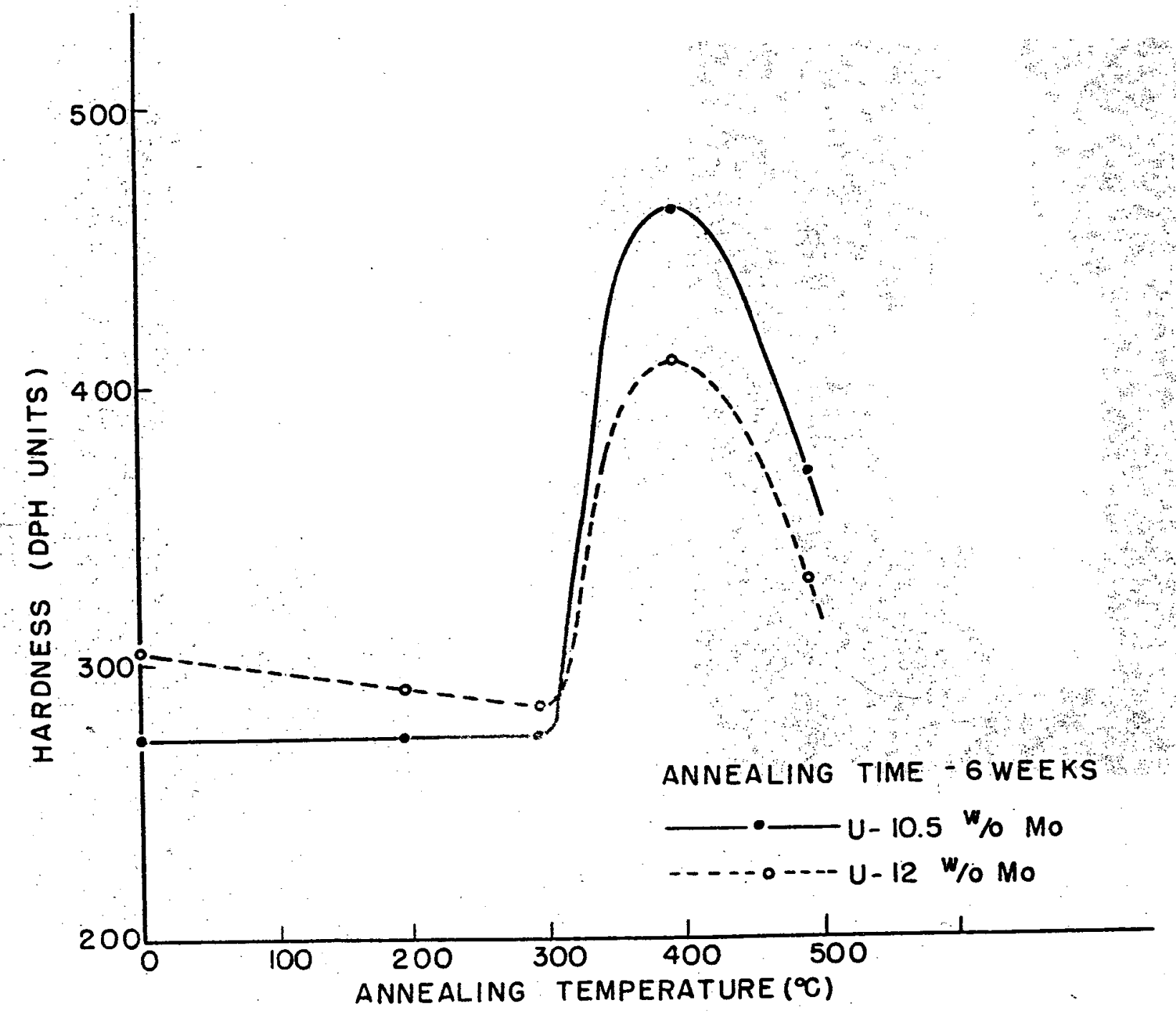

Fig. II Hardness of U-Mo Alloys vs. Arnealing Temperature

(Neg 20903-5) 
WAPD-127

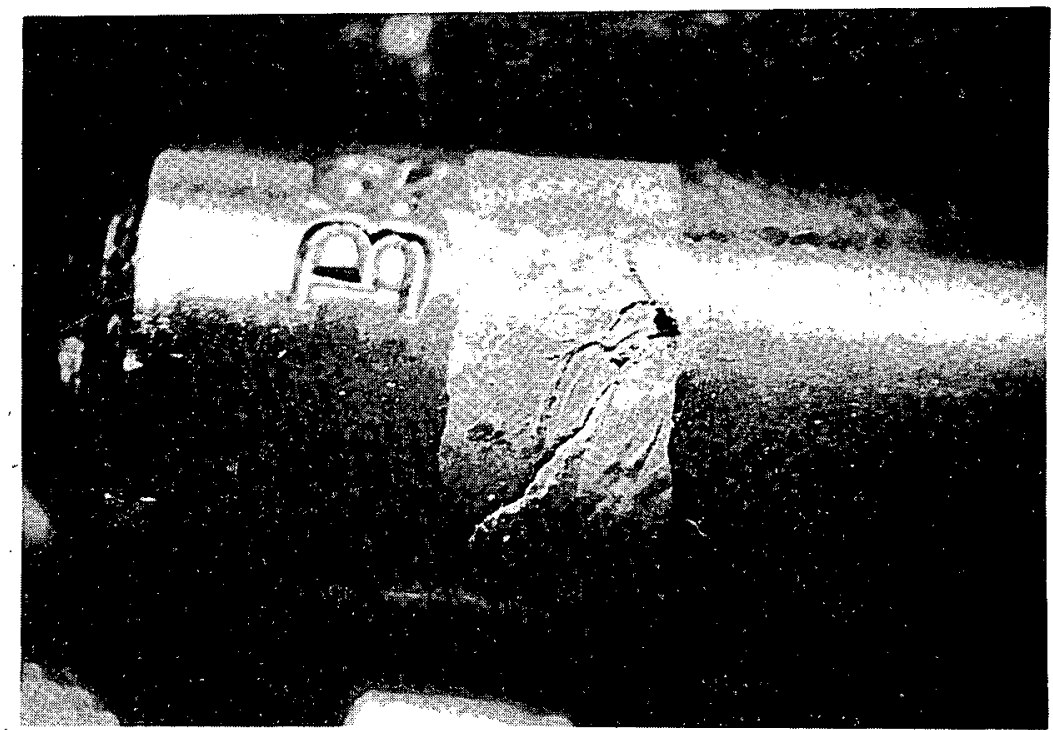

Fig. 12 Photograph of Accelerated Corrosion Failure after Irradiation in $650^{\circ} \mathrm{F}$ Water at the Zircaloy-2 Weld Contaminated with Uranium (approx. 6X)

(Neg 21955-1) 


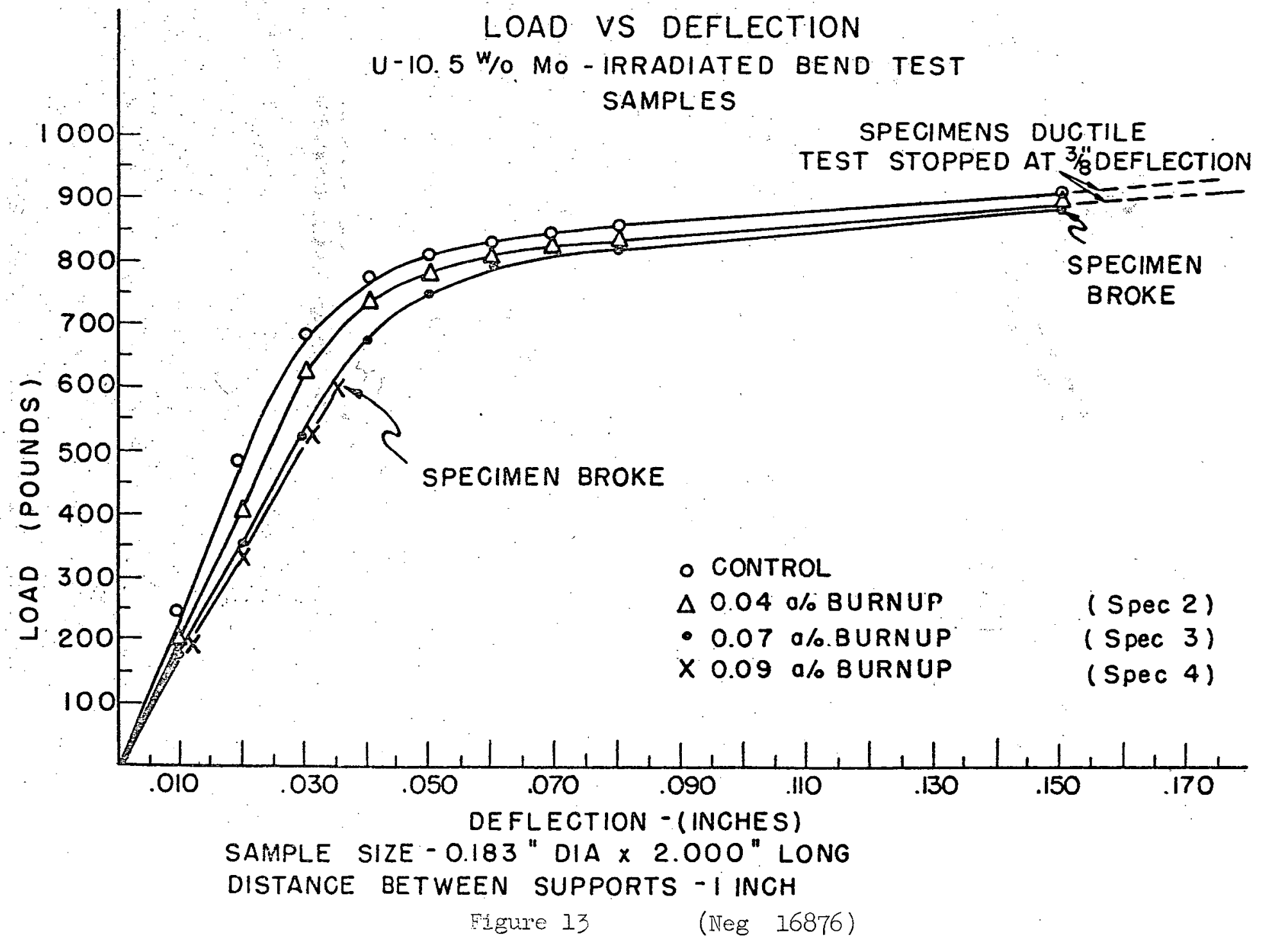




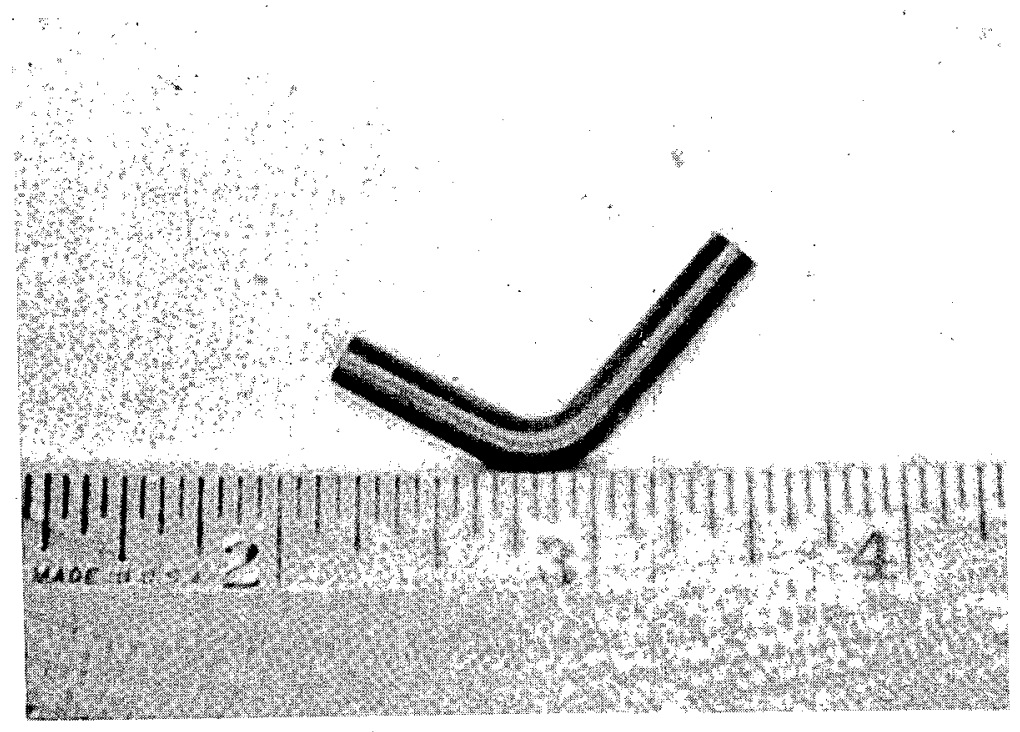

Fig. 14 Bend Test Sample (Spec. 2l) of Gamma-quenched U-12 w/O Mo after Irradiation to $115 \mathrm{MWD} / \mathrm{T}$, Showing Typical Ductile Behavior (approx. 1.25X)

(Neg 21955-5)

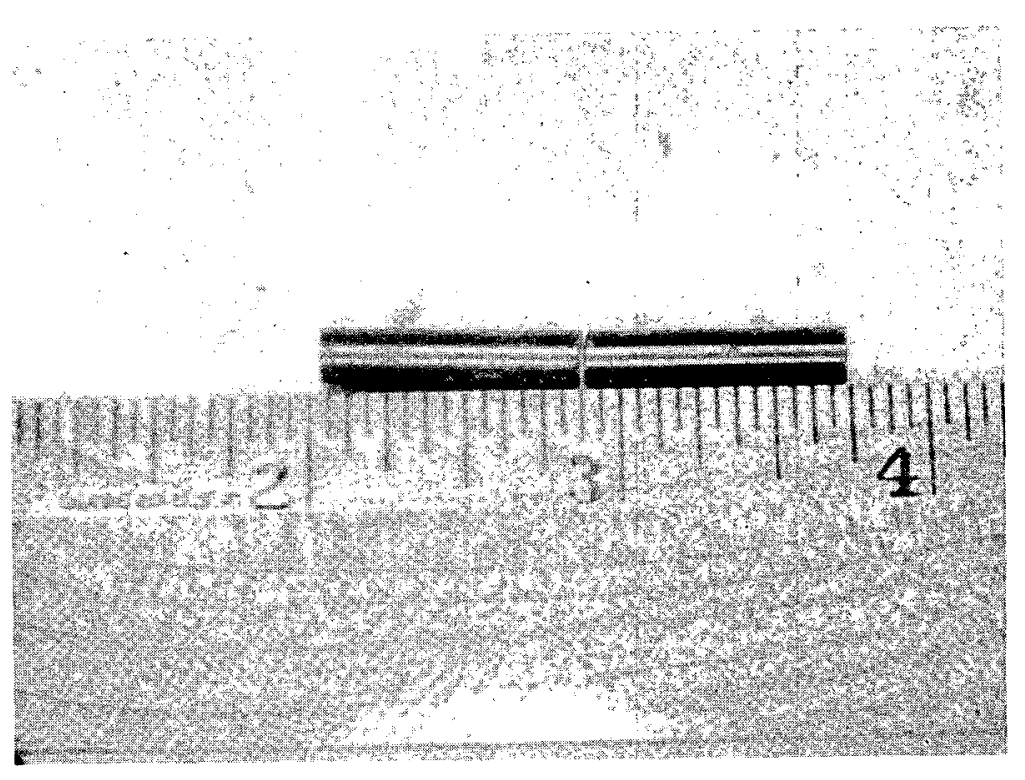

Fig. 15 Bend Test Sample (Spec. 25) of Gamma-quenched U-12 w/o Mo after Irradiation to $1050 \mathrm{MWD} / \mathrm{T}$, Showing Typical Brittle Behavior (approx. 1.25X)

(Neg 21955-6) 


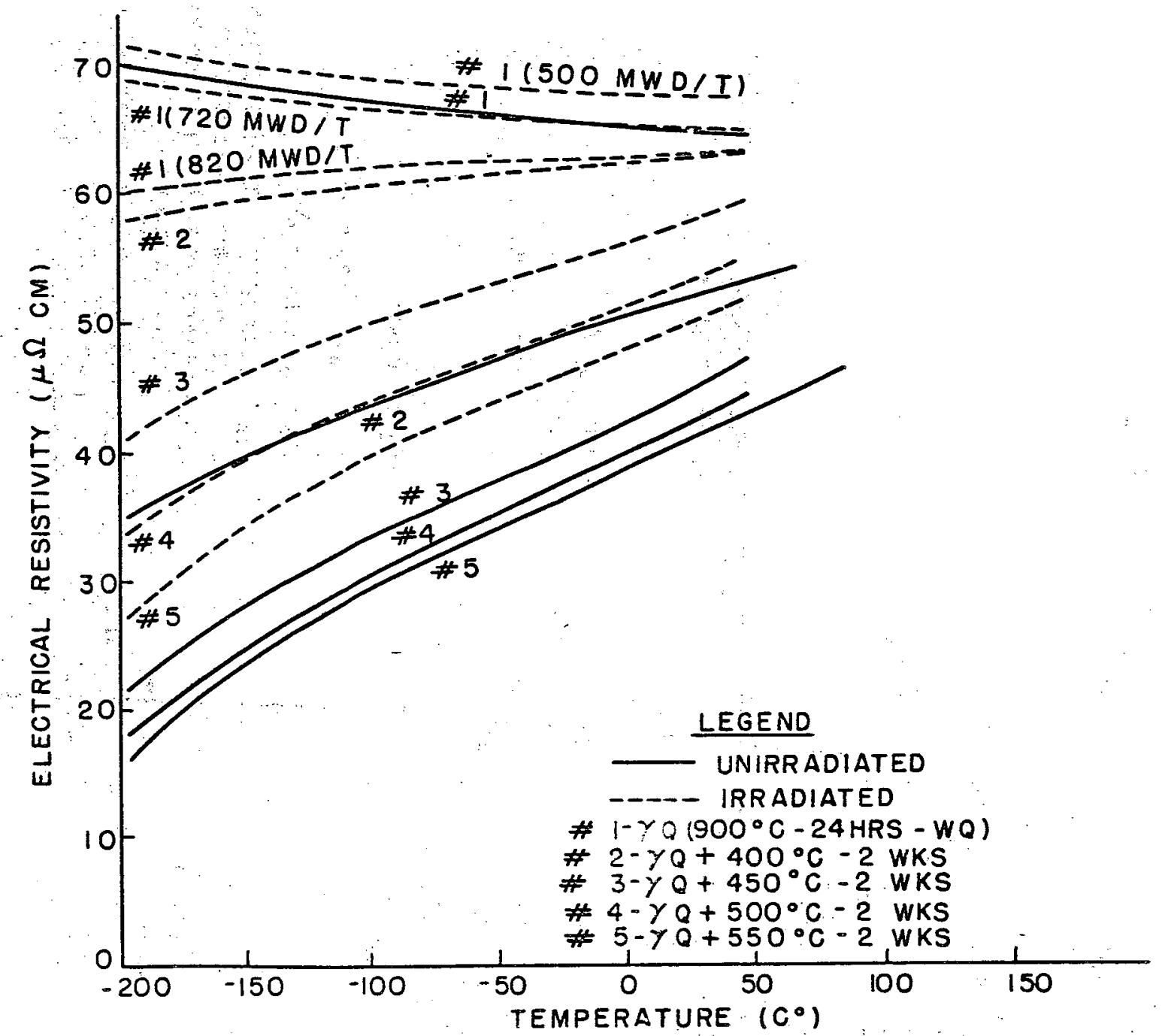

$\mathrm{Fis} \cdot 16$ Electrical Resistivity of U-10 w/O Nb Alloy vs. Temperature

(Neg 20903-3) 


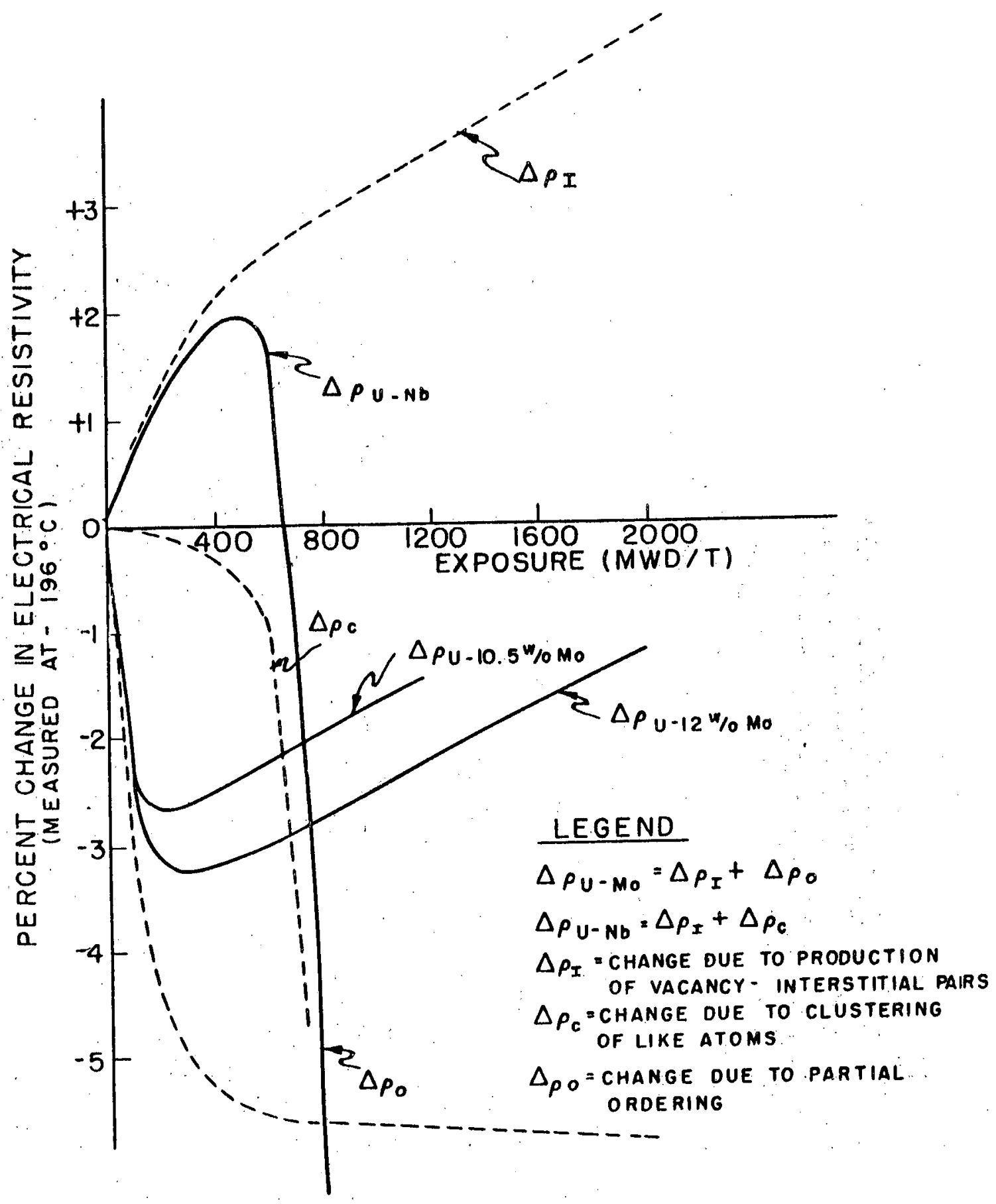

Pig. 27 Explanation of Irradiation Effects on the Electrical Resistivity of Gamma-quenched U-Mo and U-Nb Alloys

(Neg 20903-2) 


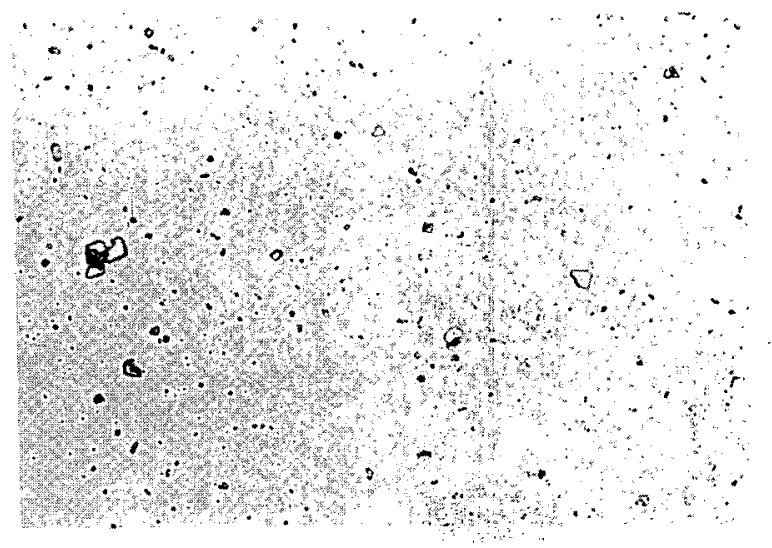

A. $900^{\circ} \mathrm{C}-24 \mathrm{hr}-\mathrm{W} \cdot \mathrm{Q} . \quad(\gamma \mathrm{Q})$

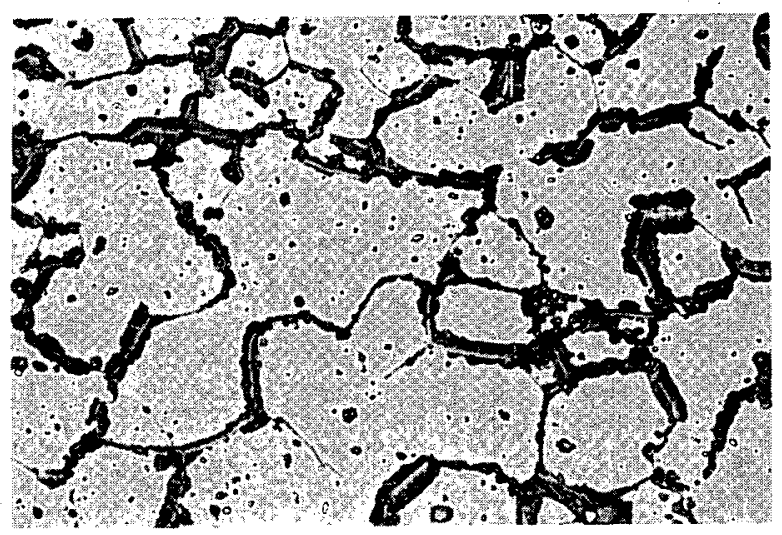

C. $\gamma Q+400^{\circ} \mathrm{C}-2$ weeks

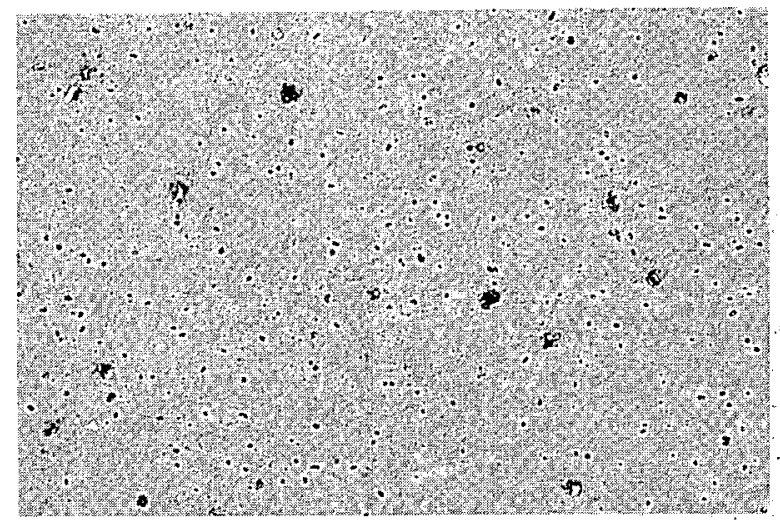

E. $\gamma Q+550^{\circ} \mathrm{C}-2$ weeks

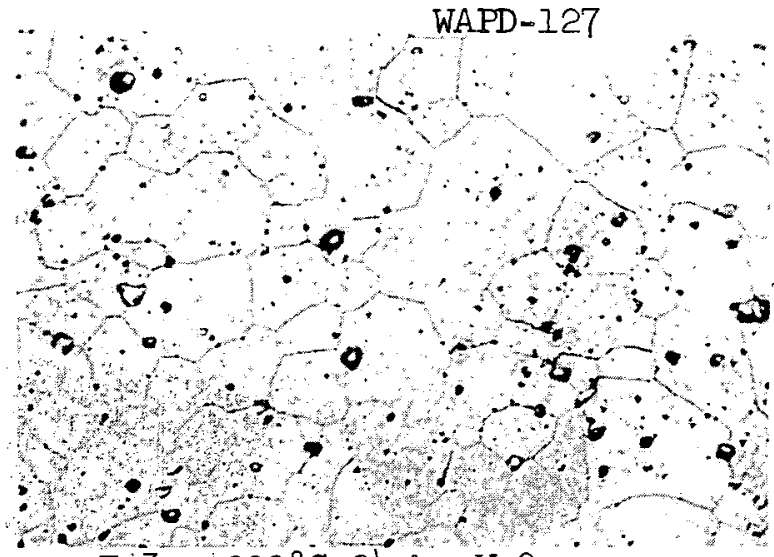

B. Spec。F-3. $900^{\circ} \mathrm{C}-24 \mathrm{hr}-\mathrm{W} \cdot \mathrm{Q}$.

$(\gamma Q)$ Irradiated to $820 \mathrm{MWD} / \mathrm{T}$

D. Spec. F-22. $\gamma Q+400^{\circ} \mathrm{C}-2$ weeks Irradiated to $310 \mathrm{MWD} / \mathrm{T}$

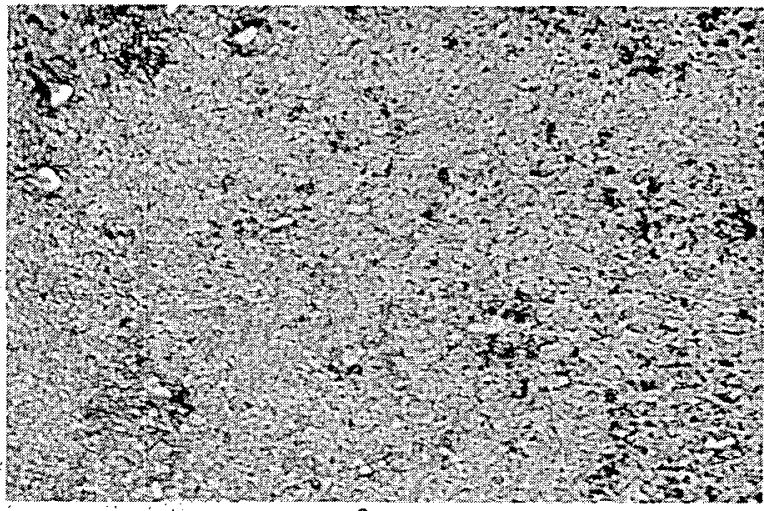

F: Spec. G-1. $\gamma Q+550^{\circ} \mathrm{C}-2$ weeks Irradiated to $810 \mathrm{MWD} / \mathrm{T}$

Fig. 18 Microstructure of U-10 w/O No Alloy, Pre- and Post-Irradiation
$(\mathrm{Neg}$
(A) 21955-13,
(B) 21955-9,
(C) 21955-12,
(D) 21955-10,
(E) 21955-14,
(F) 21955-11)

$250 \mathbf{x}$ 


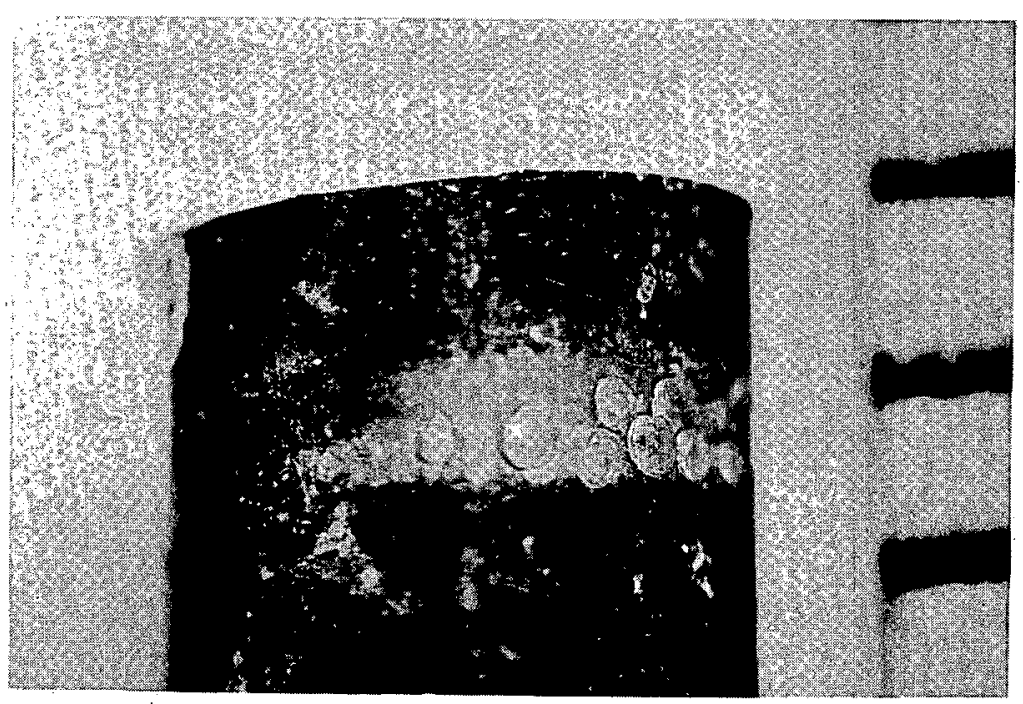

Fig. 19 spec. 16 of U-3.8 w/o si, Irradiated to $680 \mathrm{MWD} / \mathrm{T}$, Showing Typical

"Blistering" and "Banding" near End (approx. 10X)

(Neg 21955-4)

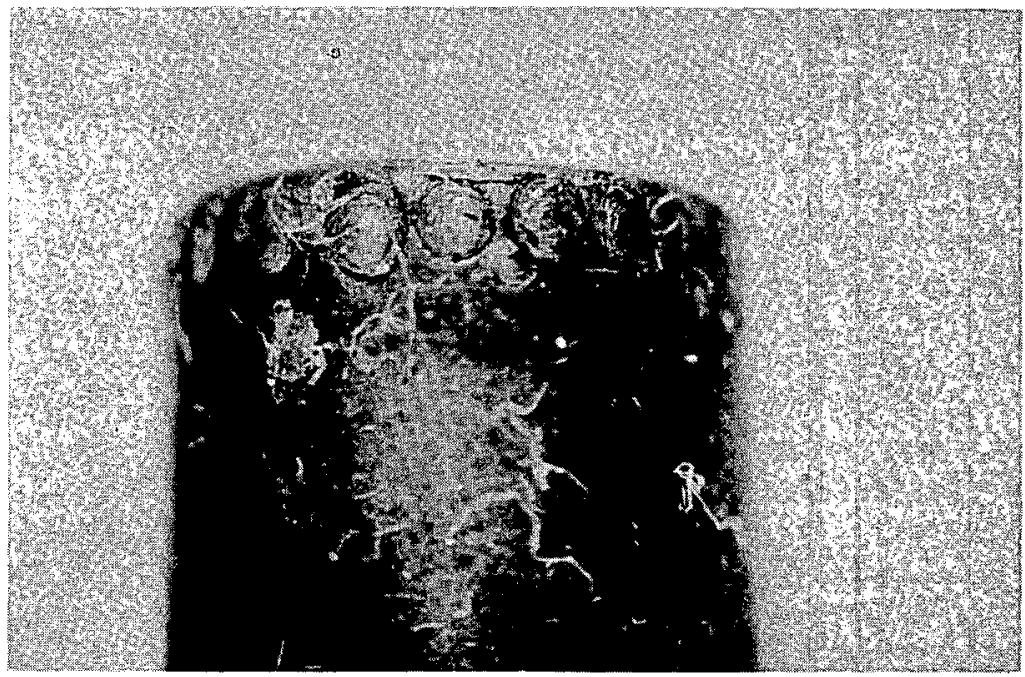

Fig. 20 Spec. 17 of U-3.8 w/o Si, Irradiated to $470 \mathrm{MWD} / \mathrm{T}$, Showing Typical

"Blistering" on End (approx. IOX)

(Neg 21955-3) 
WAPD-127

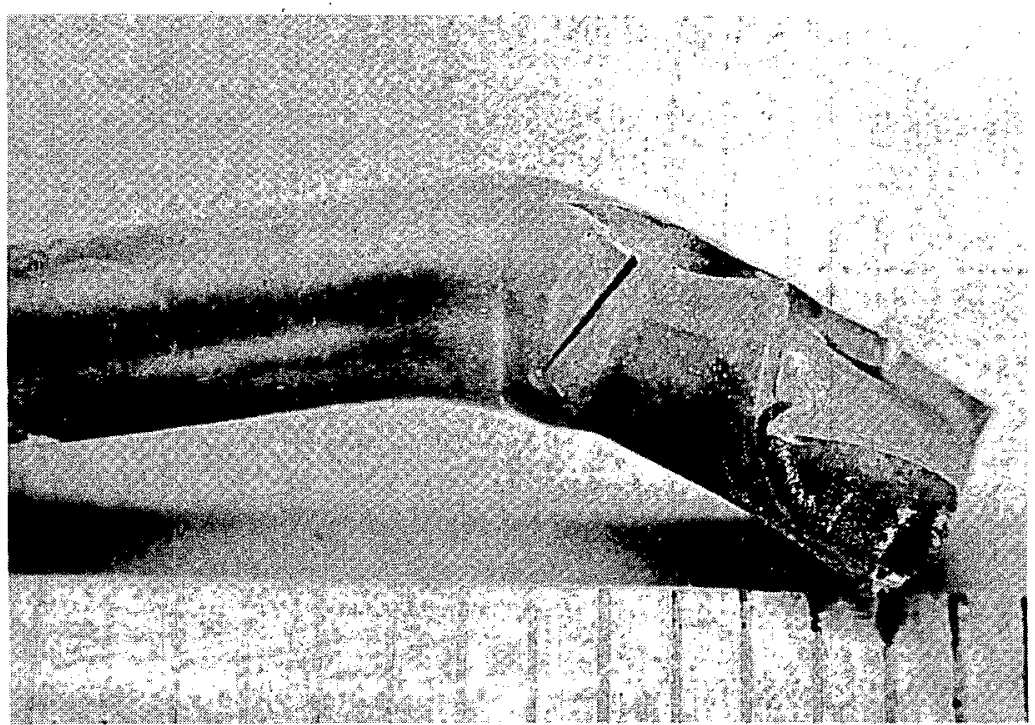

Fig. 21 Spec. 10 of U-3.8 w/o Si, Irradiated to $660 \mathrm{MWD} / \mathrm{T}$, Showing Bending and Cracking of the Specimen End (approx. 4X)

$$
\text { (Nee 21955-2) }
$$


ELECTRICAL RESISTIVITY OF U-3.8 w/O Si ALLOY AS A FUNCTION OF TEMPERATURE

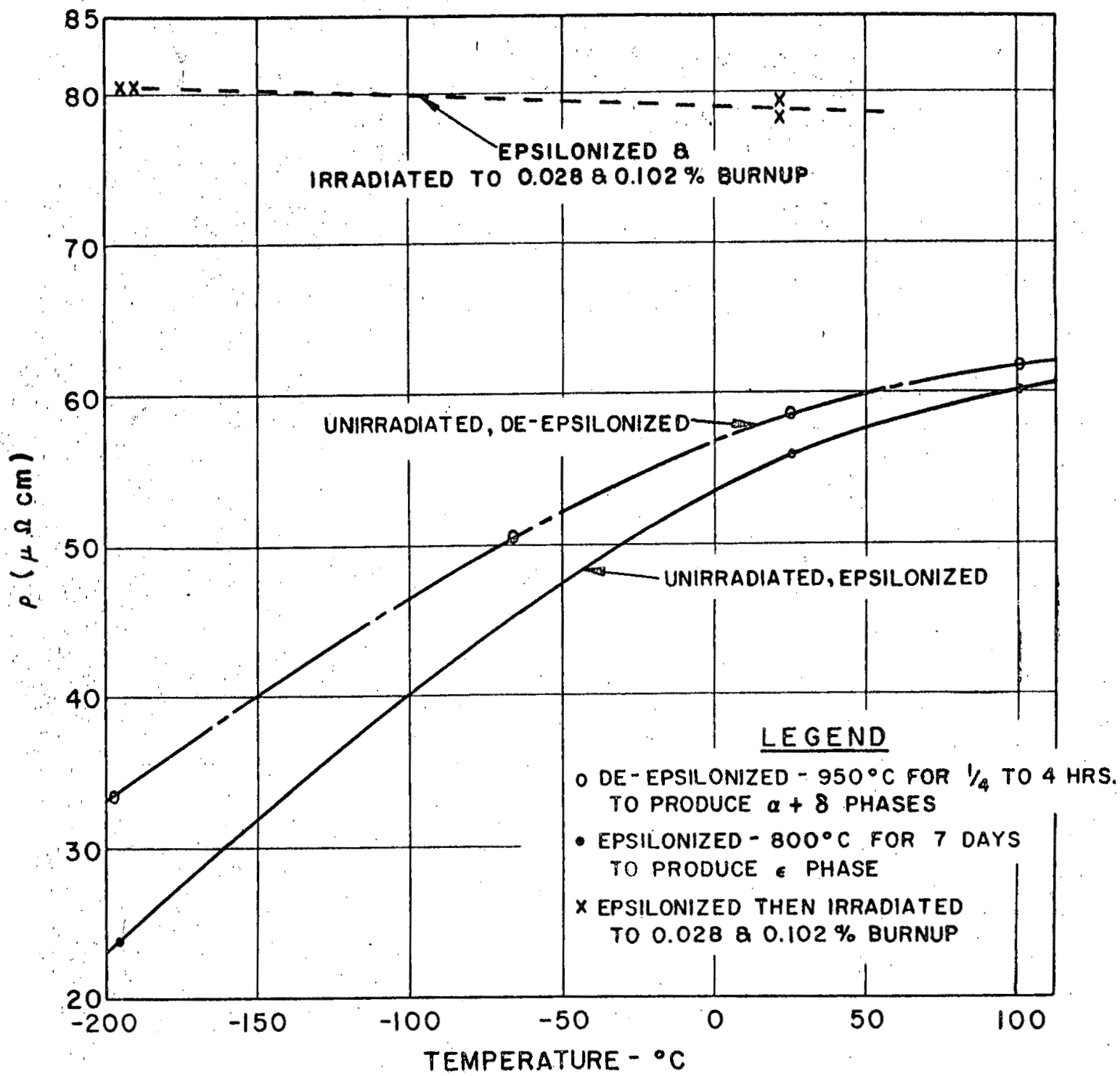

Figure 22

(NTeg 203:9-2) 


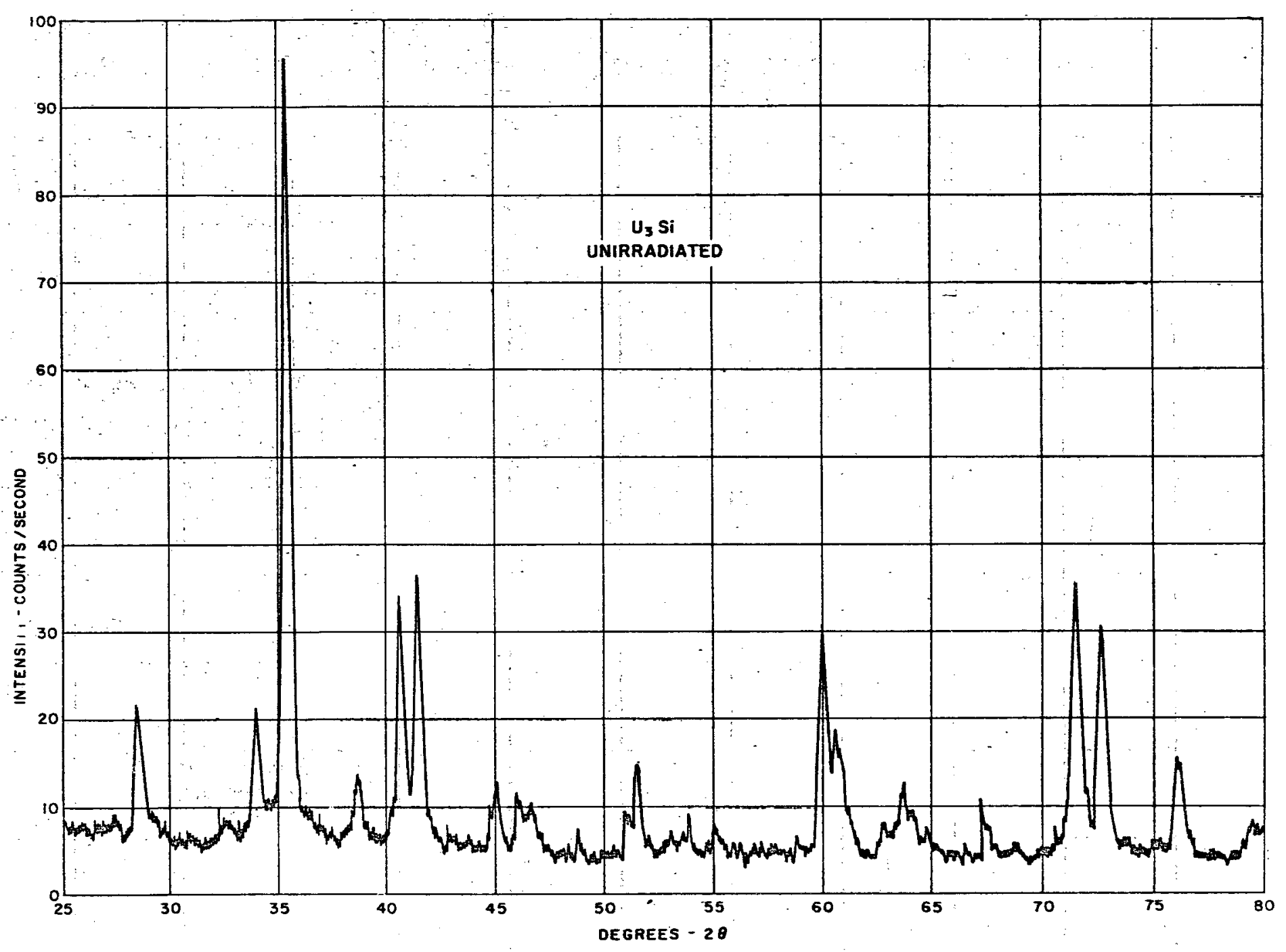

Fig. 23 X-ray Diffraction Pattern of Unirradiated Epsilonized $\mathrm{U}_{3} \mathrm{Si}$ (Neg 20399-3) 


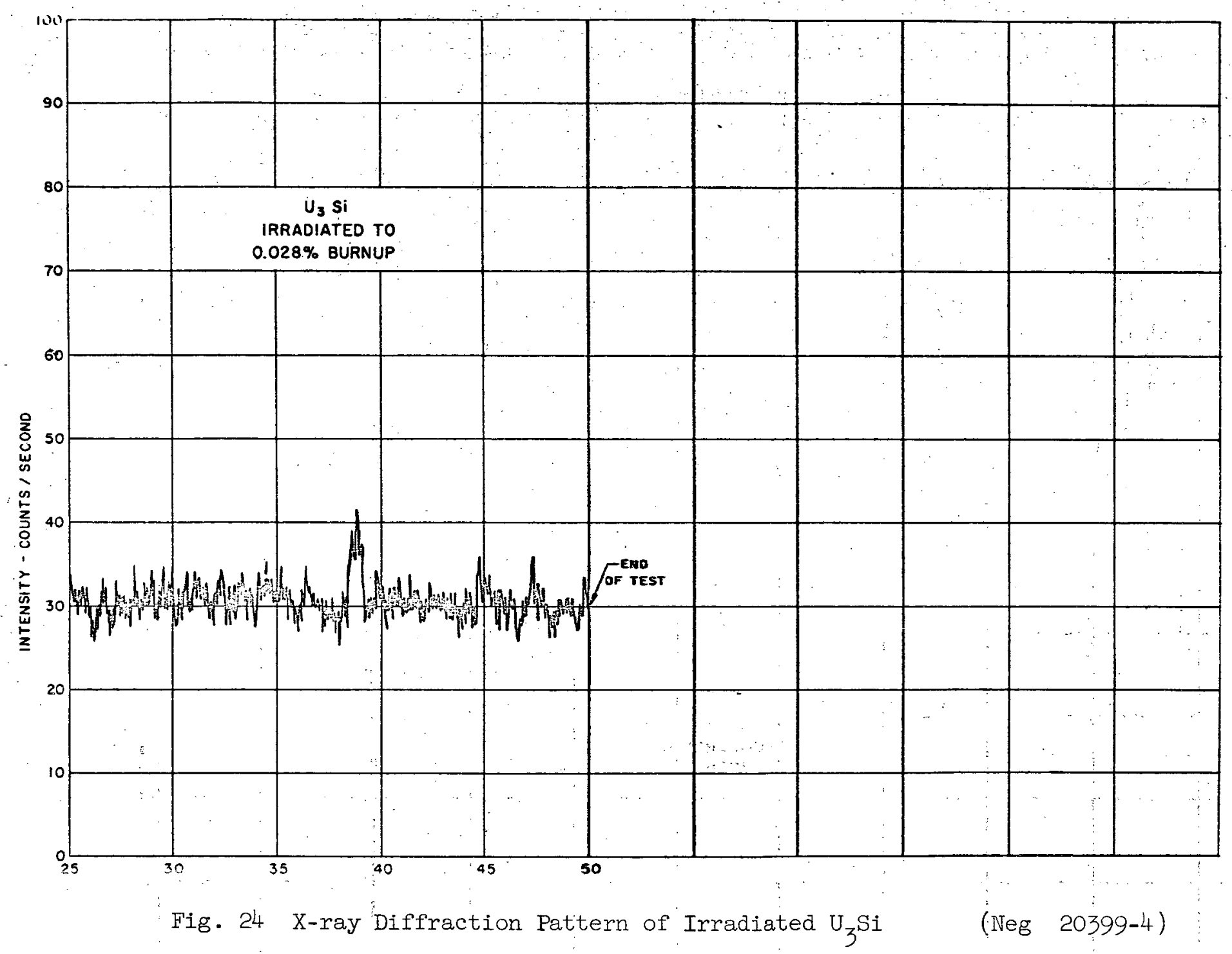

Fig. 24 X-ray Diffraction Pattern of Irradiated $\mathrm{U}_{3} \mathrm{Si}$

(Neg 20399-4) 


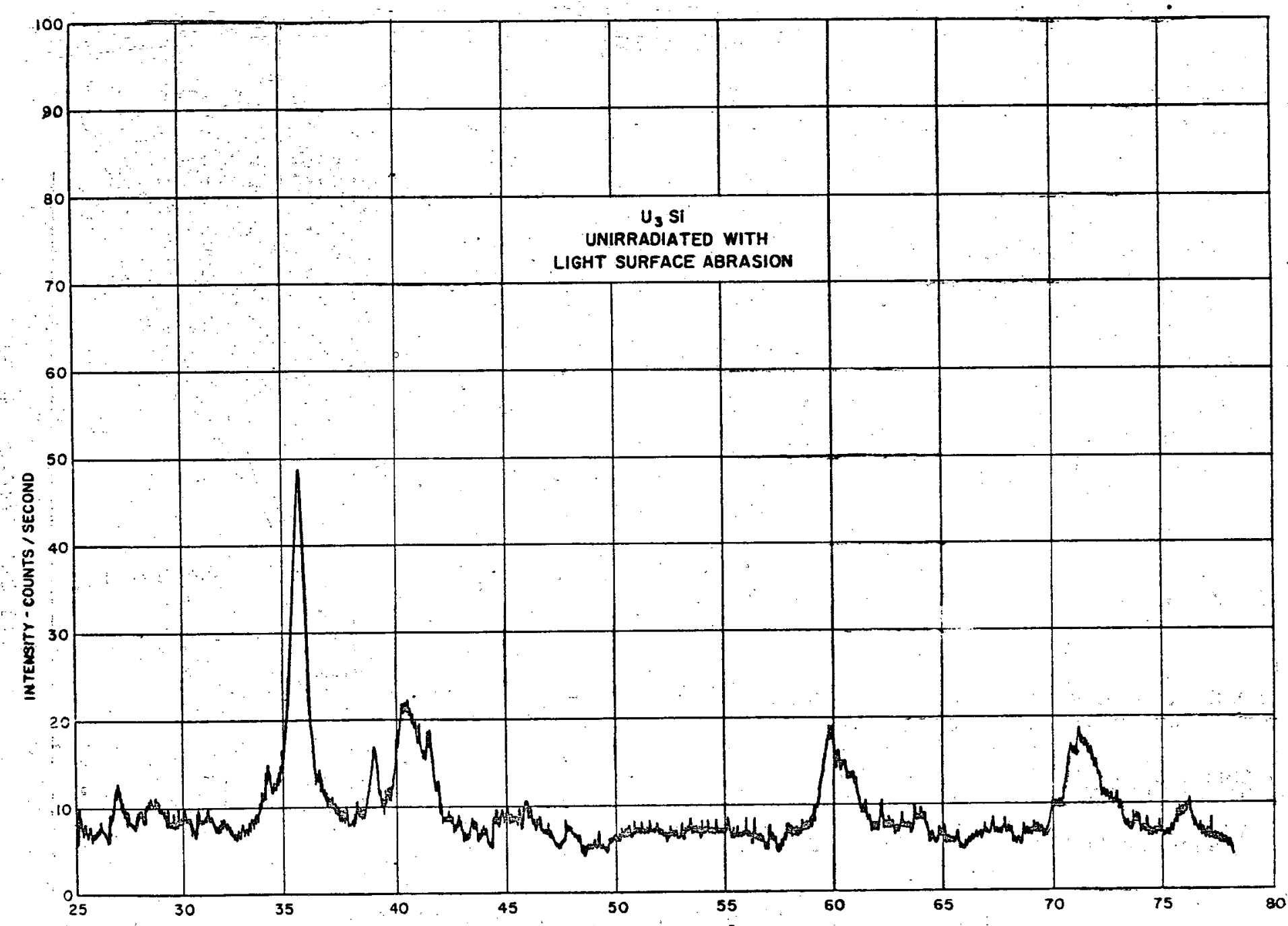




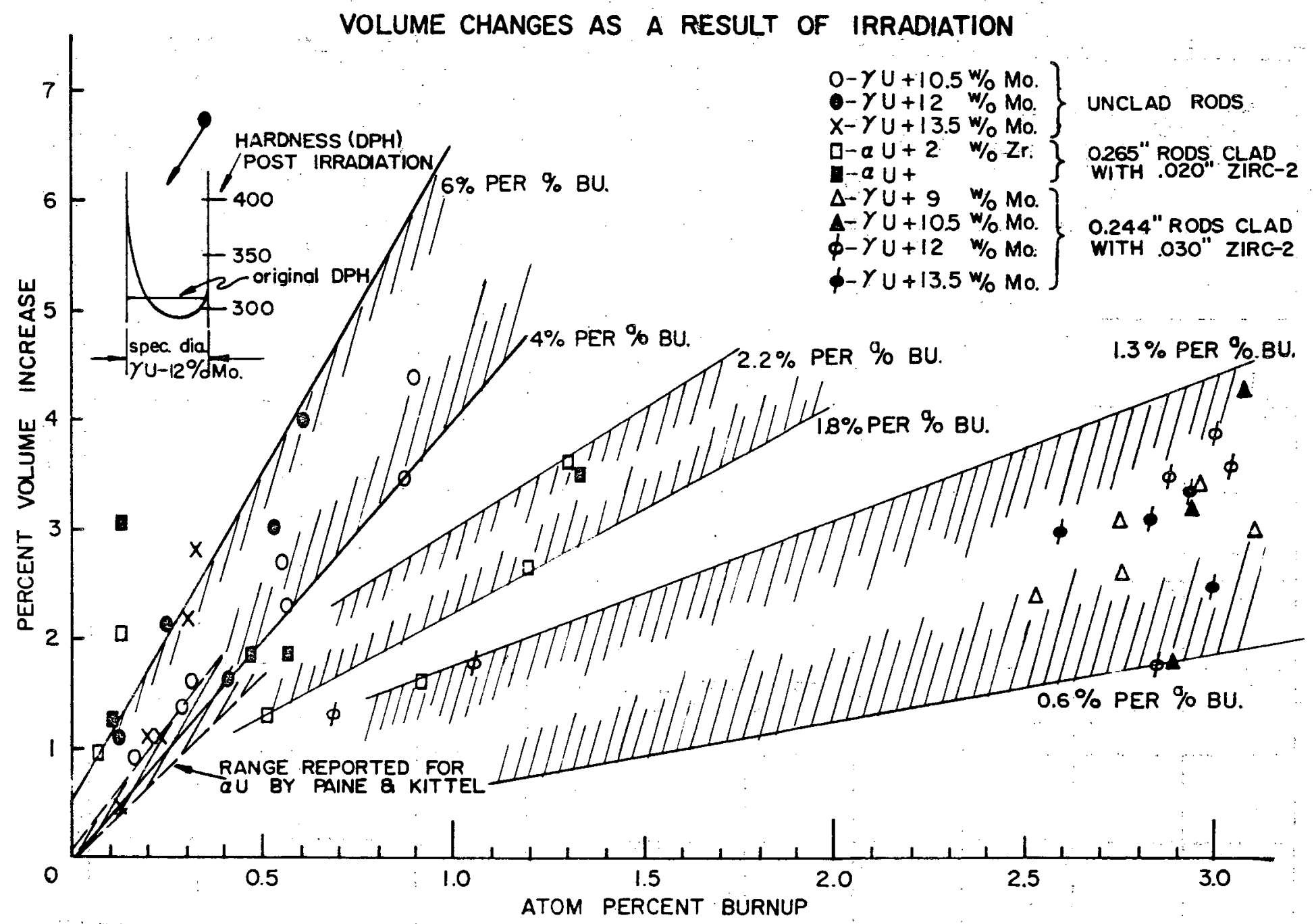

Figure 26

(Nieg ¿1865) 
WAPD -127

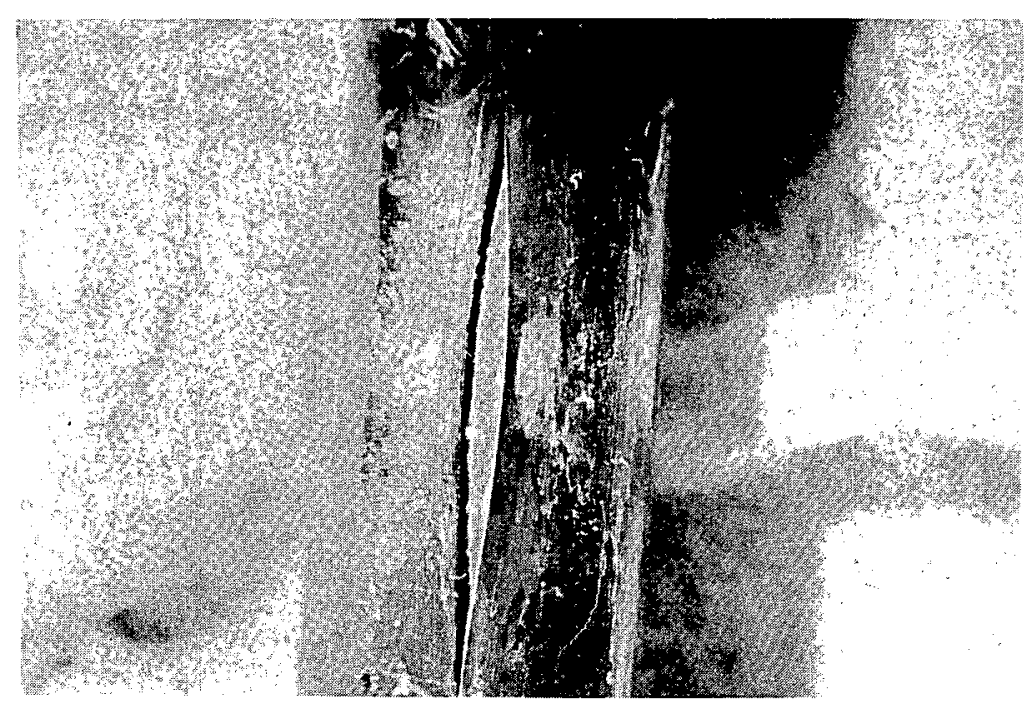

Fig. 27 Photograph of a Zircaloy-l Clad $\mathrm{U}-2 \mathrm{w} / \mathrm{O} \mathrm{Zr}$ Alloy, Irradiated to $10,250 \mathrm{MWD} / \mathrm{T}$, Showing the Splitting of the Clad Due to Volume Expansion of Core. Measured change volume, $2.7 \%$. (3.3X)

(Neg 21955-8) 